WRI-08-R012

\title{
EMISSIONS, MONITORING, AND CONTROL OF MERCURY FROM SUBBITUMINOUS COAL-FIRED POWER PLANTS - PHASE II
}

\author{
TOPICAL REPORT
}

Start Date 2005

End Date 2007

By:

Alan E. Bland

Jesse D. Newcomer

Western Research Institute

Laramie, Wyoming

Allen Kephart

Volker Schmidt

Clean Air Engineering

Pittsburgh, PA

Gerald Butcher

Western Farmers Electric Cooperative

Anadarko, Oklahoma

July 2008

Work Performed Under Cooperative Agreement

JSR Task 31 Phase II DE-FC26-98FT40323

For:

Subbituminous Energy Coalition Members

Laramie, WY

U.S. Department of Energy

National Energy Technology Laboratory

Morgantown, West Virginia

By

Western Research Institute

Laramie, Wyoming

Kamalendu Das

Task 31 


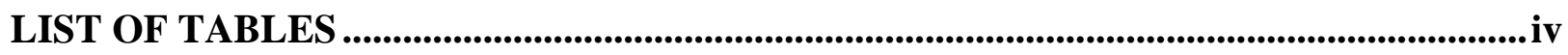

LIST OF FIGURES .............................................................................................................................. v

ABBREVIATIONS ............................................................................................................................. ix

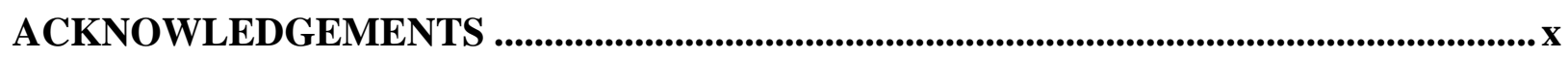

DISCLAIMER.................................................................................................................................

EXECUTIVE SUMMARY ....................................................................................................vii

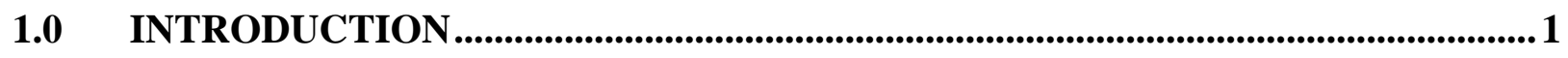

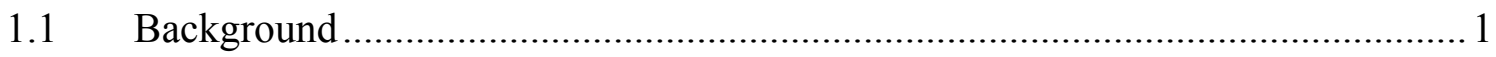

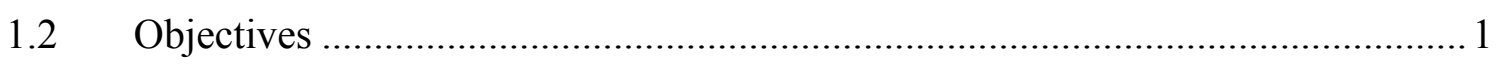

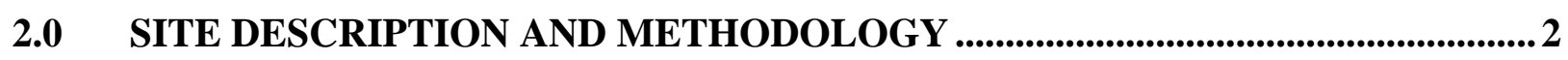

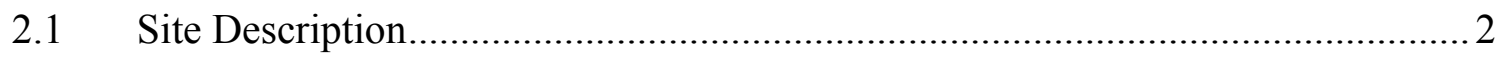

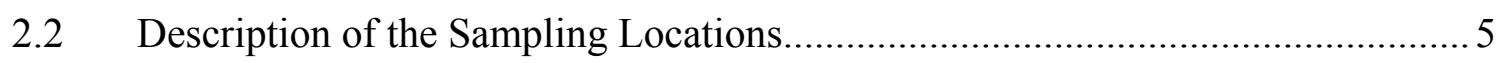

2.3 Mercury Measurement and Monitoring Methods .............................................. 7

2.3.1 Ontario Hydro Mercury Speciation Method ................................................ 7

2.3.2 Method 324 Mercury Monitoring .................................................................... 11

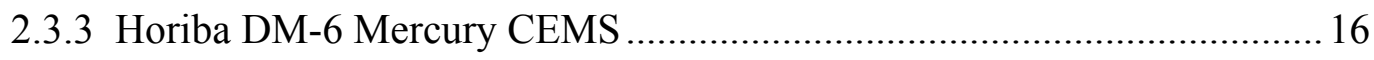

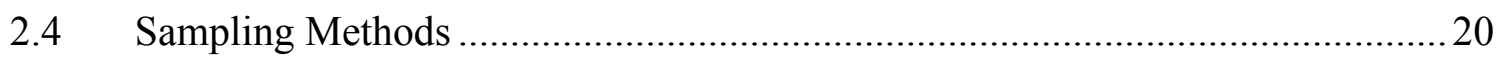

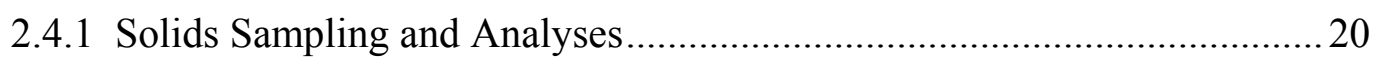

2.4.2 Emission Source Sampling and Analysis ...............................................2

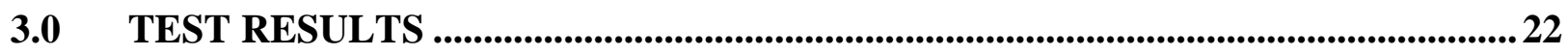

3.1 Pre-Testing Assessment of Mercury Distribution ............................................22

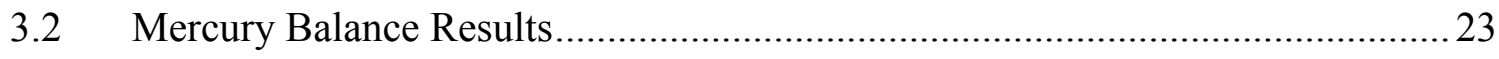

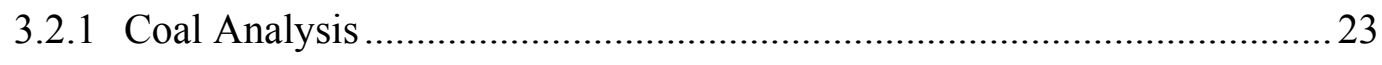

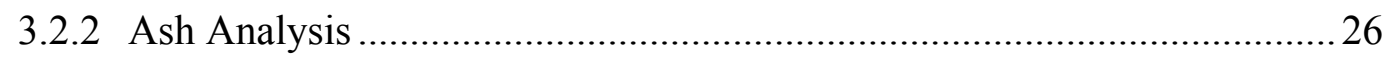

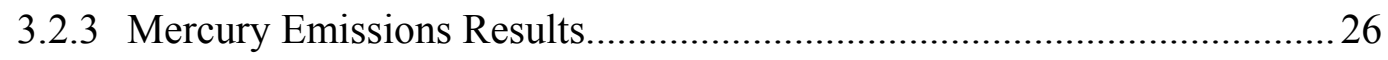

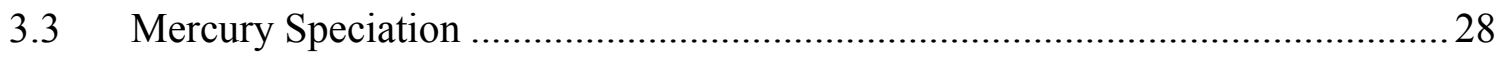

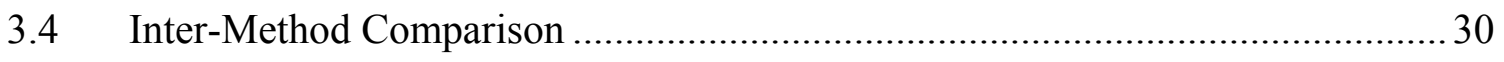

3.4.1 PS12A Reference Method - Ontario Hydro ………................................. 30

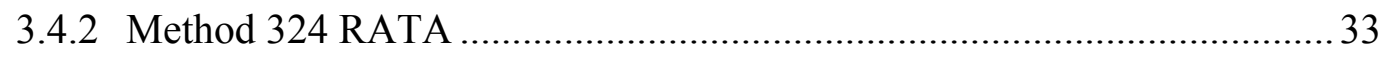




\section{TABLE OF CONTENTS (continued)}

3.4.3 Horiba DM-C CEMS ……................................................................... 36

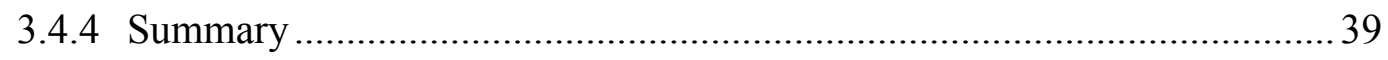

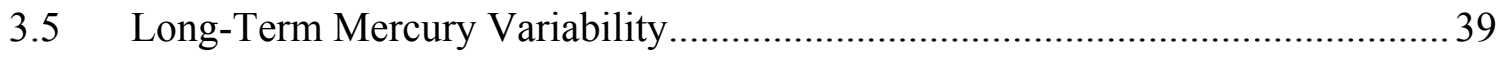

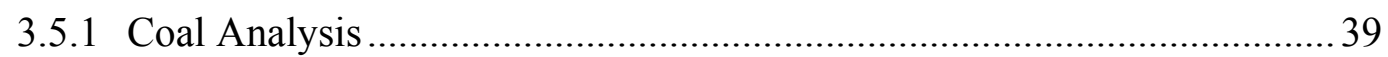

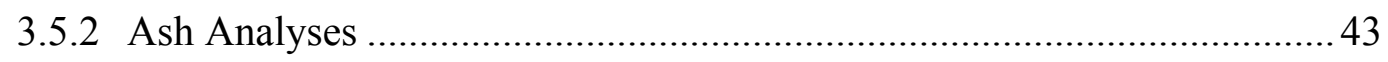

3.5.3 Mercury Emissions ......................................................................... 45

3.6 Method 324 and Horiba CEMS Long-Term Operation and

Maintenance Record ............................................................................. 47

3.6.1 Method 324 Operation and Maintenance ............................................. 47

3.6.2 Horiba DM-6 CEMS Operation and Maintenance Record....................... 52

4.0 SUMMARY AND CONCLUSIONS .......................................................................... 57

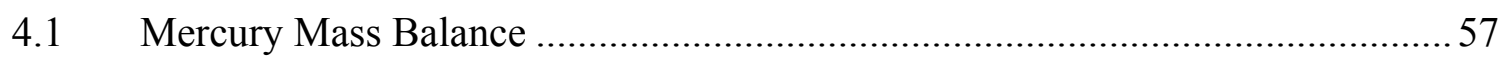

4.2 Mercury Species Distribution ................................................................. 57

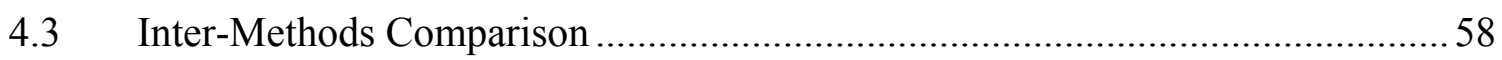

4.4 Long-Term Hg Monitoring Method Operation and Maintenance Record...........59 


\section{LIST OF TABLES}

Table

Page

Table 2.1.1 Summary of the coal analyses for Hugo's two

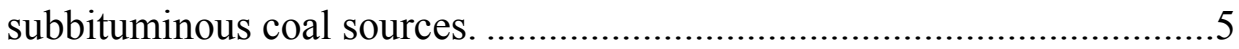

Table 2.3.1.1 Sampling Methods and Analytical Procedures ..........................................8

Table 2.3.1.2 Summary of the Source Sampling Procedures...........................................

Table 2.4.1.1 ASTM Methods Used for Coal Analyses .................................................20

Table 2.4.2.1 Summary of source sampling methods and procedures at Hugo ..............21

Table 3.2.3.1 Hg mass flow rate across Hugo facility ...................................................2

Table 3.2.3.2 Hg mass flow rate across ESP ……………………..........................2

Table 3.3.1 Hg Speciation Mass Results..................................................................28

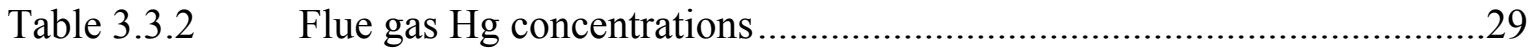

Table 3.6.1.1 Summary of Test Results for Long-Term Sorbent Trap Monitoring.......48

Table 3.6.1.2 Summary of the Laboratory Spike and CRM Recoveries ........................49

Table 3.6.1.3 Sorbent Trap Breakthrough Performance ……………………................49

Table 3.6.1.4 Summary Log of Major Sorbent Trap Maintenance Events.....................51

Table 3.6.2.1 Summary Log of Major Hg-CEMS Maintenance Events.........................53 


\section{LIST OF FIGURES}

Figure

$\underline{\text { Page }}$

Figure 2.1.1 Photograph of the WFEC Hugo Generating Station

located near Hugo, Oklahoma..................................................................2

Figure 2.1.2 Process Schematic and photograph of the Hugo plant layout......................

Figure 2.1.3 Schematic of plant configuration, side view..............................................

Figure 2.1.4 Schematic of the Hugo site, plan view......................................................

Figure 2.2.1 Diagram of emissions source sampling traverse points at

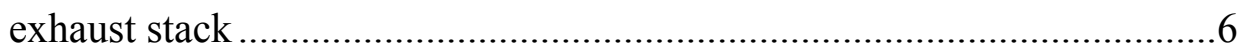

Figure 2.2.2 Diagram of emissions source sampling traverse points at

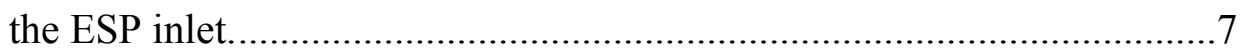

Figure 2.3.1.1 Schematic of the Ontario Hydro testing apparatus ....................................

Figure 2.3.1.2 Photographs of the Ontario-Hydro probe at the stack .............................10

Figure 2.3.1.3 Photographs of the Ontario-Hydro rotameters and impingers

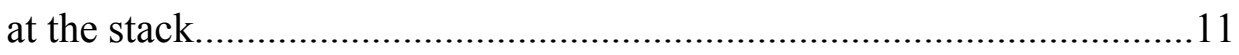

Figure 2.3.1.4 Photographs of installation of equipment and probes at the ESP inlet....11

Figure 2.3.2.1 Sorbent trap sampling train schematic ...................................................12

Figure 2.3.2.2 Sampling system used at WFEC Hugo plant............................................13

Figure 2.3.2.4 Photographs of the probe connections for the Method 324 equipment ...13

Figure 2.3.2.5 Photographs of the Method 324 equipment and penetration

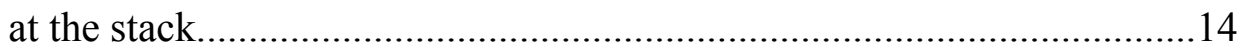

Figure 2.3.2.3a Photographs of the sorbent traps used in the study ................................15

Figure 2.3.2.3b Photographs of the sorbent traps used in the study ................................15

Figure 2.3.3.1 Schematic of the Horiba Hg CEM system..............................................16

Figure 2.3.3.2 Hg-CEM system installation at stack test platform .................................17

Figure 2.3.3.3 Hg-CEM system penetration into the stack ..........................................18

Figure 2.3.3.4 Hg CEM flue gas conditioning unit ........................................................18 
Figure

\section{LIST OF FIGURES (continued)}

Figure 2.3.3.5 Hg-CEM detector and data acquisition system setup ............................19

Figure 2.3.3.6 Photograph of the internals of the Horiba DM 6 unit..............................19

Figure 3.1.1 Pre-Hg balance test program coal and ash sample results .......................22

Figure 3.2.1.1 Ash variability of Hugo feed coal during inter-method comparison

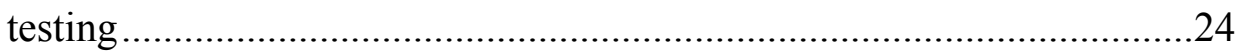

Figure 3.2.1.2 Heating value variability of Hugo feed coal during inter-method

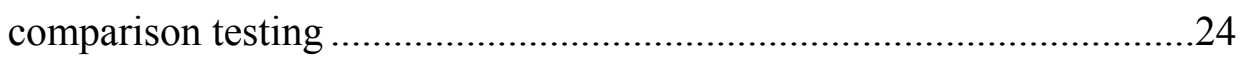

Figure 3.2.1.3 Pyritic sulfur variability of Hugo feed coal during inter-method

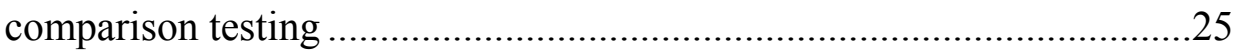

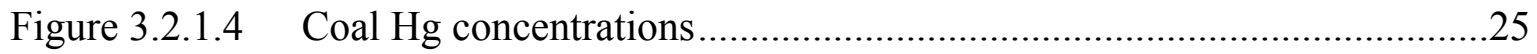

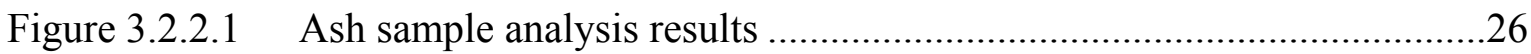

Figure 3.2.3.3 Average total mercury concentrations per sorbent trap sampling run .....28

Figure 3.3.1 Hg speciation results ...................................................................29

Figure 3.4.1.1 Ontario-Hydro- elemental Hg per train..................................................30

Figure 3.4.1.2 Ontario-Hydro - elemental Hg relative deviation per run ........................31

Figure 3.4.1.3 Ontario-Hydro- oxidized Hg per train....................................................31

Figure 3.4.1.4 Ontario-Hydro - oxidized Hg relative deviation per run..........................32

Figure 3.4.1.5 Average total gaseous $\mathrm{Hg}$ result for each paired

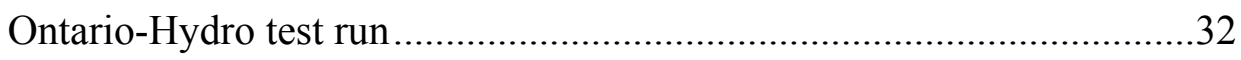

Figure 3.4.1.6 Hg results for each Ontario-Hydro train .................................................33

Figure 3.4.2.1 Hg results for each paired sorbent trap test..............................................34

Figure 3.4.2.2 Hg results for each paired sorbent trap test run .......................................34

Figure 3.4.2.3 Average Hg result for each paired sorbent trap test run ...........................35

Figure 3.4.2.4 Sorbent trap results vs. Ontario-Hydro results..........................................35 
Figure

\section{LIST OF FIGURES (continued)}

Figure 3.4.3.1 Hg-CEMS results vs. Ontario-Hydro results for June 29, 2005 36

Figure 3.4.3.2 Hg-CEMS results vs. corresponding Ontario-Hydro

results for June 30, 2005 37

Figure 3.4.3.3 Ontario-Hydro vs. M324(sorbent tube) vs. Hg-CEMS.........................37

Figure 3.4.4.1 Mercury emissions and load for 7 July through 31 July 2005 ...............38

Figure 3.4.4.2 Mercury emissions and load for 1 August through 7 September 2005....38

Figure 3.5.1.1 Ash content of the feed coals on a monthly basis over the 6-month monitoring period.

Figure 3.5.1.2 Heating value content of the feed coals on a monthly basis over the 6-month monitoring period

Figure 3.5.1.3 Monthly Hg averages for the Hugo feed coal over the 6-month evaluation

Figure 3.5.1.4 Individual $\mathrm{Hg}$ content in coal samples over the 6-month evaluation period

Figure 3.5.1.5 Coal $\mathrm{Hg}$ analysis results for the three testing period (daily, weekly and monthly)

Figure 3.5.1.6 Pyritic sulfur content of the feed coals on a monthly basis over the 6-month monitoring period

Figure 3.5.2.1 Monthly mercury results for the fly ash over the 6-month evaluation period 44

Figure 3.5.2.2 Monthly mercury content of the bottom ash samples

Figure 3.5.3.1 Mercury emissions and load for 7 July through 31 July 2005 45

Figure 3.5.3.2 Mercury emissions and load for 1 August through 7 September 2005....45

Figure 3.5.3.3 Mercury emissions and load for 8 September through 10 October 2005 .46

Figure 3.5.3.4 Mercury emissions and load for11 October through 21 November 2005 .46 


\section{LIST OF FIGURES (continued)}

$\underline{\text { Figures }}$

$\underline{\text { Page }}$

Figure 3.5.3.5 Mercury emissions and load for21 November through

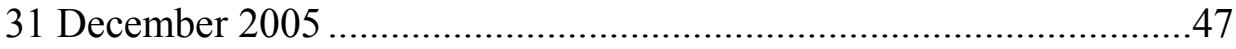

Figure 3.6.2.1 Photograph sequence of the changing of Horiba CEM catalysts..............55

Figure 3.6.2.2 Photographs of changing of the filter....................................................56 


\section{ABBREVIATIONS}

APCD - $\quad$ Air Pollution Control Devises

CESP - Cold-side Electrostatic Precipitator

ESP- Electrostatic precipitator

F- $\quad$ Normalized gas flow factor, $\mathrm{F}_{\mathrm{c}}$ (carbon-based) and $\mathrm{F}_{\mathrm{d}}$ (total flue gas)

FF - $\quad$ Fabric Filter

HAP- $\quad$ Hazardous Air Pollutants (i.e. $\mathrm{Hg}$ )

Hg - $\quad$ Mercury

$\mathbf{H g}^{\mathbf{0}} \quad$ Mercury-Elemental

$\mathbf{H g}^{2+} \quad$ Mercury - Oxidized

$\mathbf{H g}^{\mathrm{PB}} \quad$ Mercury-Particulate

$\mathbf{H g}^{\mathrm{T}} \quad$ Mercury-Total

MMBtu/hr - Fuel Use, Millions of British Thermal Units Per Hour

MWe-G - Megawatts-Gross

MWe-N- Megawatts-Net

PM - $\quad$ Particulate Matter

QA/QC- Quality Assurance/Quality Control

SEC - $\quad$ Subbituminous Energy Coalition

gr/dscf - $\quad$ Particulate Concentration, Grains Per Dry Standard (68 F, 1 atm) Cubic Foot

lb/hr - $\quad$ Mass Emission Rate, Pounds Per Hour

lb/MMBtu - Mass Emission Rate, Pounds Per Million British Thermal Units

lb/TBtu - $\quad$ Mass Emission Rate, Pounds Per Trillion British Thermal Units

$\mathbf{m g} / \mathbf{k g}$ - $\quad$ Milligrams Per Kilogram

$\mathbf{p p b}_{\mathbf{d}}$ - $\quad$ Parts per Billion, Dry Basis

$\mathbf{\mu g} / \mathbf{d s c m}-\quad$ Mercury Concentration, Micrograms per Dry Standard Cubic Meter 


\section{ACKNOWLEDGEMENTS}

The authors acknowledge the funding support provided by the United States Department of Energy, National Energy Technology Laboratory under Cooperative Agreement Jointly Sponsored Research Program DE-FC26-98FT40323, Western Farmers Electric Cooperative (WFEC), Missouri Basin Power Project, DTE Energy, Entergy, Grand River Dam Authority, and Nebraska Public Power District, all members of the Subbituminous Energy Coalition (SEC).

The authors acknowledge the contributions to the project from Western Farmers Electric Cooperative's Hugo plant manager Charles Collier. And finally, the authors are especially indebted to Kamalendu Das and Charles Miller of U.S. DOE National Energy Technology Laboratory for their thoughtful suggestions and guidance. 


\section{DISCLAIMER}

This report was prepared as an account of work sponsored by an agency of the United States Government. Neither the United States Government nor any agency thereof, nor any of their employees makes any warranty, express or implied, or assumes any legal liability or responsibility for the accuracy, completeness, or usefulness of any information, apparatus, product, or process disclosed or represents that its use would not infringe on privately owned rights. Reference herein to any specific commercial product, process, or service by trade name, trademark, manufacturer, or otherwise does not necessarily constitute or imply endorsement, recommendation, or favoring by the United States Government or any agency thereof. The views and opinions of authors expressed herein do not necessarily state or reflect those of the United States Government or any agency thereof. 


\section{EXECUTIVE SUMMARY}

Western Research Institute (WRI), in conjunction with Western Farmers Electric Cooperative (WFEC), has teamed with Clean Air Engineering of Pittsburgh PA to conduct a mercury monitoring program at the WEFC Hugo plant in Oklahoma. Sponsored by US Department of Energy Cooperative Agreement DE-FC-26-98FT40323, the program included the following members of the Subbituminous Energy Coalition (SEC) as co-sponsors.

- Missouri Basin Power Project

- DTE Energy

- Entergy

- Grand River Dam Authority

- Nebraska Public Power District

This research effort had five objectives: (1) determine the mass balance of mercury for subbituminous coal-fired power plant; (2) assess the distribution of mercury species in the flue gas (3) perform a comparison of three different $\mathrm{Hg}$ test methods; (4) investigate the long-term (six months) mercury variability at a subbituminous coal-fired power plant; and (5) assess operation and maintenance of the Method 324 and Horiba CEMS utilizing plant personnel.

\section{Mercury Mass Balance}

Mercury testing and analysis was performed on process samples, (coal, coal pyrite rejects, fly ash, and bottom ash), as well as the flue gas at the facility's boiler exhaust stack and electrostatic precipitator (ESP) inlet ( 1 of 4 inlets) over the two day period of July 6 and 7, 2005. Flue gas sampling was performed using co-located, Ontario-Hydro or OH, (ASTM D6784-02) test trains at the facilities boiler exhaust stack as well as paired $\mathrm{OH}$ trains at one of the four inlets to the ESP. Hg concentrations and other flue gas characteristics were assumed the same for each ESP inlet. Three 2-hour Ontario-Hydro test runs were performed at each test location while process samples were collected. The three 2-hour Ontario-Hydro test runs indicated $93.8 \%$ total mercury closure across the ESP and $95.6 \%$ overall mass balance closure.

\section{Mercury Species Distribution}

Mercury speciation testing of showed $89.5 \%$ elemental $\mathrm{Hg}, 8.0 \%$ oxidized $\mathrm{Hg}$ and $2.5 \%$ particulate bound $\mathrm{Hg}$ at the inlet of the ESP and $75.7 \%$ elemental $\mathrm{Hg}$, and $23.3 \%$ oxidized $\mathrm{Hg}$ at the stack. The Hg speciation results across the ESP can be seen in Figure 3.4.5. As expected, nearly all of the $\mathrm{Hg}^{\mathrm{PB}}$ is removed across the ESP. Since $\mathrm{Hg}^{\mathrm{PB}}$ constitutes only a minor fraction of the $\mathrm{Hg}^{\mathrm{T}}$ present in the flue gas, there is little removal of $\mathrm{Hg}^{\mathrm{T}}$ across the ESP. Also evident is the oxidation of some of the $\mathrm{Hg}^{0}$ to $\mathrm{Hg}^{2+}$. 


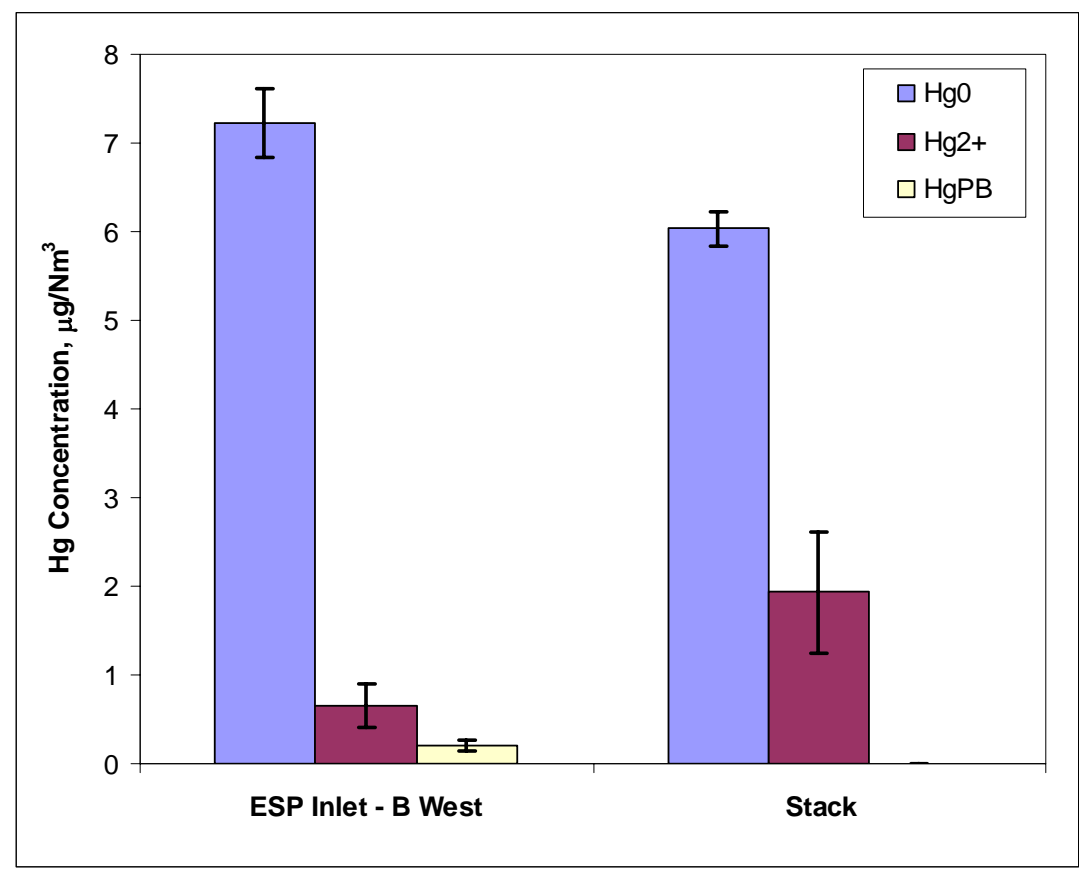

Figure ES-1. Hg speciation results.

\section{Inter-Methods Comparison}

Three different mercury test methods were concurrently performed and compared;

- Mercury continuous emissions monitoring system (Hg-CEMS);

- Former dry sorbent-tube based USEPA Method 324;

- Ontario Hydro (OH) test method (ASTM D6784-02).

In order to compare the results of different methods of measuring $\mathrm{Hg}$ concentrations in the flue gas, nine consecutive co-located Ontario-Hydro runs and Method 324 runs (with colocated sorbent traps) were performed simultaneously at the stack, while corresponding Horiba DM-6 mercury continuous emissions monitoring system using a vapor phase mercury monitor was used to monitor the $\mathrm{Hg}$ emissions in the flue gas at Hugo's exhaust stack. Testing was performed over the period of June 29-30 and July 6-7, 2005. The following results were established.

- All paired Ontario-Hydro sampling method test runs passed the minimum performance criteria for paired RM tests according to Performance Specification 12A (RD less than $10 \%$ for total gaseous $\mathrm{Hg}$ concentrations greater than $1.0 \mathrm{~g} / \mathrm{m}^{3}$ ). Particulate-bound $\mathrm{Hg}$ was negligible (non-detected). 
- All Method 324 data pairs had a relative deviation (RD) of less than 5\%. A field spike was recovered to $90 \%$ (80-120\% limit).

- The relative accuracy (RA) of Method 324 with respect to Ontario-Hydro as reference method result was $10.4 \%$ (20.00\% limit) with an absolute difference of $0.46 \mu \mathrm{g} / \mathrm{m}^{3}$ (limit of $1 \mu \mathrm{g} / \mathrm{m}^{3}$ ). As such, the Method 324 data passed the RATA.

- During the first week of testing, (June 29 and 30), the Horiba DM-6 Hg CEMS used at the stack provided data comparable to those obtained using the Ontario-Hydro and sorbent-based sampling method (10-22\% lower with Run 2 not included).

- The relative accuracy of the Horiba DM-6-6 CEMS data showed a relative accuracy of $64.8 \%$ (limit of $20 \%$ ) relative to the $\mathrm{OH}$ as the reference method and an absolute difference of $2.98 \mu \mathrm{g} / \mathrm{m}^{3}$ (limit of $1 \mu \mathrm{g} / \mathrm{m}^{3}$ ). As such, the Horiba DM-6 data does not pass the RATA.

Additional method comparisons continued over the first two months of the program using both Method 324 sorbent tubes and the Horiba Hg-CEMS. The sorbent tubes continued with weekly switch out of sorbent tubes. The mercury content of the coal, fly ash and bottom ash was also monitored over this period.

\section{Long-Term Monitoring Operations and Maintenance}

Plant personnel were trained on site on the use, care and maintenance of the sorbent tube sampling equipment and Hg-CEMS. The Horiba DM-6 Hg-CEMS and Method 324 sorbent tubes were maintained by plant personnel over a six month period.

There were several Method 324 auto sampler hardware and software, as well as sorbent trap recovery issues during the program. As a result, only one sorbent trap of each pair could be recovered successfully for the first five weeks. Nevertheless, after working through most of the issues that plagued the sorbent trap monitoring system for the first five weeks of the program, the operation and maintenance of the Method 324 sorbent traps when sampling sorbent traps on a weekly basis, required approximately 1-3 hours per week.

Maintenance of the Hg-CEMS included weekly calibration checks as well as daily inspections to ensure continued sampling. The six-month period covered emissions from June 24, 2005 until December 20, 2005. This included calibration checks and routine catalyst and filter replacements. The following Horiba DM-6 CEMS maintenance issues were observed.

- Buildup of fly ash / particulate matter in the probe and filter. The stack platform geometry required the use of a rather long (10 feet) probe with large internal diameter of the probe stinger. It is conceivable that particulate buildup along the stinger wall as well 
as in the particulate filter adsorbed mercury contained in the flue gas causing a consistently low bias of the Horiba CEM readings.

- Catalyst deactivation. The catalyst used to convert all oxidized forms of mercury to their elemental state underwent a rather rapid deactivation with an average life expectancy of approximately 2-3 weeks per catalyst. As a result, the CEM mercury readings dropped slowly over the course of 2-3 weeks subsequent to its installation.

- Cold spots / condensation in the probe. Condensation was observed in several parts of the probe, in particular in the initially unheated / not-insulated calibration tee coupling. This became of particular concern during the colder months of the monitoring part of the project and may have resulted in the scrubbing of mercury from the sample gas stream.

- Freezing of condensate in probe. On several occasions during the colder months of the year the condensate originating from the Peltier cooler removing moisture from the sample gas froze in the cooler. This led to blockage of the sampling path and eventually to an automatic suspension of the sampling activity via the Horiba CEM controller.

In summary, although mercury emissions monitoring techniques are progressing to be able to meet the regulatory needs of the promulgated CAMR rules, there is room for improvement of Hg CEMS both in performance and in maintenance and operation by plant personnel. 


\subsection{INTRODUCTION}

\subsection{Background}

The results of the 1990 Clean Air Act Amendments and the Environmental Protection Agency's (EPA) review of hazardous air pollutants has prompted development of technologies to remove mercury from coal or to capture mercury from the flue gases of coal-fired utilities. Wyoming's Powder River Basin (PRB) subbituminous coal resources are unique in their emissions characteristics, requiring special control and monitoring technologies. The Subbituminous Energy Coalition (SEC) identified the need (1) to re-test stack gas emissions from power plants that burn subbituminous coal relative to compliance with the EPA-proposed mercury control regulations for coal-fired plants, and (2) for specialized monitoring requirements associated with mercury continuous emissions monitors (CEM).

The overall objectives of the program were to develop and demonstrate solutions for the unique emission characteristics found when burning subbituminous coals. The program was to be executed in three phases: Phase I of the project covered mercury emission source sampling programs at ten (10) subbituminous coal-fired plants. Phase II compared the performance of continuous emission monitoring programs for mercury at subbituminous coal-fired power plants.

Western Research Institute (WRI) and Western Farmers Electric Cooperative and other SEC members have partnered with Clean Air Engineering to conduct a testing program that addresses the Phase II objectives. Phase II of the program, described herein, focused on obtaining a mass balance of mercury $(\mathrm{Hg})$ both total and speciated mercury across the Western Farmers Electric Cooperative (WFEC) Hugo Station subbituminous coal-fired power plant, a comparison of $\mathrm{Hg}$ source sampling methods, investigation into the variability of $\mathrm{Hg}$ emissions, and the long-term performance of continuous emission monitoring strategies for mercury.

\subsection{Objectives}

Phase II of the program focused on the following objectives:

- Performa total mercury (Hg) mass balance around the WEFC Generating Station,

- Investigate the distribution of $\mathrm{Hg}$ species across the air pollution control devise (APCD) and at the stack,

- Compare Hg source sampling methods including RATA testing of Method 324 and Horiba DM-6 continuous emission monitoring system (CEMS),

- Assess long-term mercury variability at Hugo Generating Station, and

- Document the long-term operations and maintenance of Method 324 sorbent traps and the Horiba DM-6 Hg CEMS. 
Long-term performance verification of $\mathrm{Hg}$ emissions monitoring was of direct interest to the sponsoring SEC members.

\subsection{SITE DESCRIPTION AND METHODOLOGY}

\subsection{Site Description}

Western Farmers Electric Cooperative (WFEC) produces power at the Hugo Generating Station located in Fort Towson, Oklahoma. The plant, Figure 2.1.1, is a base-loaded, front and rear fired unit (Unit 1) with a generating capacity of 450MW. The Hugo Station employs coldside ESP for particulate control

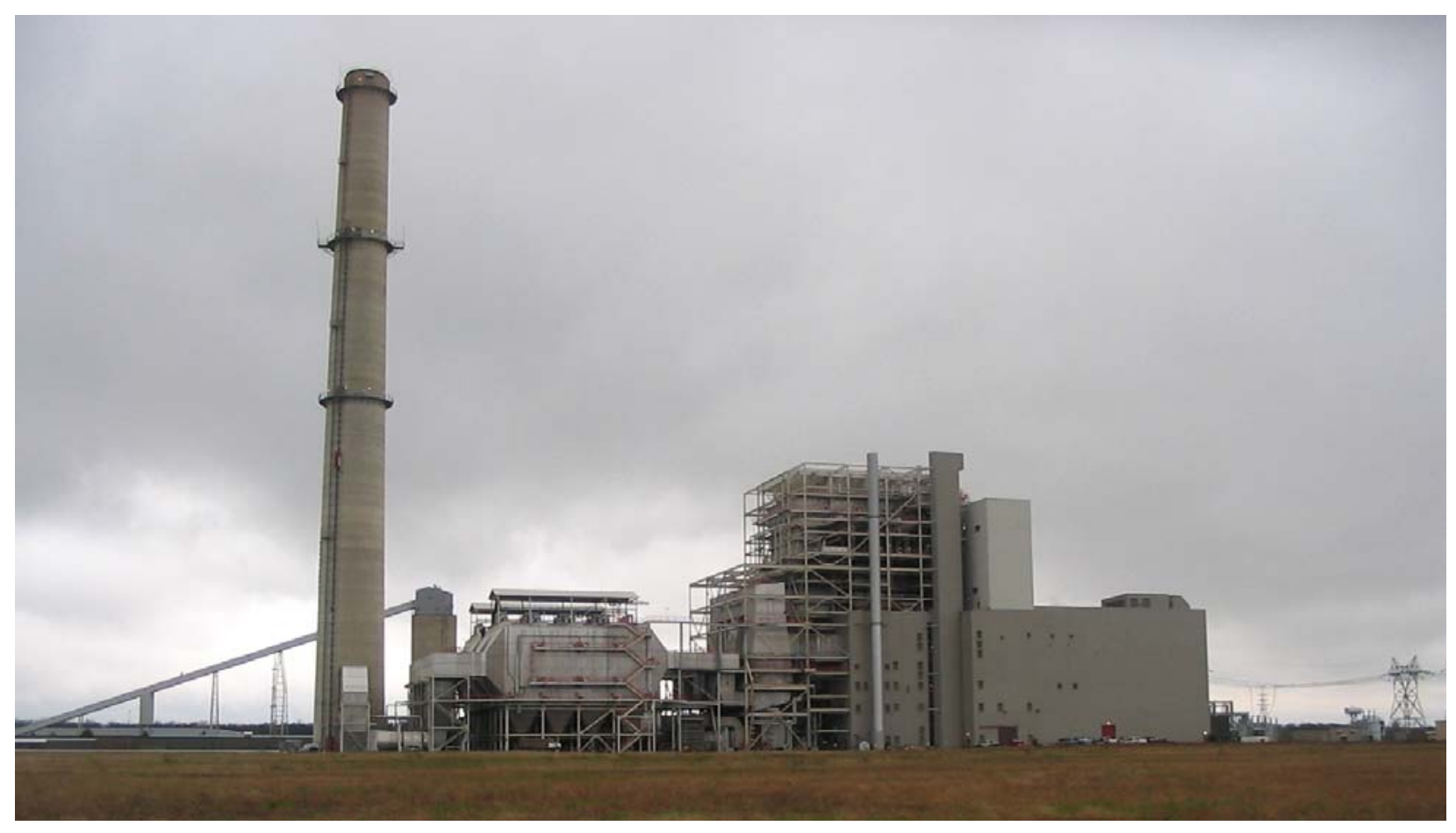

Figure 2.1.1 Photograph of the WFEC Hugo Generating Station located near Hugo, Oklahoma.

Photographs of the stack and the ESPs are shown in Figure 2.1.2. A generalized process schematic of the Hugo Station is shown in side-view and layout-view in Figures 2.1.3 and 2.1.4.

Fly ash collected in the ESP hoppers is transported into storage silos and sold as concrete admixture. From the boiler, the flue gas ductwork splits into four smaller ducts which lead to parallel electrostatic precipitators (ESP). 


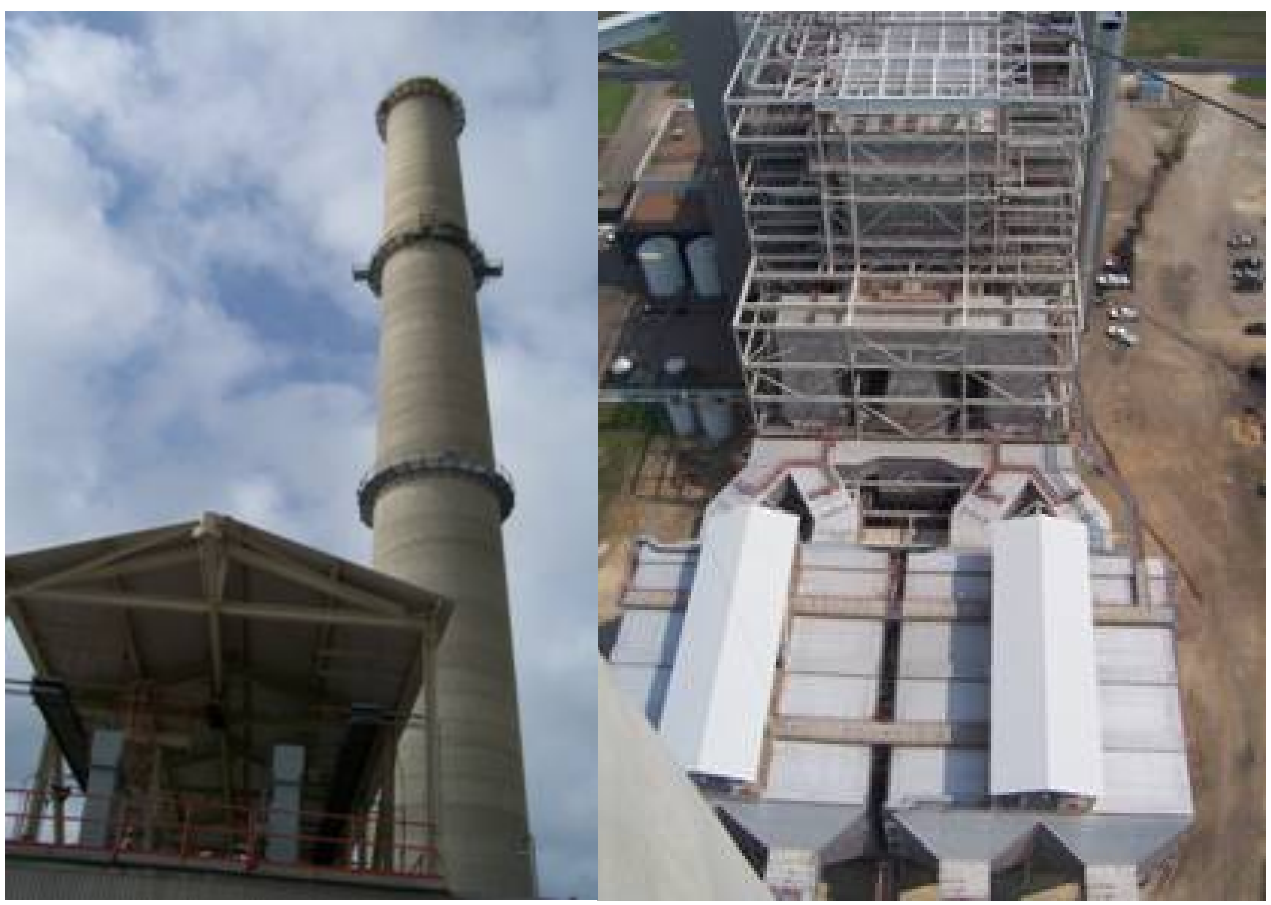

Figure 2.1.2 Process Schematic and photograph of the Hugo plant layout

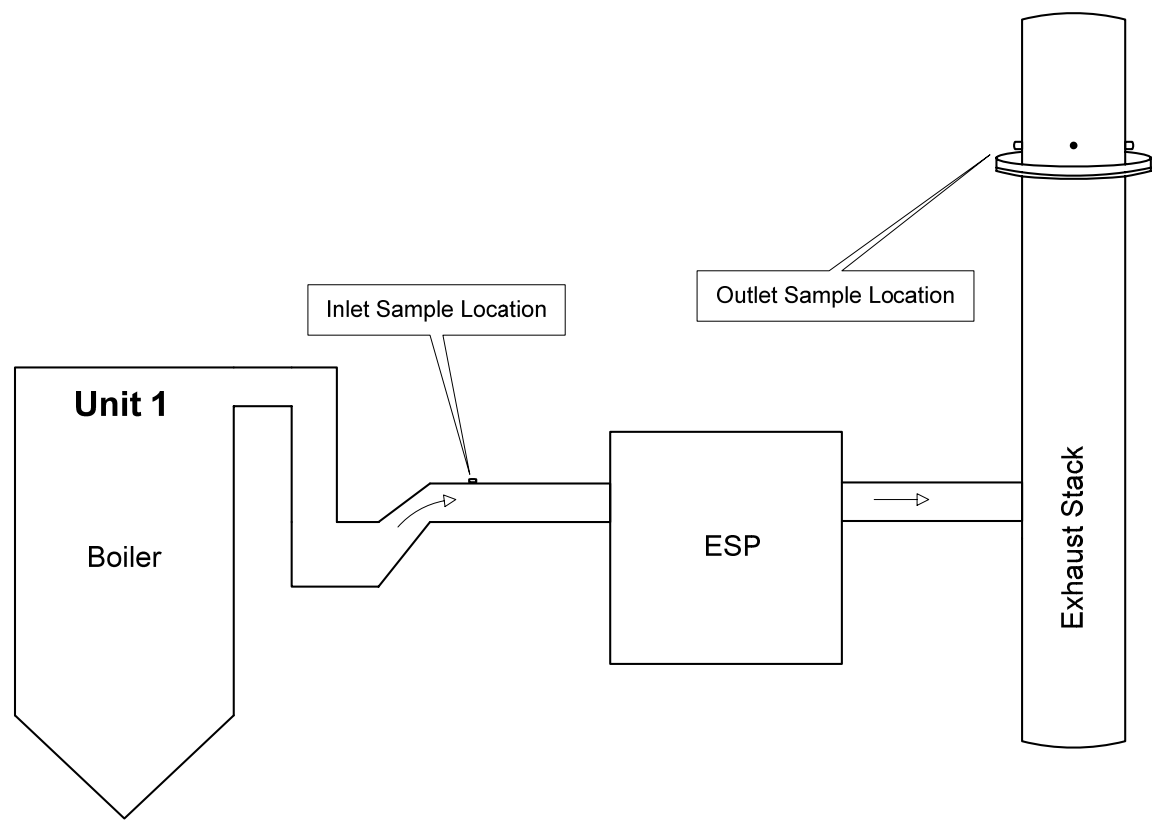

Figure 2.1.3 Schematic of plant configuration, side view. 


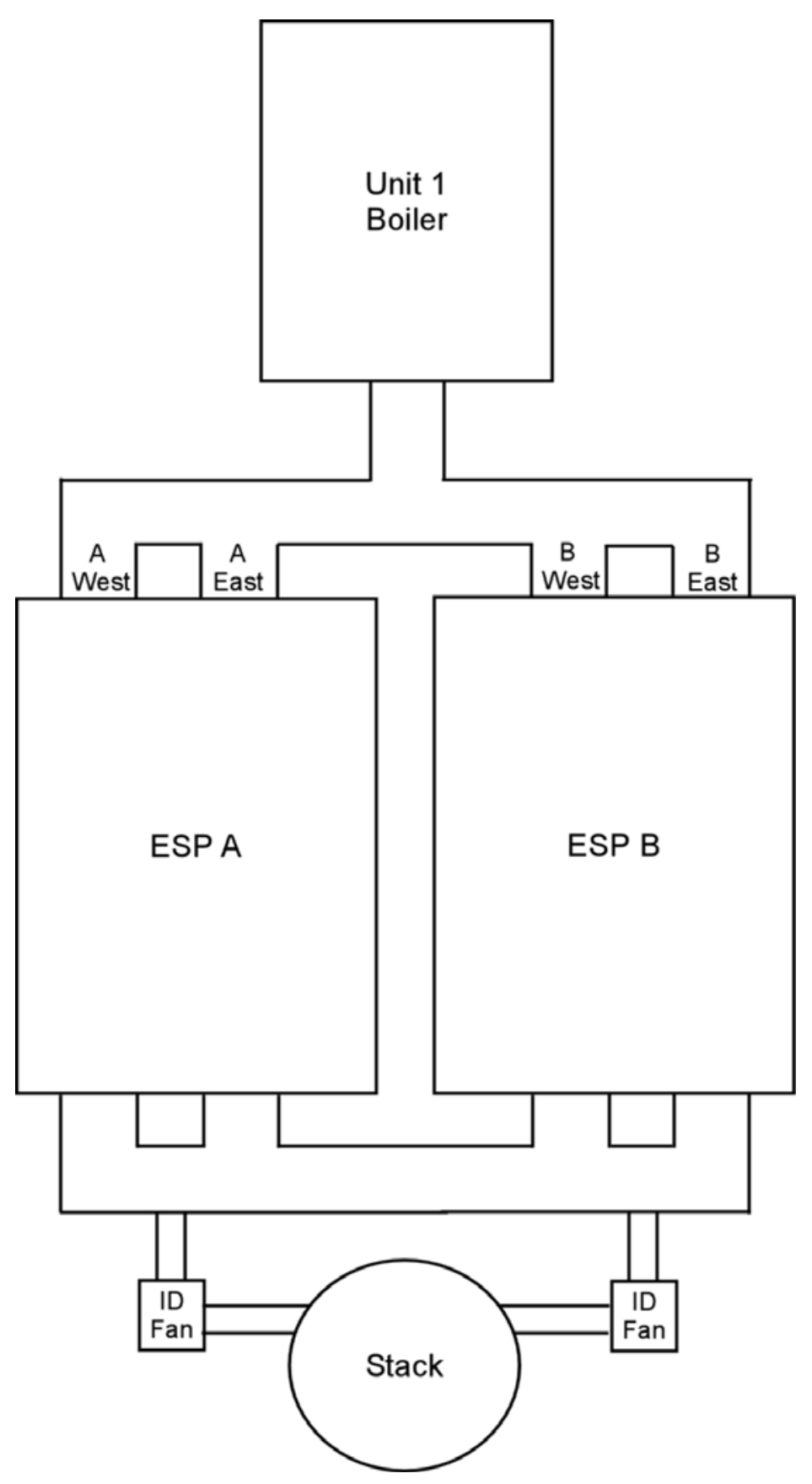

Figure 2.1.4 Schematic of the Hugo site, plan view.

The flue gas entering the ESPs each feeds a row of eight hoppers. From the ESPs, flue gas is pulled through two (2) induced draft fans and routed to the flue gas exhaust stack. The flue gas exhausts through an approximately 450 feet high stack that is 28.3 feet in diameter, equipped with an EPA testing platform that is located approximately 360 feet above ground level and which is accessible via an elevator. 
The plant burns approximately 250 tons per hour of pulverized subbituminous low-sulfur coal originating from two mines in the Powder River Basin area near Gillette, Wyoming. The two coals have remarkably similar compositional characteristics as shown in Table 2.1.1.

Table 2.1.1 Summary of the coal analyses for Hugo's two subbituminous coal sources.

\begin{tabular}{lll}
\hline & Mine A (Buckskin) & Mine B (Eagle Butte) \\
\hline Proximate (wt.\%) & 30.01 & 30.75 \\
Moisture & 4.77 & 4.67 \\
Ash & 34.81 & 34.40 \\
Fixed Carbon & 30.41 & 30.18 \\
Volatile Matter & & \\
Ultimate Analysis (wt. \%) & 49.25 & 49.18 \\
C & 3.19 & 3.07 \\
H & 0.64 & 0.60 \\
N & 0.33 & 0.21 \\
Sulfur & 8405 & ??? \\
Heating Value (Btu/lb, dry) & & 0.00 \\
Forms of Sulfur (wt. \%) & 0.00 & 0.21 \\
Sulfate & 0.24 & 0.00 \\
Organic & 0.09 & 0.070 \\
Pyritic & 0.068 & \\
Mercury (ppm, dry) & & \\
\hline
\end{tabular}

\subsection{Description of Sampling Locations}

WRI and Clean Air Engineering of Pittsburgh, PA, installed a dry thermo-catalytic Horiba-NIC Model DM-6 $\mathrm{Hg}^{\mathrm{T}}$ CEMS at the stack sampling location. A sorbent trap-based monitoring system was also installed at the sampling location. All inlet source sampling reported in this document was performed on one of the four ESP inlets. The inlet duct labeled 'B-West' was chosen for sampling as it was the most representative sampling location for flue gas constituents. All flue gas exhaust outlet sampling occurred at the stack sampling platform.

Traverse point 1 involved a port to point distance (in.) 109.77 inches; traverse point 2 involved a port to point distance of 65.82 inches, traverse point 3 involved a 35.56 inches and Travers point 4 involved a port to point distance of 10.97 inches. Duct diameters upstream from the flow disturbance (A) were 8.0 with a limit of 0.5 ; and duct disturbance downstream from the flow disturbance (B) was 8 with a limit of 2.0. A diagram of sampling points is shown in Figure 2.2.1 below. 


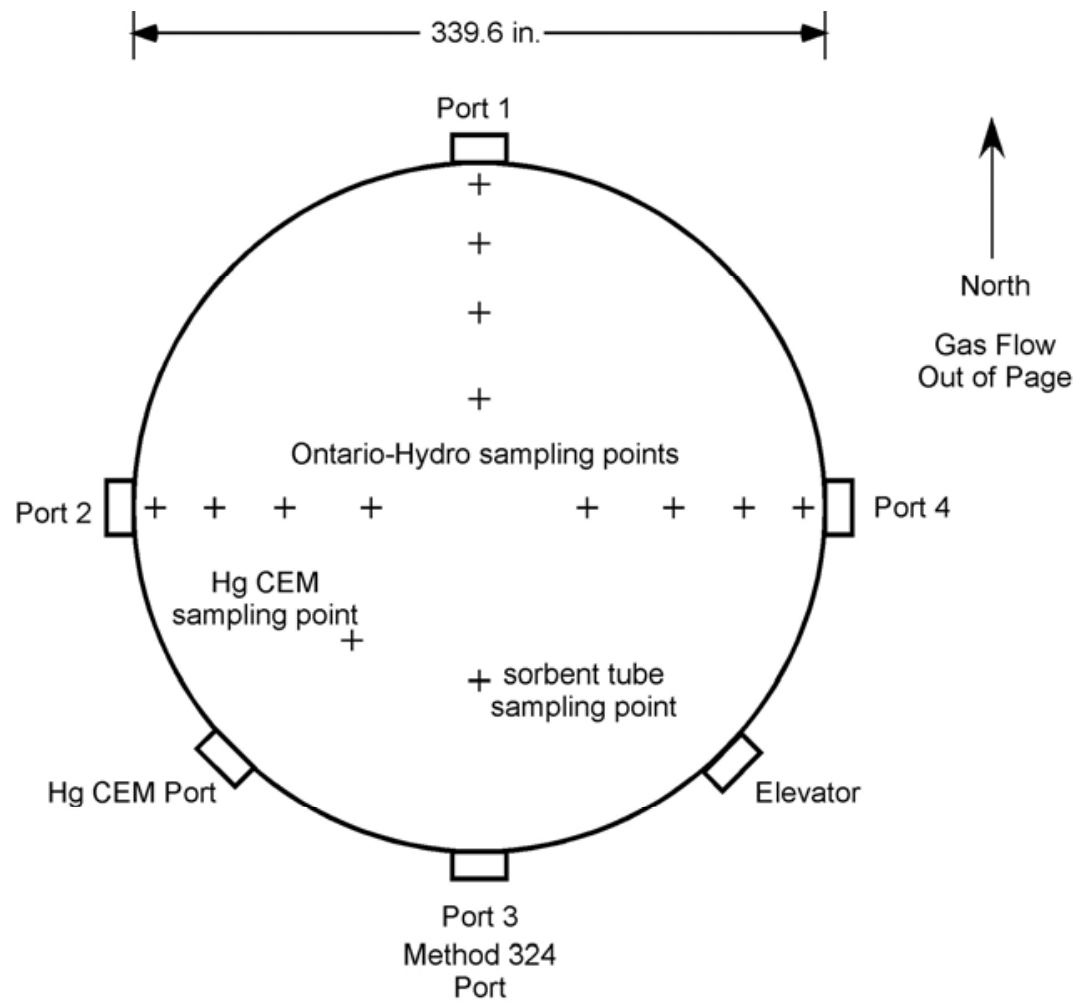

Figure 2.2.1 Diagram of emissions source sampling traverse points at exhaust stack.

Ontario Hydro testing at the ESP inlet B-West duct and stack were performed using paired trains. These trains were labeled A \& B. Run 1A and 1B were voided due to a plant trip at the half-way point of the test run. The labeling of the stack test runs, 7 through 9 , although different from the ESP inlet run numbering were indeed sampled simultaneously to the ESP inlet test runs. The stack test runs were part of the $\mathrm{Hg}$ test methods and monitoring inter-comparison in addition to $\mathrm{Hg}$ mass balance testing.

Sample points at the exhaust stack platform location conformed to EPA Method 1. The sorbent tube sampling point and Hg-CEMS sampling point at the stack sampling location were in accordance with the guidelines of EPA Performance Specification 12-A. All sampling at the ESP inlet location was also in accordance with EPA Method 1 as seen in Figure 2.2.2. 


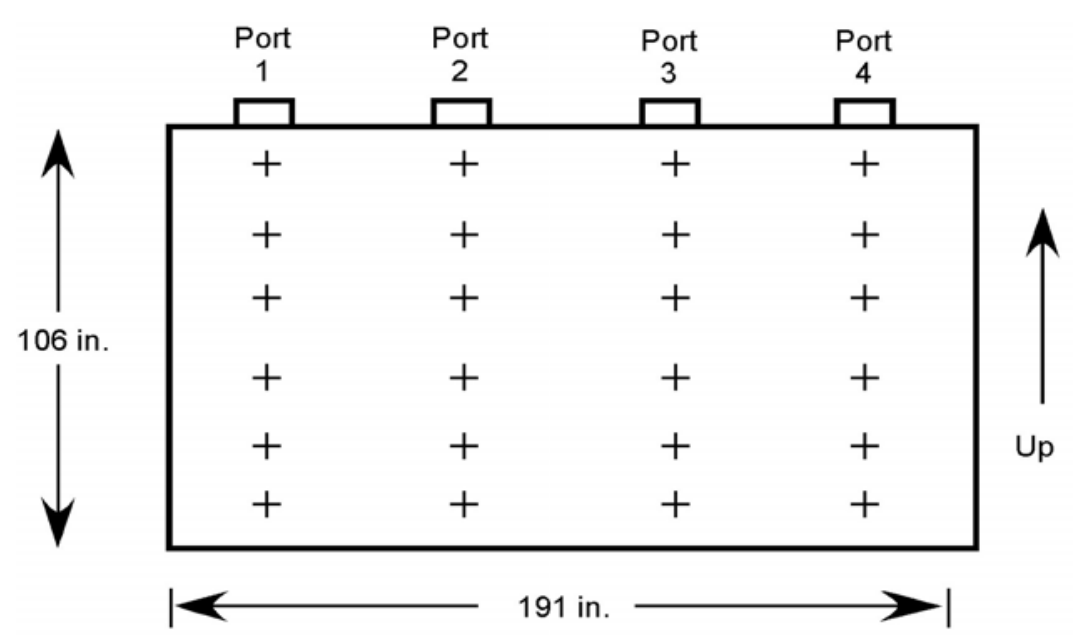

Figure 2.2.2 Diagram of emissions source sampling traverse points at the ESP inlet

Traverse point 1 involved a port t o point distance (in.) 109.77 inches; traverse point 2 involved a port to point distance of 65.82 inches, traverse point 3 involved a 35.56 inches and traverse point 4 involved a port to point distance of 10.97 inches. Duct diameters upstream from the flow disturbance (A) were 8.0 with a limit of 0.5 ; and duct disturbance downstream from the flow disturbance (B) was 8 with a limit of 2.0. A diagram of sampling points is shown in Figure 2.2.2 above.

\subsection{Mercury Measurement and Monitoring Methods}

Three methods were used in the study to determine the mercury concentration in the flue gases at Hugo. These methods were installed at the ESP inlet B West duct as described earlier. These methods were ASTM 6784-02 (Ontario Hydro) that measures both total gaseous Hg emissions, as well as species of mercury; EPA Method 324 (carbon tube) that measures total gaseous mercury; and dry thermo-catalytic CEM (Horiba NIC DM 6) which also measures the total gaseous mercury.

\subsubsection{Ontario-Hydro Mercury Speciation Method}

Ontario Hydro method is a standard test method for speciated mercury measurement. The method measures particulate-bound mercury $(\mathrm{HgP})$, elemental $(\mathrm{Hg} 0)$, and oxidized forms $(\mathrm{Hg} 2+)$. The Ontario Hydro provides good results with a level of sensitivity of $<0.5 \mathrm{mg} / \mathrm{m}^{3}$. The measurements range from 0.5 to $100 \mathrm{mg} / \mathrm{m}^{3}$. The Ontario Hydro method measurements are typically time integrated between 2-3 hours. The isokinetic gas sample volume ranges between $1000 \mathrm{~L}$ to $2500 \mathrm{~L}$. The collected solutions from the impingers are analyzed off-site at a laboratory using cold-vapor atomic absorption spectoscopy (CVAAS) or cold-vapor atomic fluorescence spectroscopy (CVAFS). A schematic of the OH testing setup is shown in Figure 2.3.1.1. 


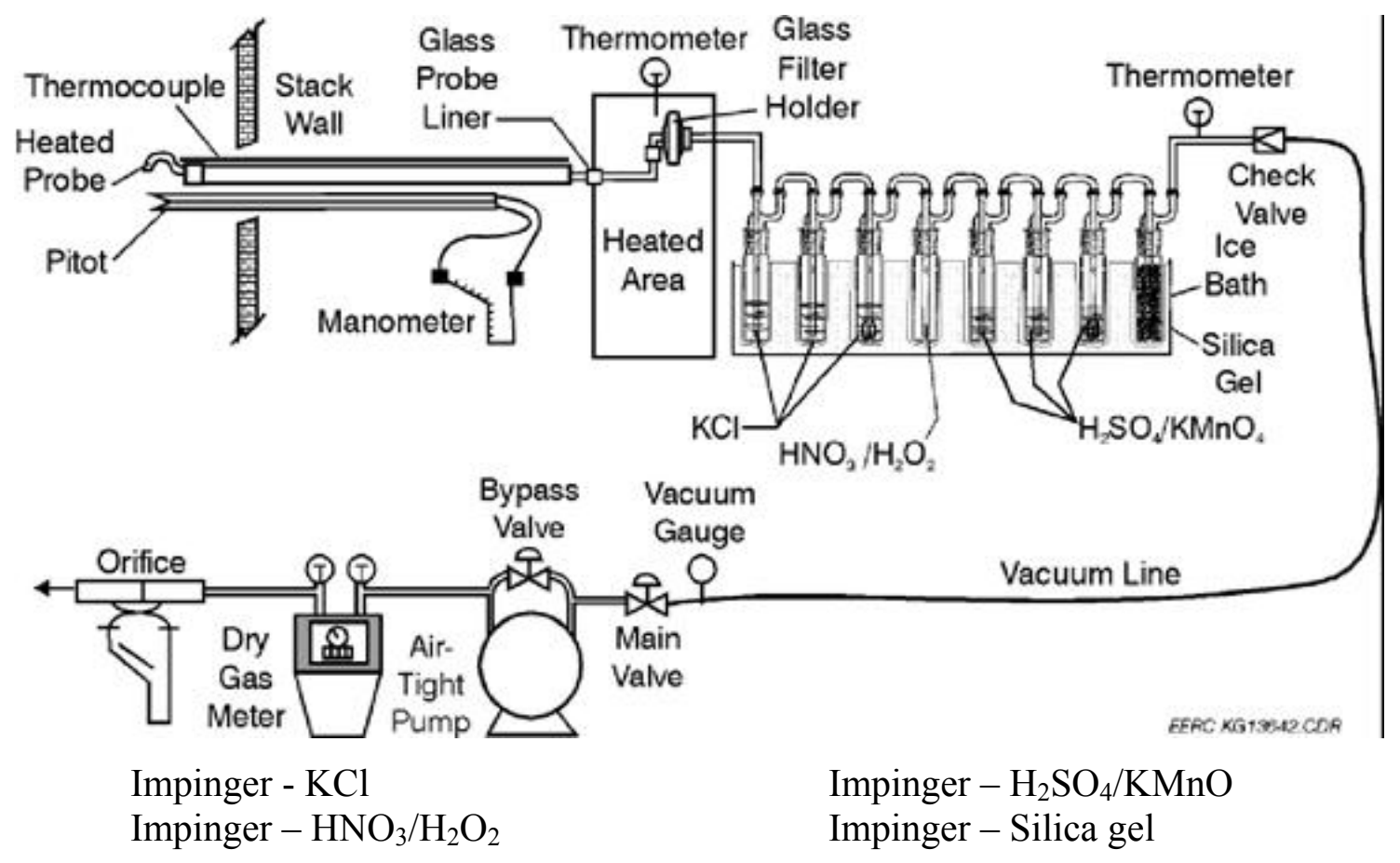

Figure 2.3.1.1 Schematic of the Ontario Hydro testing apparatus

Table 2.3.1.1 summarizes the type of standard sampling and analytical methods used during sample collection. A single contractor (Clean Air Engineering of Pittsburgh, PA) and a single analytical laboratory were used for the emission testing and analysis. This procedure reduced the inter-laboratory and contractor-related data variability. Both companies have extensive experience plant emission source sampling and mercury analyses. Samples and data were collected as per established procedures by the ASTM and the EPA. Table 2.3.1.2 shows the sample or data collected and the procedure used to obtain and/or analyze the same.

Table 2.3.1.1 Sampling Methods and Analytical Procedures

\begin{tabular}{|c|c|c|c|}
\hline Parameter & $\begin{array}{c}\text { Sampling } \\
\text { Method }\end{array}$ & Analytical Method & Laboratory \\
\hline Gas Flow & Methods 1 and 2 & draft gauge, S-type pitot tube & \multirow{3}{*}{$\begin{array}{l}\text { Clean Air } \\
\text { Engineering } \\
\text { On-Site }\end{array}$} \\
\hline $\mathrm{O}_{2} / \mathrm{CO}_{2}$ & Method 3 & $\begin{array}{l}\text { wet chemical } \\
\text {-Orsat instrument }\end{array}$ & \\
\hline Moisture $\left(\mathrm{H}_{2} \mathrm{O}\right)$ & Method 4 & gravimetric & \\
\hline $\begin{array}{l}\text { Particulate } \\
\text { Matter }\end{array}$ & $\begin{array}{l}\text { Method } 5 \text { (Outlet) } \\
\text { or } 17 \text { (Inlet) }\end{array}$ & gravimetric & $\begin{array}{l}\text { Clean Air } \\
\text { Engineering } \\
\text { Pittsburgh, PA }\end{array}$ \\
\hline $\begin{array}{l}\text { Speciated } \\
\text { Mercury }\end{array}$ & $\begin{array}{l}\text { Ontario Hydro } \\
\text { Method }\end{array}$ & $\begin{array}{l}\text { Cold Vapor Atomic } \\
\text { Absorption (CVAAS) }\end{array}$ & Element One \\
\hline
\end{tabular}


$\mathrm{OH}$ testing was tested in accordance with the following USEPA and ASTM source emissions test methods. Methods 1 through 4, 5 and 17 are referenced in 40 CFR Part 60, Appendix A. The Ontario Hydro Method is a Preliminary Draft Test Method (designated as PRE 3) and may be found at www.epa.gov/ttn/emc/prelim.html.

Table 2.3.1.2 Summary of the Source Sampling Procedures
Method 1
Sample and Velocity Traverses for Stationary Sources
Method 2
Method 3
Method 4
Determination of Stack Gas Velocity and Volumetric Flow Rate (S-Type Pitot Tube)
Method 5
Gas Analysis for the Determination of Dry Molecular Weight
Determination of Moisture Content in Stack Gases
Method 17
Determination of Particulate Emissions from Stationary Sources
Determination of Particulate Emissions from Stationary Sources (In-Stack Filtration)
PRE 3
Standard Test Method for Elemental, Oxidized, Particle-Bound and Total Mercury in Flue Gas Generated from Coal-Fired Stationary Sources (Ontario-Hydro Method)

Gas flow rate, particulate matter (PM), and speciated $\mathrm{Hg}$ levels were determined in accordance with EPA Methods 1, 2, 3, 4, 5 or 17, and PRE 3 (the Ontario Hydro Method).

Each sampling period consisted of conducting a temperature and differential pressure traverse of the duct with a K-type thermocouple and an S-type pitot tube. Concurrently, a gas sample was extracted at an isokinetic flow rate for a 120-minute period. At the inlet, the gas sample passed through an in-stack Teflon-coated nozzle and filter holder assembly, through a heated Teflon probe liner and through a series of eight impingers. At the outlet, the gas sample passed through a heated Teflon-coated nozzle, through a heated Teflon probe and a heated filter, and through a series of eight impingers. Integrated gas samples were collected in Tedlar bags during each run for diluent $\left(\mathrm{O}_{2}\right.$ and $\left.\mathrm{CO}_{2}\right)$ analysis using a Fyrite instrument. Additionally, carbon dioxide $\left(\mathrm{CO}_{2}\right)$ values taken from the plant CEMS (Continuous Emissions Monitoring System) data were used for Method 19 calculations.

Prior to sampling, the first three impingers were each seeded with 100 milliliters $(\mathrm{ml})$ of potassium chloride $(\mathrm{KCl})$. The fourth impinger was seeded with nitric peroxide $\left(\mathrm{HNO}_{3} / \mathrm{H}_{2} \mathrm{O}_{2}\right)$. The fifth, sixth, and seventh impingers were each seeded with $100 \mathrm{ml}$ of acidified potassium permanganate $\left(\mathrm{KMnO}_{4}\right)$. The eighth impinger was seeded with approximately 250 grams of dried silica gel.

Following sampling, the moisture gain in the impingers was measured gravimetrically to determine the moisture content of the stack gas. The filters and a series of acetone rinses of the nozzle and sampling hardware upstream of the filters were quantitatively recovered for gravimetric analysis to determine the particulate matter (PM) and particulate $\mathrm{Hg}$ content of the 
gas streams. The impinger contents were recovered according to the procedures provided in the Ontario Hydro Method to determine the oxidized and elemental $\mathrm{Hg}$ content of the gas streams.

The above data were combined to calculate the gas velocity and volumetric flow rate in units of feet per second ( $\mathrm{ft} / \mathrm{sec}$ ), actual cubic feet per minute (acfm), dry standard cubic feet per minute $(\mathrm{dscfm})$, and pounds per hour $(\mathrm{lb} / \mathrm{hr})$. The PM levels were calculated in units of grains per dry standard cubic foot (gr/dscf), pounds per million British thermal units (lb/MMBtu), and $\mathrm{lb} / \mathrm{hr}$. Each Hg fraction (particulate bound, oxidized, elemental and total) was calculated in units of micrograms per dry standard cubic meter $(\mu \mathrm{g} / \mathrm{dscm})$, trillion British thermal units (lb/TBtu), and $\mathrm{lb} / \mathrm{hr}$.

Photographs of the equipment used for the paired train at the stack are shown in Figures 2.3.1.2 and 2.3.1.3.

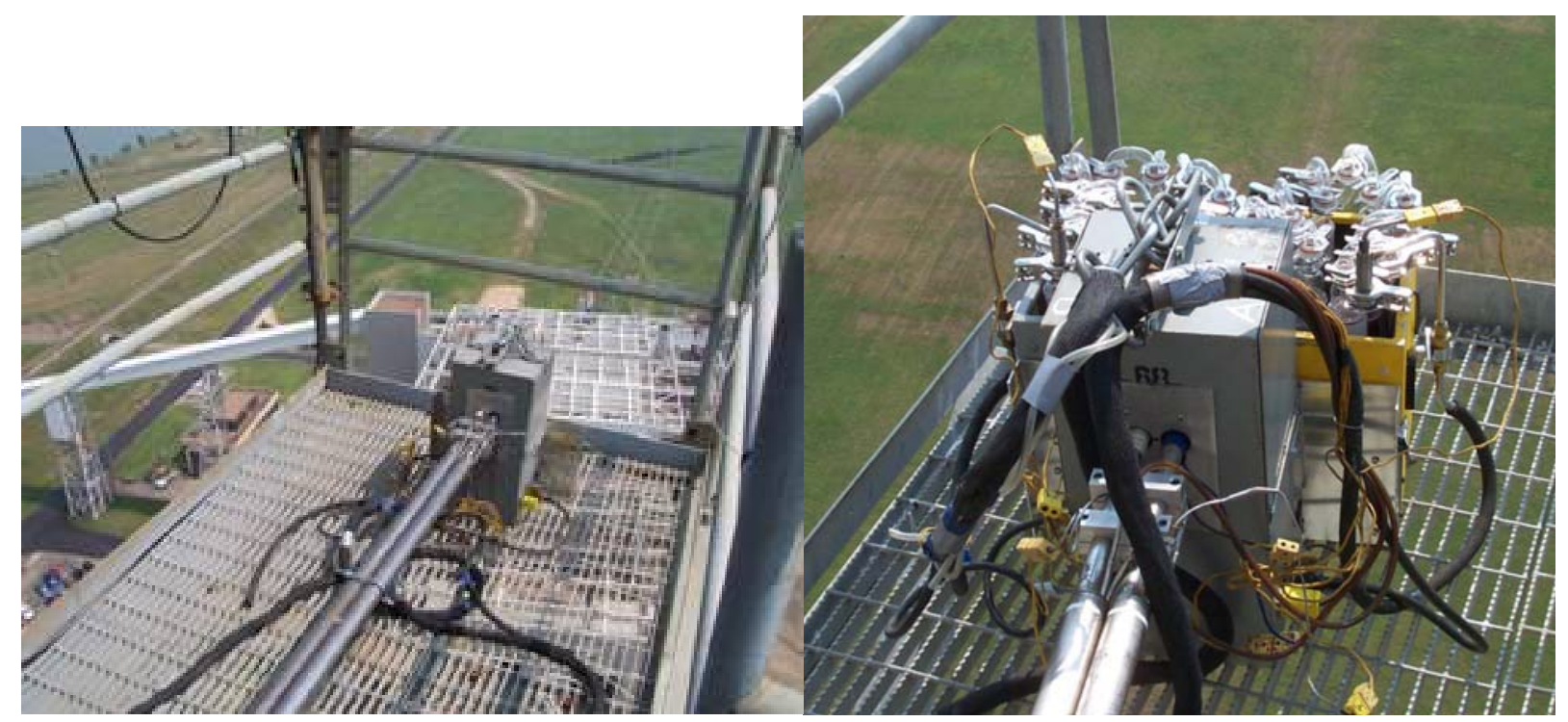

Figure 2.3.1.2 Photographs of the Ontario-Hydro probe at the stack 


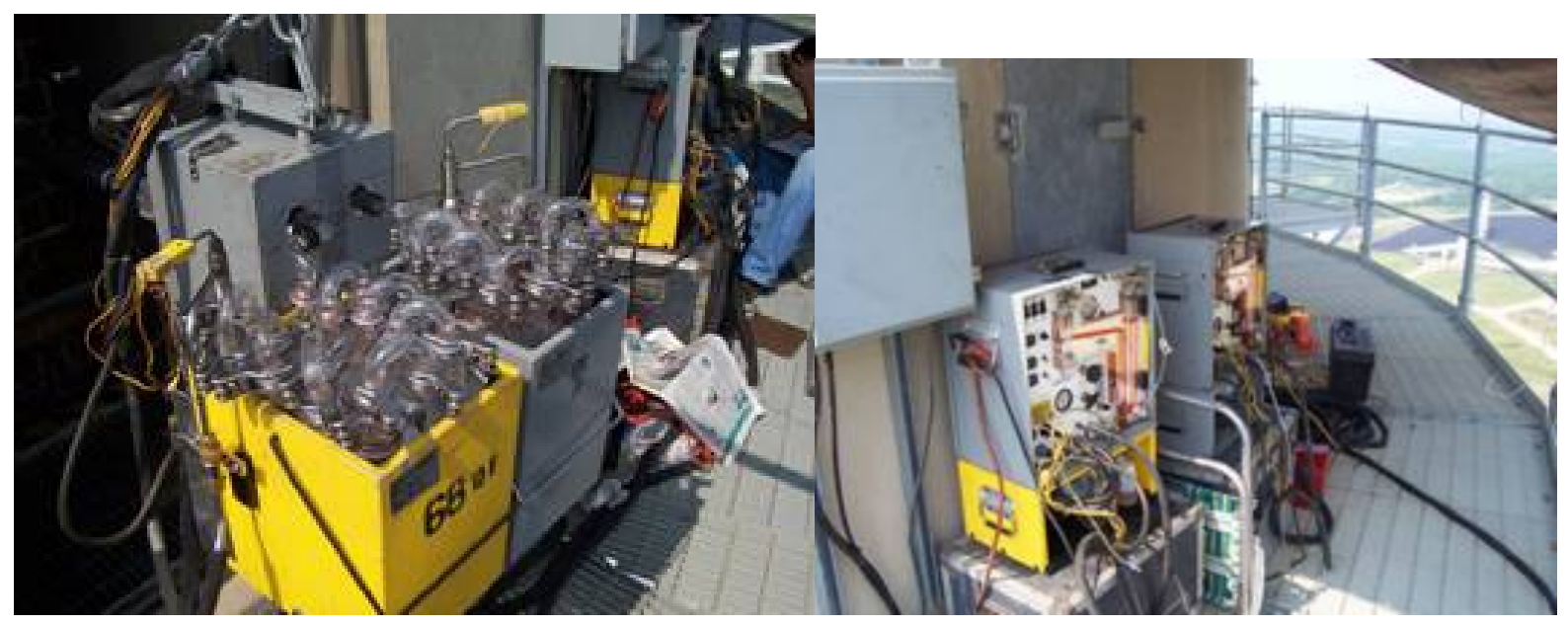

Figure 2.3.1.3 Photographs of the Ontario-Hydro rotameters and impingers at the stack

In addition, a paired train for the $\mathrm{OH}$ analysis was also installed and tested at the ESP inlet. A sampling rig was installed (see Figure 2.3.1.4) for testing at that location.

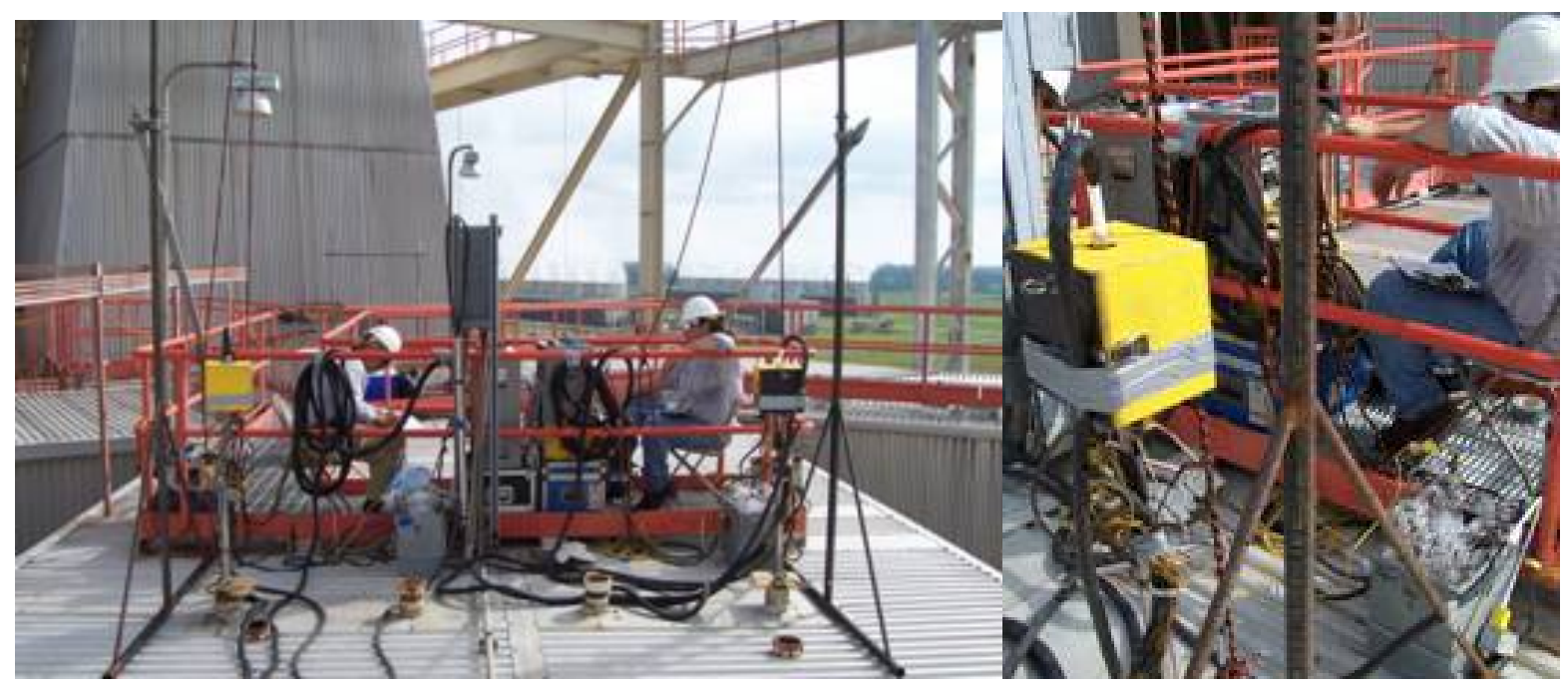

Figure 2.3.1.4 Photographs of installation of equipment and probes at the ESP inlet

\subsubsection{Method 324 Mercury Monitoring}

Method 324 measures gaseous mercury in low-dust applications. Gaseous mercury is trapped on iodine impregnated activated carbon traps and is then analyzed off-site by cold vapor atomic fluorescence spectrometry (CVAFS). The duration of sampling on a single trap is 30 minutes to 10 days. As such, it does not provide actual continuous analysis of the mercury in the flue gas, but rather an average of mercury in the flue gas over the sampling interval. 
An automated sorbent trap-sampling system was installed to perform the sorbent trap monitoring. The sorbent trap monitoring was conducted in accordance with the now withdrawn previously proposed US EPA Method 324 (Determination of Vapor Phase Flue Gas Mercury Emissions from Stationary Sources Using Dry Sorbent Trap Sampling).

The complete system consisted of two independent gas sampling trains (designated A and $\mathrm{B}$ in this report) is illustrated in Figure 2.3.2.1. Each sampling train included an auto-sampler, a moisture removal system and a heated sample line. The only exception to this was a single probe accommodating both sorbent traps at a distance of approximately 1-inch. As a result, two samples were collected simultaneously from the same general spatial point in the flue gas stream. The insertion depth of the sampling probe into the stack was approximately 36 inches. The probe was not heated as the average temperature of the stack was well above $300^{\circ} \mathrm{F}$.

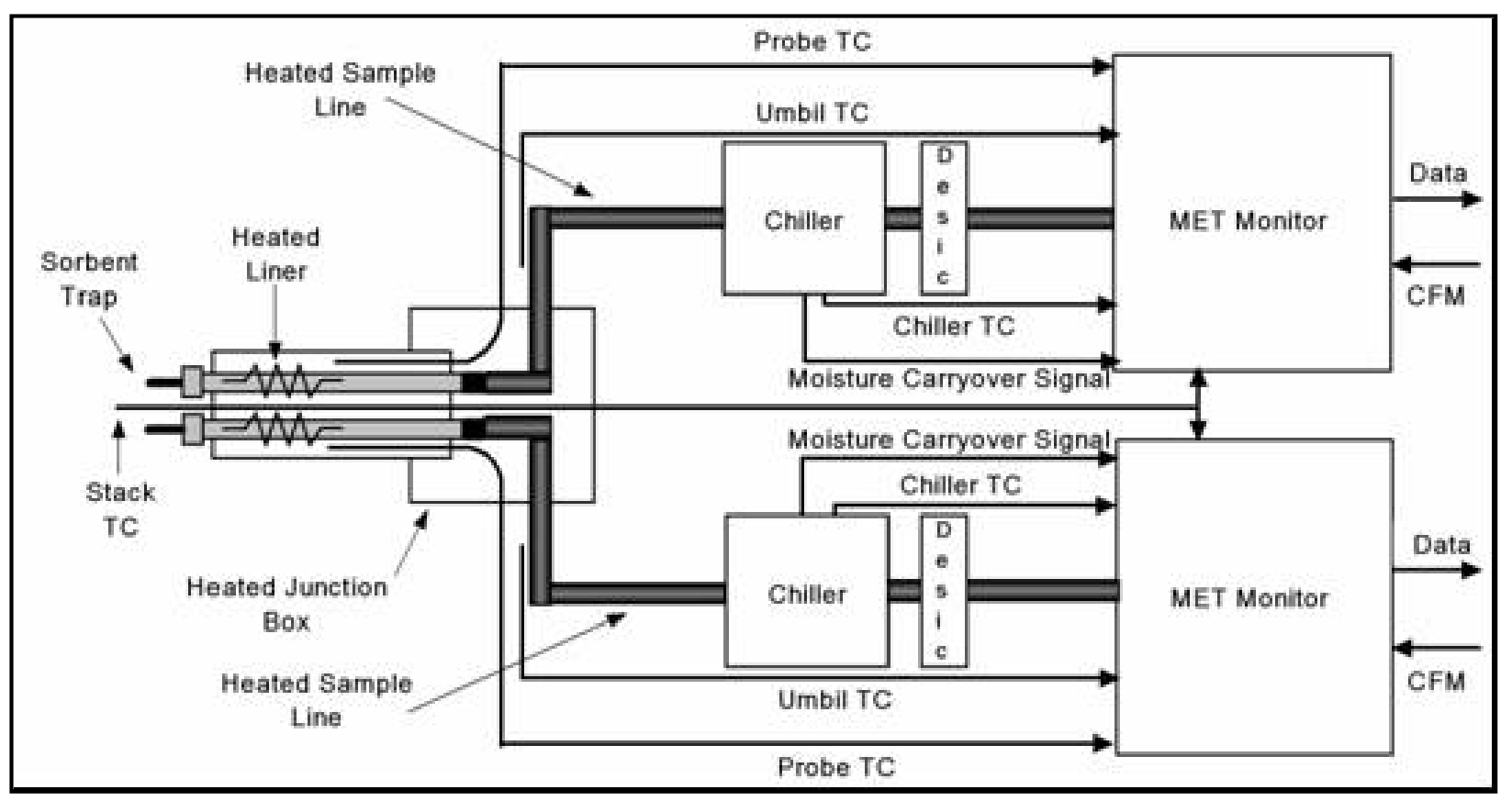

Figure 2.3.2.1 Sorbent trap sampling train scematic

The system (excluding the probe) was housed in a shelter at the main stack sampling platform (Figure 2.3.2.2). 


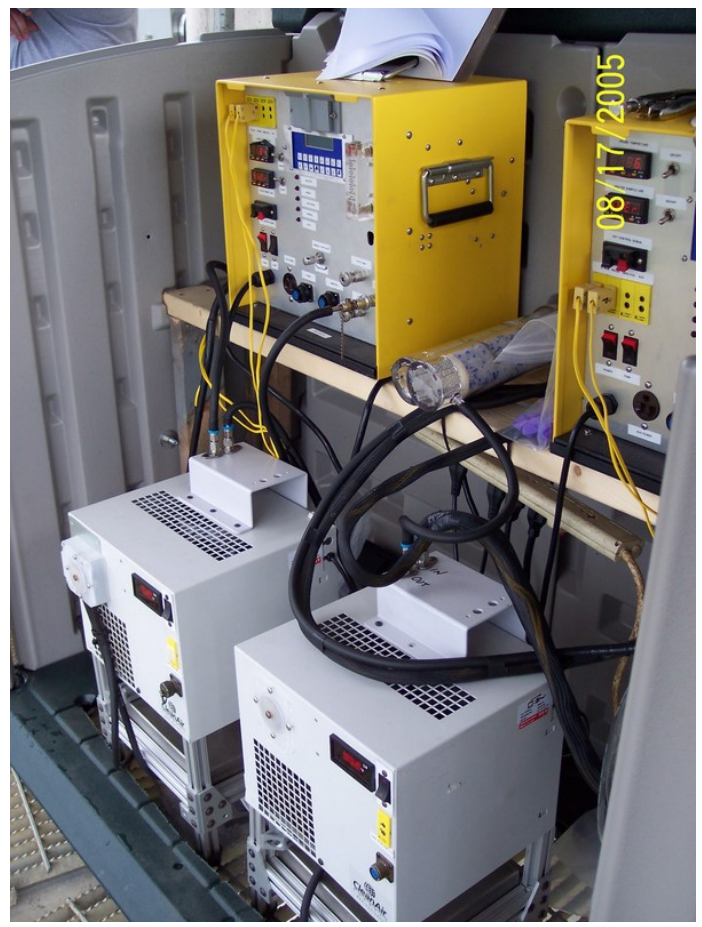

\section{Figure 2.3.2.2 Sampling system used at WFEC Hugo plant}

Photographs of the details of the probe ends of the Method 324 eqipment used in the Hugo testing is presented in Figure 2.3.2.4. and photographs of the installation of Method 324 equipment at the stack (Figure 2.3.2.5).

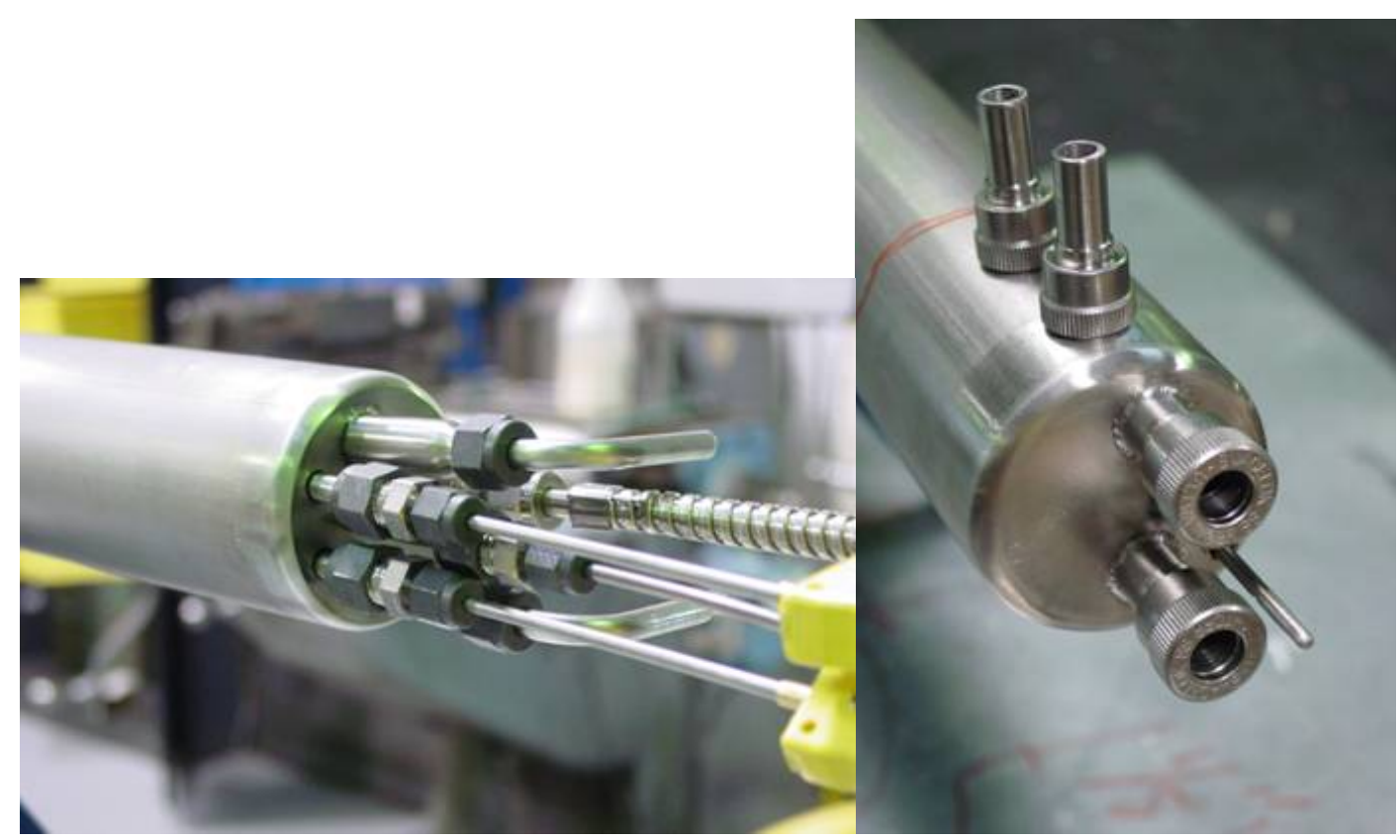

Figure 2.3.2.4 Photographs of the probe connections for the Method 324 equipment 


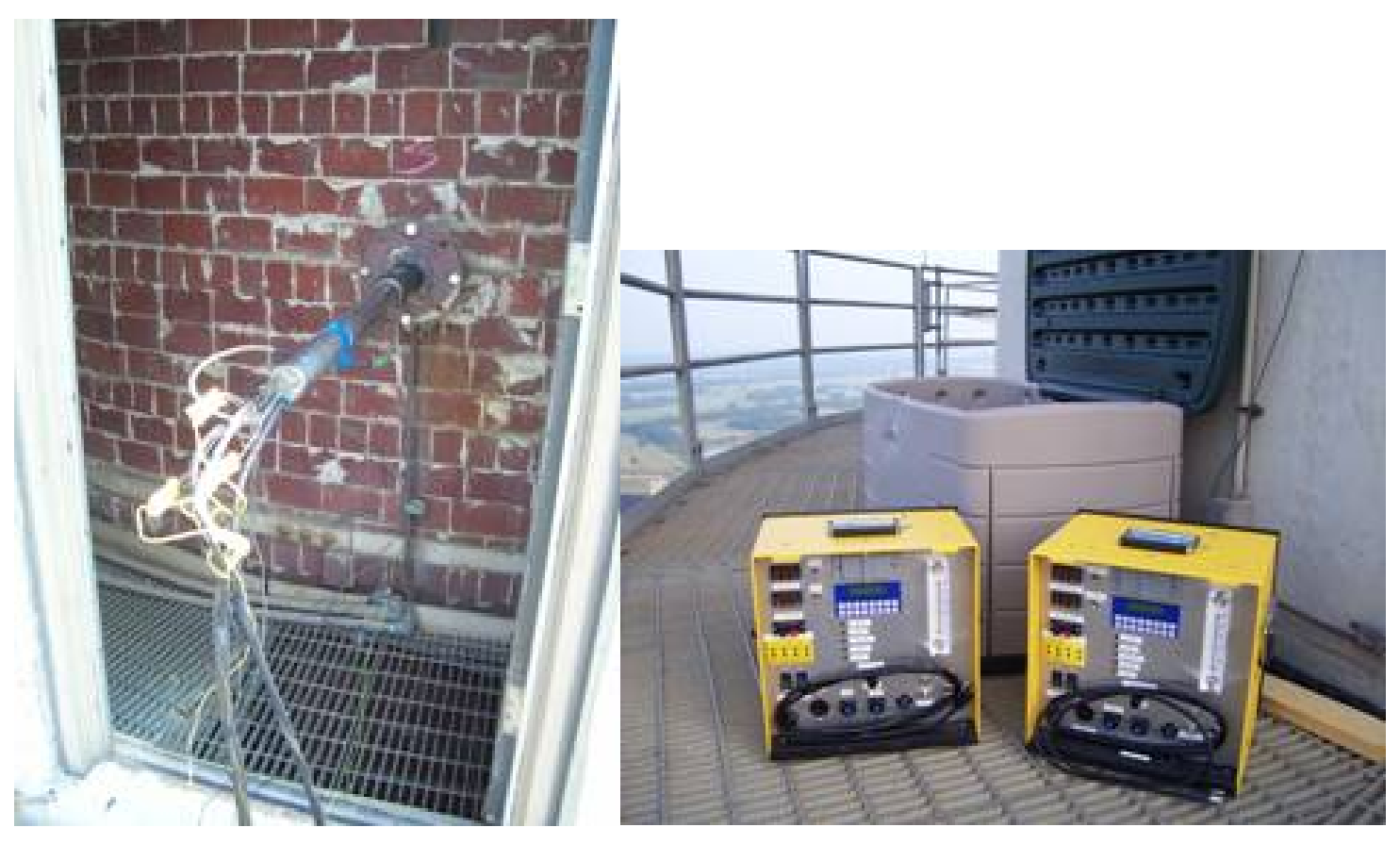

Figure 2.3.2.5 Photographs of the Method 324 equipment and penetration at the stack

Data was continuously acquired and stored by both auto-samplers in 10-minute intervals and included:

- Stack temperature

- Sample vacuum pressure

- Probe temperature

- Barometric pressure

- Heated umbilical temperature

- Sample volume

- Sample flow rate

- Sample temperature

- Stack flow rate surrogate $(4-20 \mathrm{~mA})$

The moisture removal system used for this program consisted of a compressor-type gas conditioner in addition to a desiccant container downstream of the conditioner constituting the final stage of the moisture removal system.

Sorbent traps used for this study consisted of two equal-mass sections of iodinated activated carbon separated by a quartz-wool plug and were in accordance with US EPA Method 324 (67 FR 4467) (Figures 2.3.2.3a and b). The first section denoted the main section is exposed 
to the flue gas sample, while the second section represents the backup or breakthrough section. All sorbent traps used in this study were obtained from Frontier Geosciences, Inc.

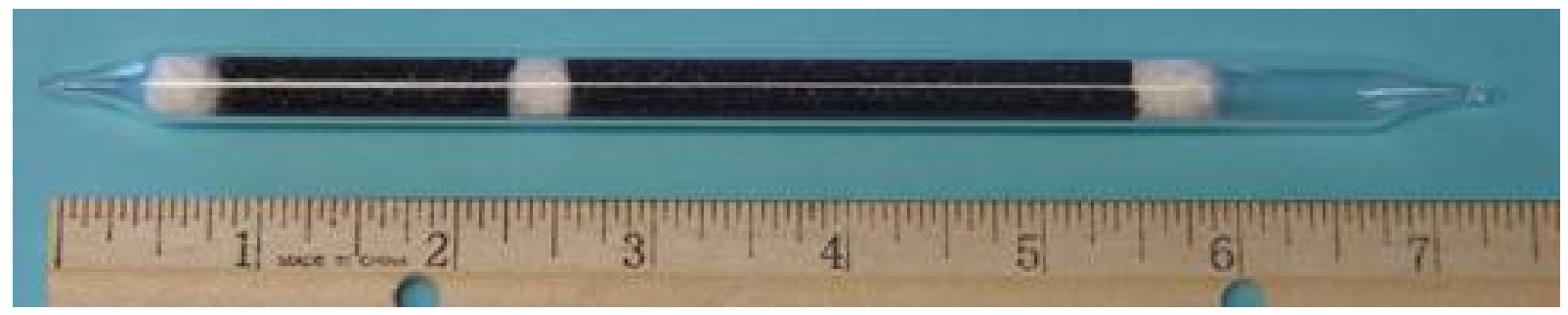

Figure 2.3.2.3a Photographs of the sorbent traps used in the study

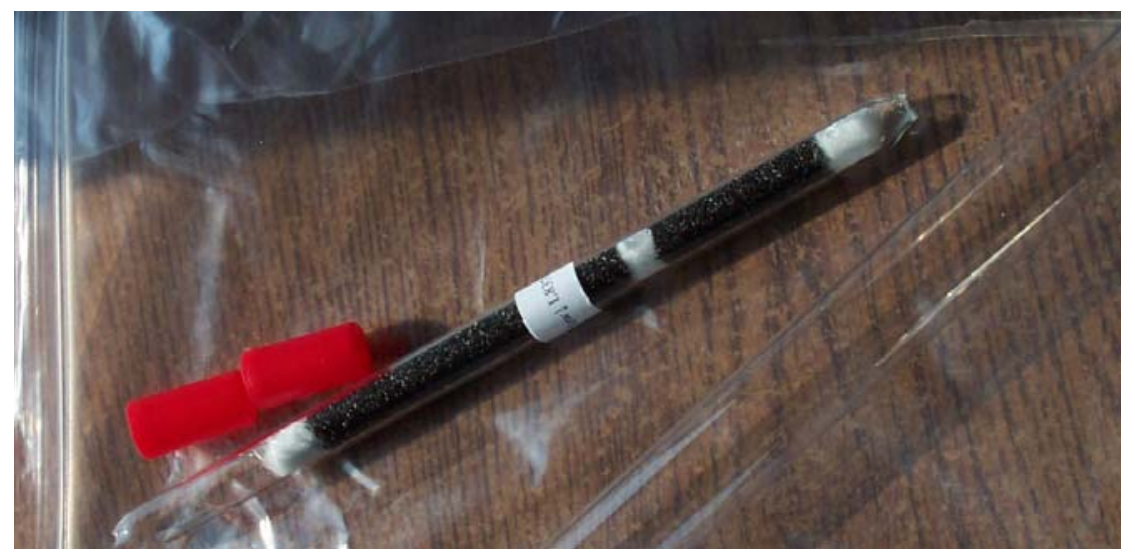

Figure 2.3.2.3b Photographs of the sorbent traps used in the study

For sample quality control, Method 324 Section 9.0 required that the mercury mass loading of each breakthrough section did not exceed $2 \%$ of the mercury mass loaded onto the main section, in order for the sample to be considered valid. In addition to these QC criteria, the Method 324 (Table 324-2 Section 9.0) required that a known mass of gaseous, elemental mercury be spiked onto the first section of each third sorbent trap, constituting a field spike that was to be recovered in the laboratory to $80-120 \%$. In the course of the monitoring part of this project, one sorbent trap was sampled and retrieved containing a spike on the first section being equal to three to four times the anticipated mercury loading of a regular sorbent trap. This spiked amount was suggested by Frontier Geosciences.

The analyses of each sorbent trap followed Method 324 protocol and employed acid digestion and cold vapor atomic fluorescence spectroscopy (CVAFS). All materials associated with each trap section were combined and analyzed together, i.e., any supporting substrate that the sample gas passed through prior to entering a media section (e.g., glass wool, etc.) was analyzed with that segment. 
As specified in Section 8.2.4 of Method 324, the gas sampling was intended to be performed at a sampling rate that was proportional to the stack flow rate using an analog signal from the plant flow monitor. After an unexpected break down of the stack flow surrogate (4$20 \mathrm{~mA}$ signal) supplied to the sorbent-trap sampling system, this approach was abandoned in favor of constant-flow sampling consistent with Section 8.2.3 of Method 324. The sample flow rate was set to approximate $0.4 \mathrm{Lpm}$.

Initially, sorbent trap exchanges were scheduled to be performed on a weekly basis. However, due to unexpected sampling system problems and depending on plant personnel schedule, sampling duration ranged from 2 to 7 days.

\subsubsection{Horiba DM-6 Mercury CEMS}

The third mercury measurement and monitoring method is the dry thermo-catalytic continuous emission monitor (CEM) via the Horiba NIC DM 6. The Horiba Hg CEM measures the total gaseous mercury on a real-time basis. The method consists of pre-treatment unit (dry thermo-catalytic converter) and elemental mercury detector (CVAA). The pre-treatment probe is located at the stack. The detection unit with data acquisition system was located in the Hg CEM trailer. The two are connected via a heated sample line. The probe is powered via a detecter unit and there is a separate data acquisition system. A schematic of the Horiba DM-6 CEMS is shown in Figure 2.3.3.1.

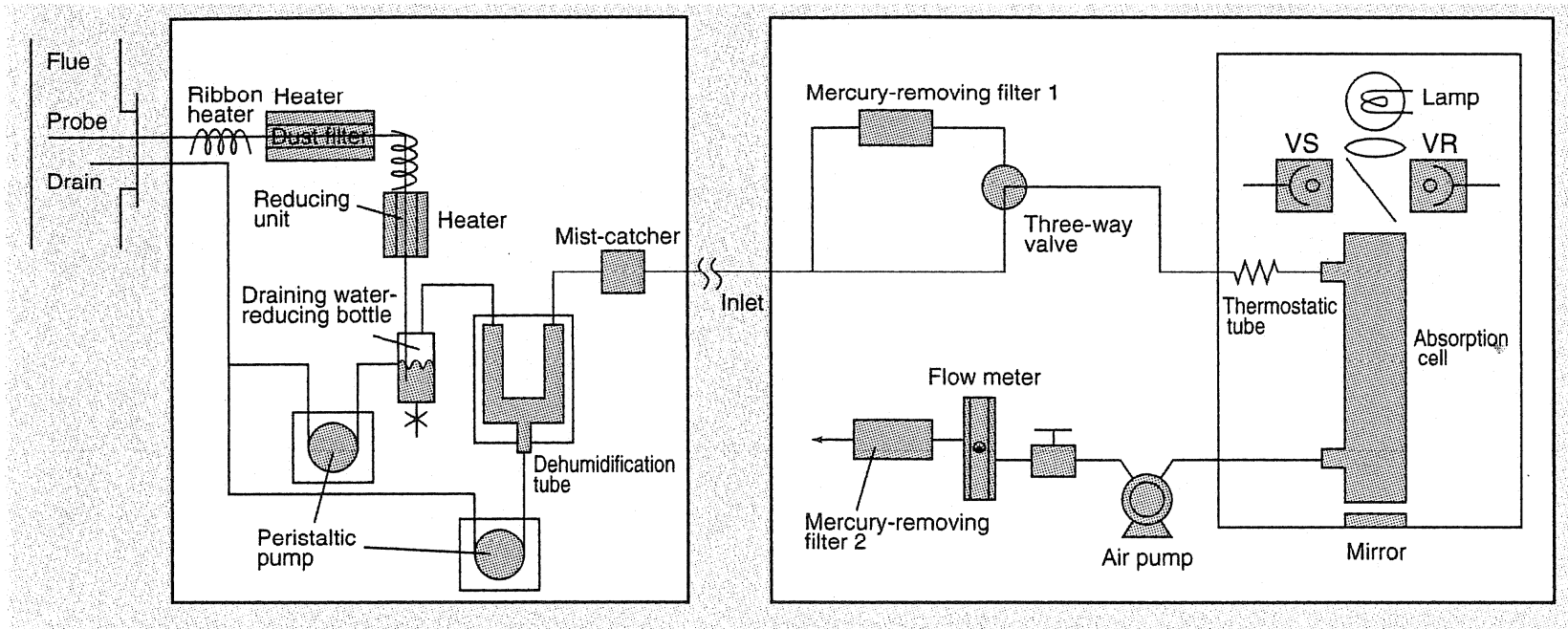

Figure 2.3.3.1 Schematic of the Horiba Hg CEM system

The Horiba's DM-6 detector is a cold-vapor atomic absorption (CVAA) instrument that is limited to measuring elemental mercury $\left(\mathrm{Hg}^{0}\right)$ only. Therefore, in order to determine the total gaseous $\mathrm{Hg}$ content in the flue gas, all ionic $\mathrm{Hg}$ forms (e.g., mercuric chloride) must be converted to the elemental state and the sample gas conditioned before being introduced into the detector. This is achieved through the instrument's pre-treatment system via a solid reducing catalyst followed by a liquid separator tube as well as thermo-electric cooling unit. The pre- 
treatment system of the Horiba DM-6 was connected directly to the probe and installed at the stack testing platform (Figure 2.3.3.2).

Due to the peculiarities of the stack location, the mercury CEM probe was used in conjunction with a 10-feet heated Teflon stinger in order to penetrate the stack annulus and reach the flue gas. This Teflon stinger was extended into the flue gas by approximately 36 inches (Figure 2.3.3.3).

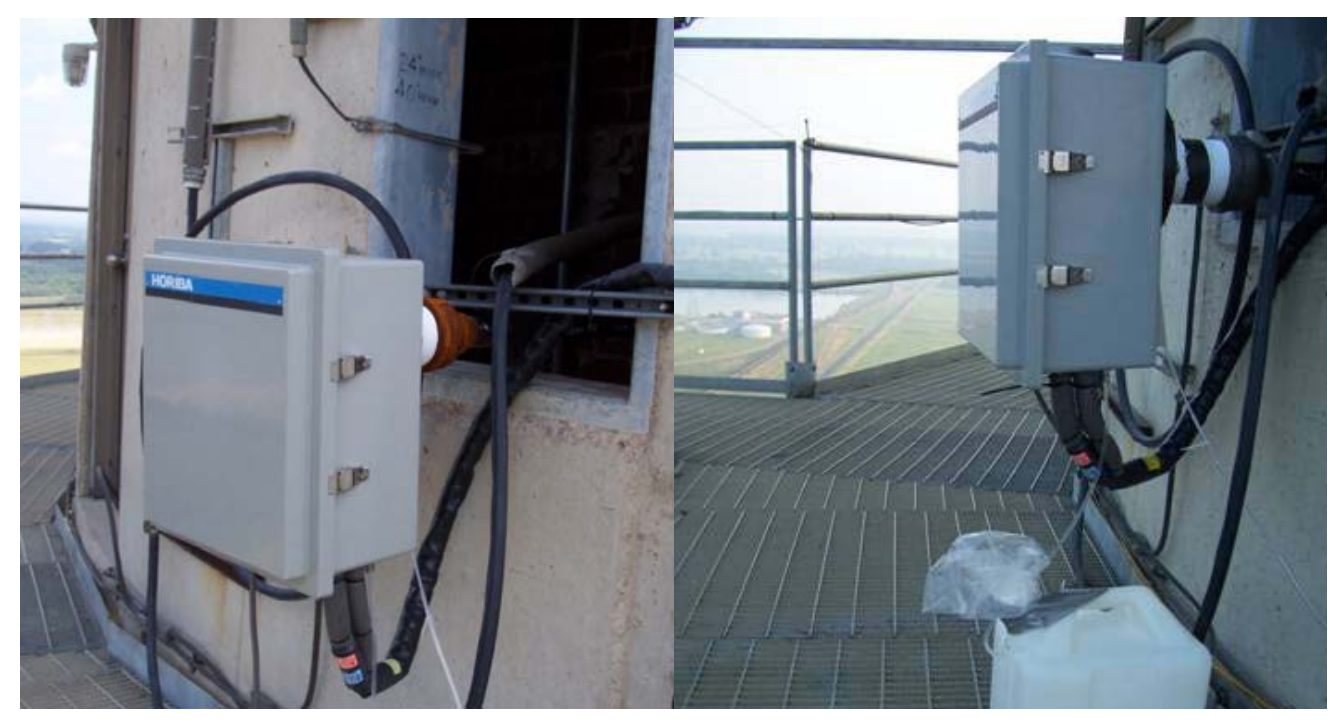

Figure 2.3.3.2 Hg-CEM system installation at stack test platform 


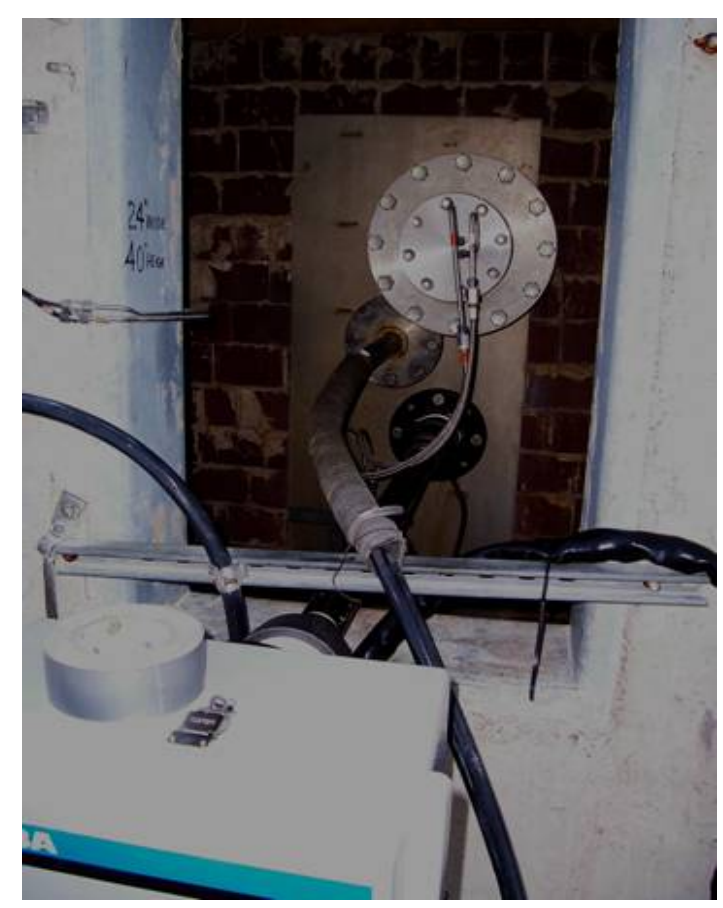

Figure 2.3.3.3 Hg-CEM system penetration into the stack

The pre-treatment system was connected to the detector via a 450 -ft sample line, which was heated to approximately $250^{\circ} \mathrm{F}$. Before entering the detector, the sample gas was passed through a $1 \mathrm{~N} \mathrm{KOH}$ solution for $\mathrm{SO}_{2}$ removal, as $\mathrm{SO}_{2}$ constitutes an interferant for the detection of gaseous elemental $\mathrm{Hg}$ via CVAAS (Figure 2.3.3.4).

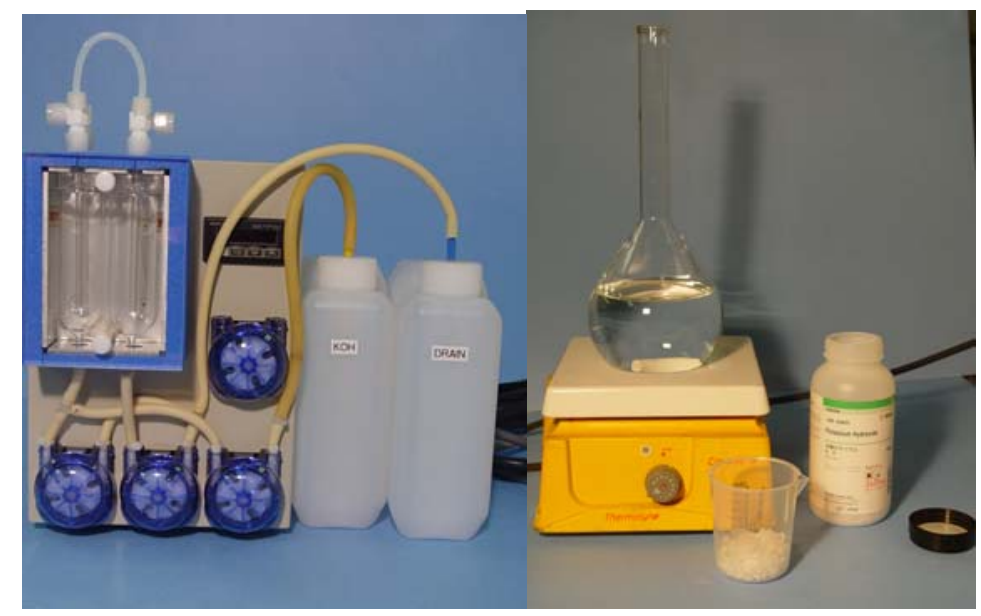

Figure 2.3.3.4 Hg CEM flue gas conditioning unit

The detector was located in an environmentally-controlled trailer. All data acquisition was facilitated via a data logger (ESC Model 8816), which was connected to a laptop PC for 
remote monitoring and frequent data back up. The setup of the CEM detector unit can be seen in Figure 2.3.3.5 and 2.3.3.6.

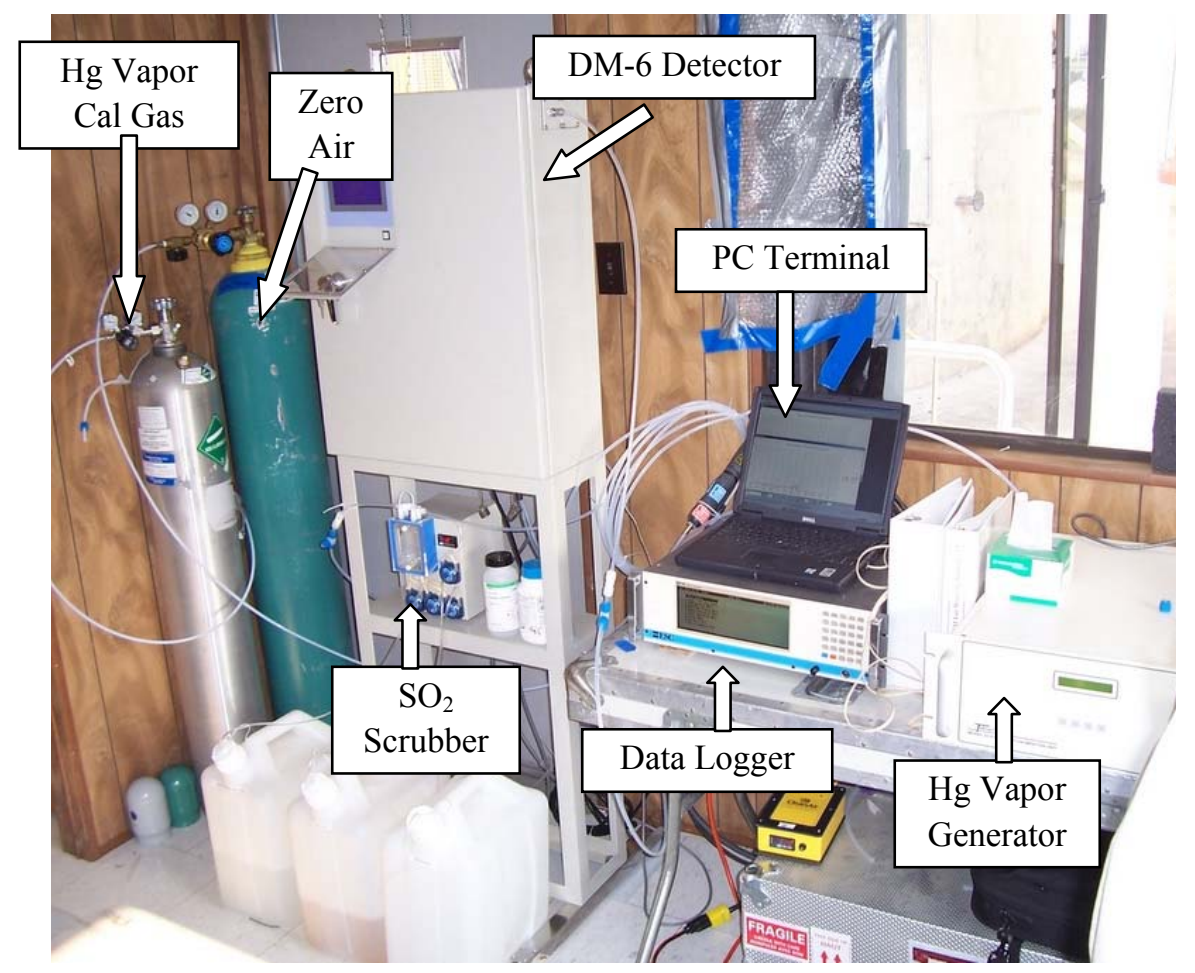

Figure 2.3.3.5 Hg-CEM detector and data acquisition system setup

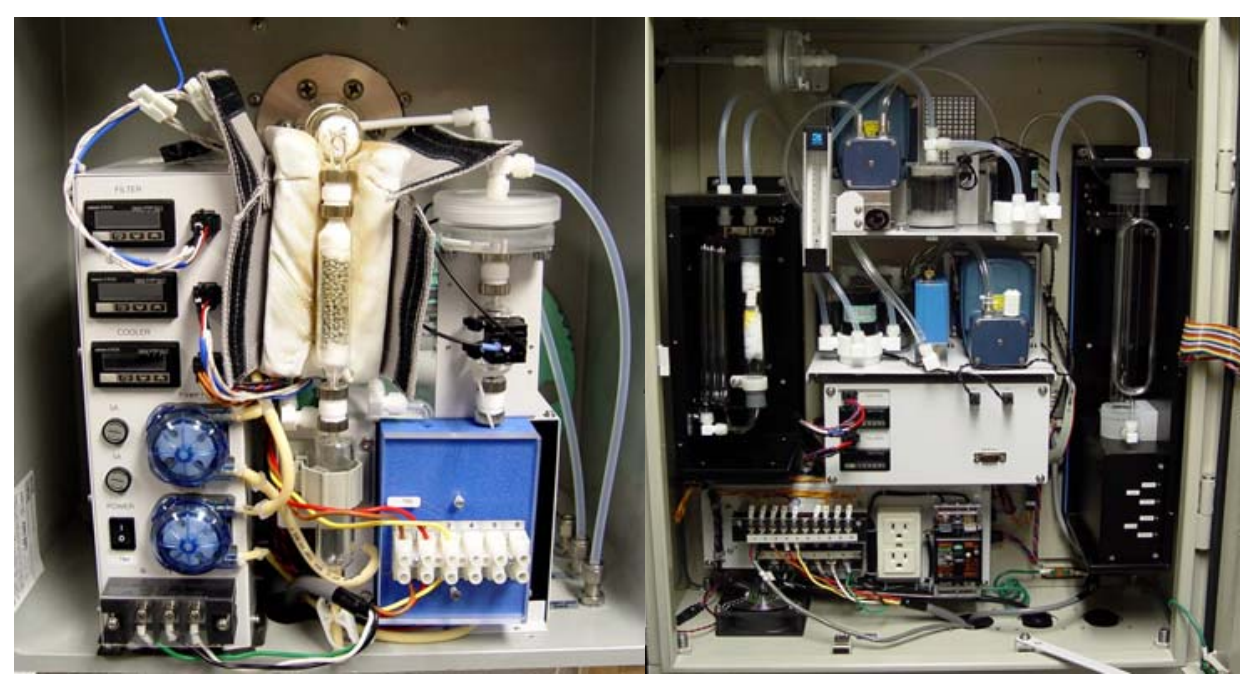

Figure 2.3.3.6 Photograph of the internals of the Horiba DM 6 unit 
The mercury CEMS was initially calibrated using Tekran's Series 3310 mercury calibration unit. However, for subsequent span calibrations during the extended monitoring period, the mercury CEMS calibration was performed once a week by plant personnel using certified gas cylinders from Spectra Gases containing $5.5 \mathrm{~g} / \mathrm{Nm}^{3}( \pm 10 \%)$ of elemental mercury in a balance of nitrogen in conjunction with an all Teflon valve and rotameter.

\subsection{Sampling Methods}

\subsubsection{Solids Sampling and Analyses}

Daily fuel and ash sampling with weekly composite analysis were conducted concurrently with the $\mathrm{Hg}$ sampling. Coal from the plant's auto-sampler was used for coal analysis. The coal analyses included ultimate and proximate analyses, in addition to heating value forms of sulfur and mercury. The analytical methods for analysis of coal samples are presented in Table 2.4.1.1.

Fly ash was collected from the sampling ports in the conveyance piping from the ESP hoppers. During 07/06 - 07/07/2005, fly ash samples from the corresponding ESP hoppers were collected in the middle of each Ontario-Hydro method sampling run. For the remainder of the project, fly ash samples were targeted to be collected daily and analyzed as a weekly composite. The ash samples were tested according to ASTM D6721 in Table 2.4.1.1.

As for the bottom ash, sampling was taken from the ash sluicing hopper prior to conveyance during the actual mass balance testing. The coal pulverizer pyrite rejects were also sampled during initial testing.

Table 2.4.1.1 ASTM Methods Used for Coal Analyses

\begin{tabular}{ll}
\hline $\begin{array}{c}\text { Proximate Analysis } \\
\text { Moisture }\end{array}$ & ASTM D3180 \\
Ash & ASTM D3302 \\
Fixed Carbon & ASTM D3174 \\
Volatile Matter & ASTM D5142 \\
$\underline{\text { Ultimate Analysis (CHNS) }}$ & ASTM D5142 \\
$\underline{\text { Heating Value }}$ & ASTM D5373 \\
$\underline{\text { Forms of Sulfur }}$ & ASTM D5865 \\
$\underline{\text { Mercury }}$ & ASTM D2492 \\
$\underline{\text { Chlorine }}$ & ASTM D6721 \\
& ASTM D2361 \\
\hline
\end{tabular}




\subsubsection{Emission Source Sampling and Analysis}

During all emission source sampling, the procedures as detailed in U.S. EPA Title 40, Code of Federal Regulations, Appendix A, Methods 1- 5 and 17, PS-12A, former Method 324, and ASTM D6784-02 were used. Table 2.4.2.1 summarizes the methods and their respective sources.

\section{Table 2.4.2.1 Summary of source sampling methods and procedures at Hugo}

\begin{tabular}{|c|c|}
\hline \multicolumn{2}{|c|}{ Summary of Sampling Procedures } \\
\hline Method 1 & Sample and Velocity Traverses for Stationary Sources \\
\hline Method 2 & Determination of Stack Gas Velocity and Volumetric Flow Rate (S-Type Pitot Tube) \\
\hline Method 3 & Gas Analysis for the Determination of Dry Molecular Weight \\
\hline Method 4 & Determination of Moisture Content in Stack Gases \\
\hline Method 5 & Determination of Particulate Emissions from Stationary Sources \\
\hline Method 17 & Determination of Particulate Emissions from Stationary Sources (In-Stack Filtration) \\
\hline & Title 40 Code of Federal Regulations Part 60 Appendix A Test Methods \\
\hline \multirow[t]{2}{*}{ PS-12A } & $\begin{array}{l}\text { Specifications and Test Procedures for Total Vapor Phase Mercury } \\
\text { Continuous Emissions Monitoring Systems in Stationary Sources }\end{array}$ \\
\hline & Title 40 Code of Federal Regulations Part 60 Appendix B Performance Specifications (PS) \\
\hline \multirow[t]{2}{*}{ Method 324} & $\begin{array}{l}\text { Determination of Vapor Phase Flue Gas Mercury Emissions from } \\
\text { Stationary Sources Using Dry Sorbent Trap Sampling }\end{array}$ \\
\hline & Former US EPA Promulgated Test Method \\
\hline ASTM D6784-02 & $\begin{array}{l}\text { Standard Test Method for Elemental, Oxidized, Particle-Bound and Total Mercury in } \\
\text { Flue Gas Generated from Coal-Fired Stationary Sources (Ontario-Hydro Method) } \\
\text { American Society for Testing and Materials (ASTM) Methods }\end{array}$ \\
\hline
\end{tabular}

The methods in Table 2.4.2 appear in detail in the Code of Federal Regulations (CFR) and on the World Wide Web at http://www.epa.gov/ttn/emc/promgate.html.

Sampling protocol at the ESP inlet followed US EPA Method 17 (in-stack filtration). The in-stack filter was a quartz fiber thimble encased in a stainless-steel Siltek ${ }^{\circledR}$ coated thimble holder. The stainless steel nozzle at the probe tip was also coated. The flue gas sample remained above dew point temperatures using a heated Teflon jumper connection from the probe to the impinger train setup. The stack location source sampling used the out-of-stack US EPA Method 5 filtration setup.

Specific quality assurance and quality control (QA/QC) procedures as outlined in the individual methods and in the US EPA "Quality Assurance Handbook for Air Pollution Measurement Systems: Volume III Stationary Source-Specific Methods”, EPA/600/R-94/038C were followed. 


\subsection{TEST RESULTS}

\subsection{Pre-Testing Assessment of Mercury Distribution}

Prior to assessing the amount of sampling necessary to characterize the Hugo plant, an assessment of mercury distribution in the different areas of the plant was conducted. Representative samples of the coals, the plant's first and second ESP rows of both A and B side fly ash composite, economizer ash, pulverizer pyrite reject and plant's bottom ash. The mercury concentration in these samples is presented in Figure 3.1.1.

It is clear from the data that the mercury in the coals is essentially identical. There is little discernable difference in the mercury concentration in the ESP ashes. The economizer ash had a low mercury concentration and the mercury in the bottom ash was slightly less than the ESP ashes.

The coal pyrite rejects were also sampled during initial testing. The Hg concentration in the pyrites was relatively high. However, the quantity of the pyrites accumulated is very low. As a result, the $\mathrm{Hg}$ mass flow rate for this pathway was deemed insignificant and was not considered in the plant $\mathrm{Hg}$ mass balance.

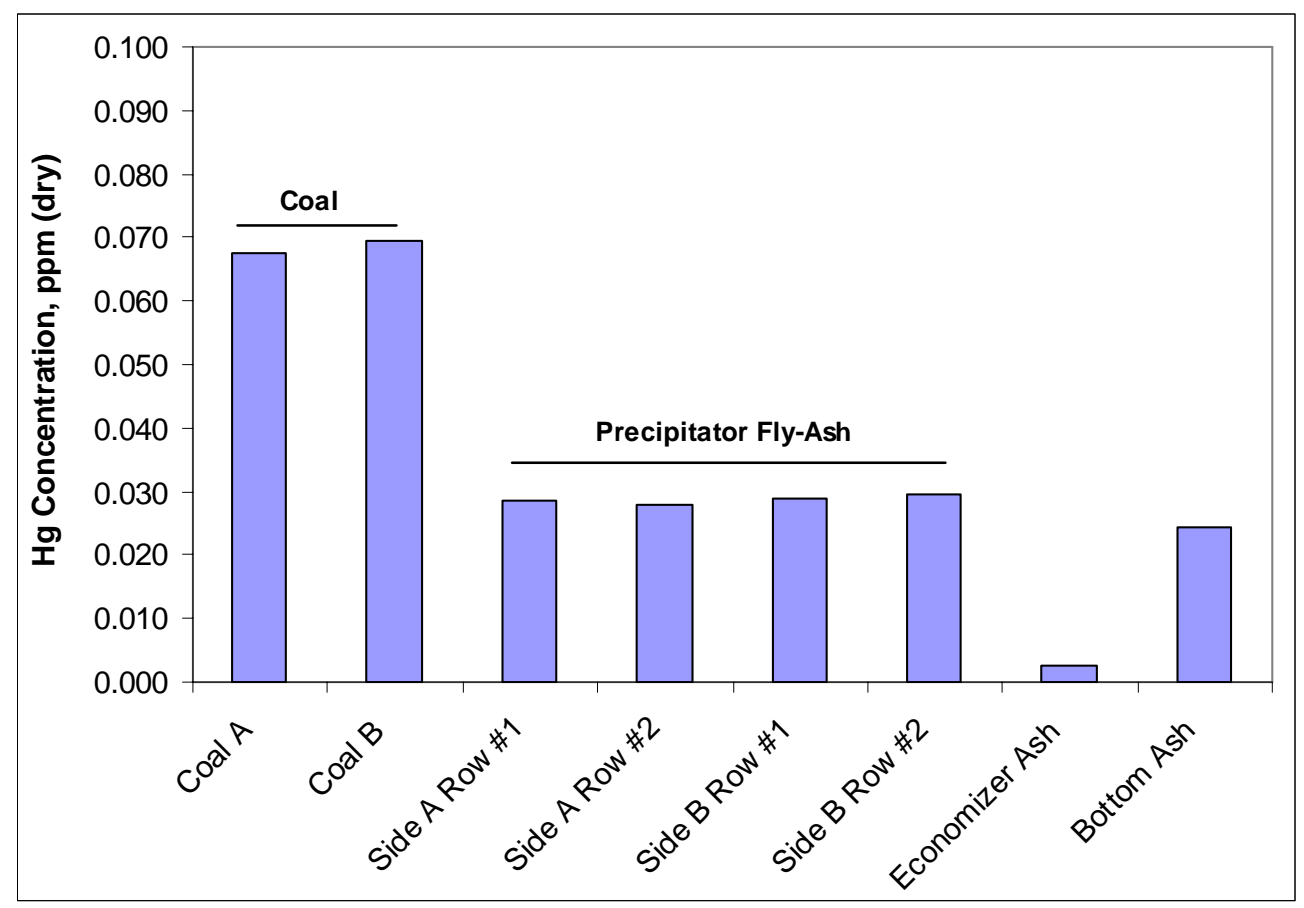

Figure 3.1.1 Pre-Hg balance test program coal and ash sample results

Mercury can leave the plant either through the stack or with the ash collected in the various hoppers along the process stream. It was decided based on initial test results (see Figure 3.1.1) that the main pathways of $\mathrm{Hg}$ leaving the system, besides through the stack, are with the ESP hopper ash and the bottom ash. 
In order to obtain the rate of $\mathrm{Hg}$ leaving the system with the ESP hopper ash, the amount of fly ash removed was calculated on the basis of the actual ash content in the coal during the mass balance sampling and the expected partitioning of the resulting ash between fly ash and bottom ash. This partitioning depends on the boiler design. For the Hugo plant, it was assumed to be $80 \%$ fly ash and $20 \%$ bottom ash. Subsequently, the Hg leaving the system via the ESP was calculated based on the measured $\mathrm{Hg}$ concentrations in the ash. The same considerations were followed for determining the amount of $\mathrm{Hg}$ leaving the system via the bottom ash.

As a result of this analysis, it was decided that sampling of only one side of the ESP was adequate to meet project objectives. OH sampling efforts were only completed at one of the gas streams (B-West duct) assuming that the flue gas was well mixed and that concentrations for each $\mathrm{Hg}$ species were the same in each gas stream.

\subsection{Mercury Balance Results}

One of the primary objectives of the program was to assess the mercury mass balance for the Hugo plant and especially around the plant's cold-side ESP. In order to assess the mercury mass balance, flue gas Hg measurements using both Ontario-Hydro method (ASTM D 6784-02) and sorbent traps were completed at two locations: inlet to the electrostatic precipitator (ESP) and at the flue gas exhaust stack shown earlier (Figures 2.3.1.2 through 2.3.1.4).

The mercury mass balance was conducted by completing three (3) ASTM D6784-02 $(\mathrm{OH})$ sample runs concurrently at the inlet and outlet locations. The arrangement of the paired probes at the stack was in accordance with specifications of US EPA Method 301 for co-located sampling. The inlet location also used paired probes but the probes could not be co-located due to test equipment and test location limitations. Sampling protocol at the ESP inlet followed US EPA Method 17 (in-stack filtration). The in-stack filter was a quartz fiber thimble encased in a stainless-steel Siltek ${ }^{\circledR}$ coated thimble holder. The stainless steel nozzle was also coated. The flue gas remained heated using a heated Teflon jumper connection from the probe to the impinger train setup. The stack location used an out-of-stack filtration setup. During the $\mathrm{OH}$ testing coal, fly ash and bottom ash samples were also collected and analyzed for total $\mathrm{Hg}$.

\subsubsection{Coal Analysis}

The consistency of the coal feed during the plant mercury balance testing was conducted and presented in the following figures. Figure 3.2.1.1 show the variability of the ash content in the feed coal on a dry basis over the first two-week period. With the exception of the coal sample for July 7, 2005, the ash variability was relatively low $6.65 \% \pm 0.95 \%(1)$. The cause for the ash spike on July $7^{\text {th }}$ is currently unknown.

Figure 3.2.1.2 show the variability of the feed coal's heating value over the testing period. The variability of the heating value content is remarkable constant with the exception of the low value for the July $7^{\text {th }}$ sample. 


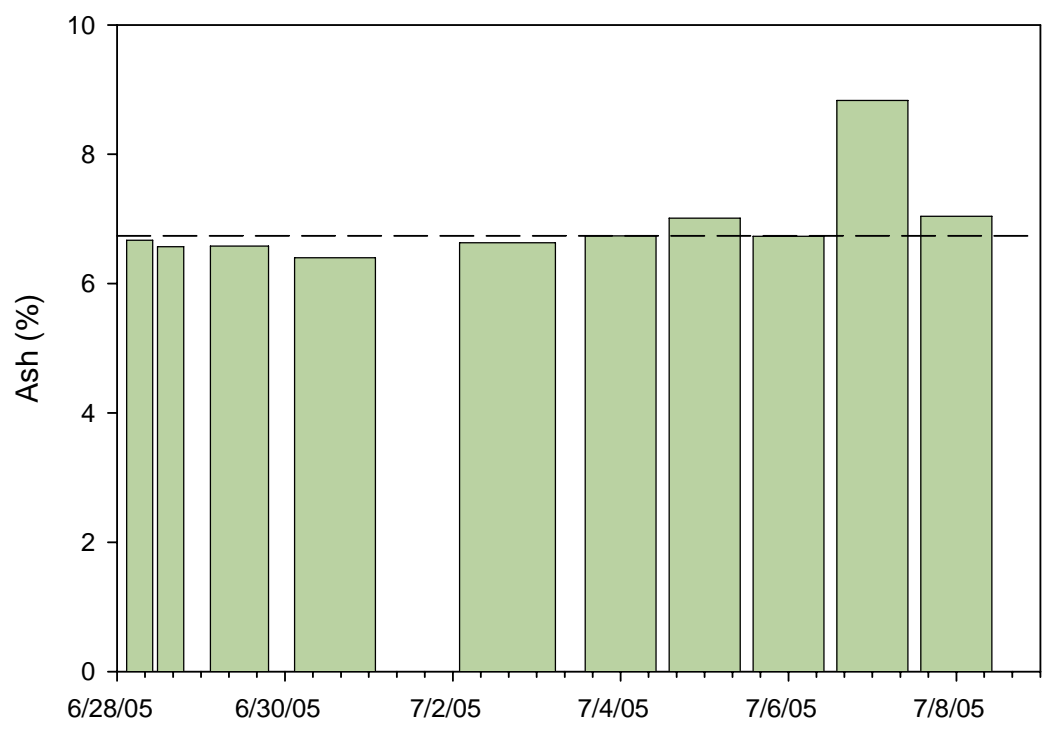

Figure 3.2.1.1 Ash variability of Hugo feed coal during inter-method comparison testing. (The line represents the value from the initial per-test evaluation.)

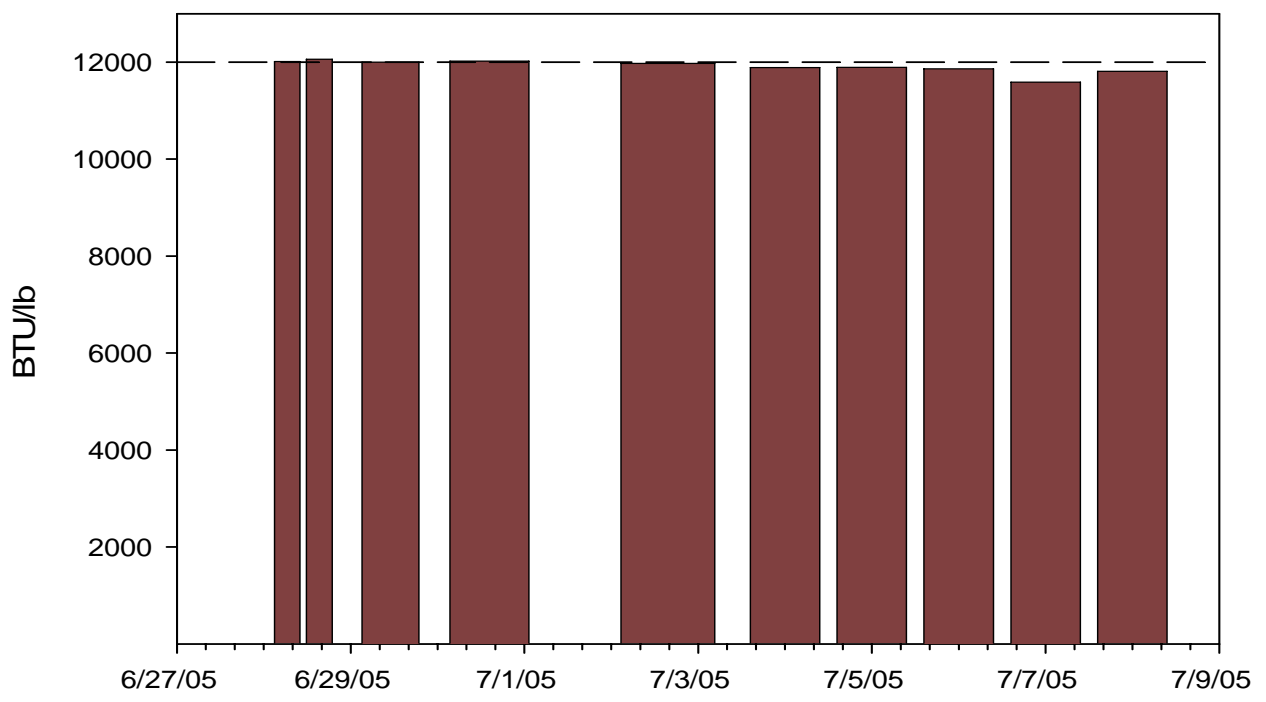

Figure 3.2.1.2 Heating value variability of Hugo feed coal during inter-method comparison testing. (The line represents the value from the initial per-test evaluation.)

Figure 3.2.1.3 shows the variability of the feed coal's pyritic sulfur content over the first two-week period of testing. The pyritic sulfur content of the feed coal burned at Hugo is relatively low but highly variable $\mathbf{0 . 0 5 \%} \pm \mathbf{0 . 0 3 \%}(\mathbf{1})$. Although the concentration of $\mathrm{Hg}$ in pyrite is relatively high, the small concentration of pyrite in the coal is assumed to have a limited impact on mercury variability in the feed coal. 


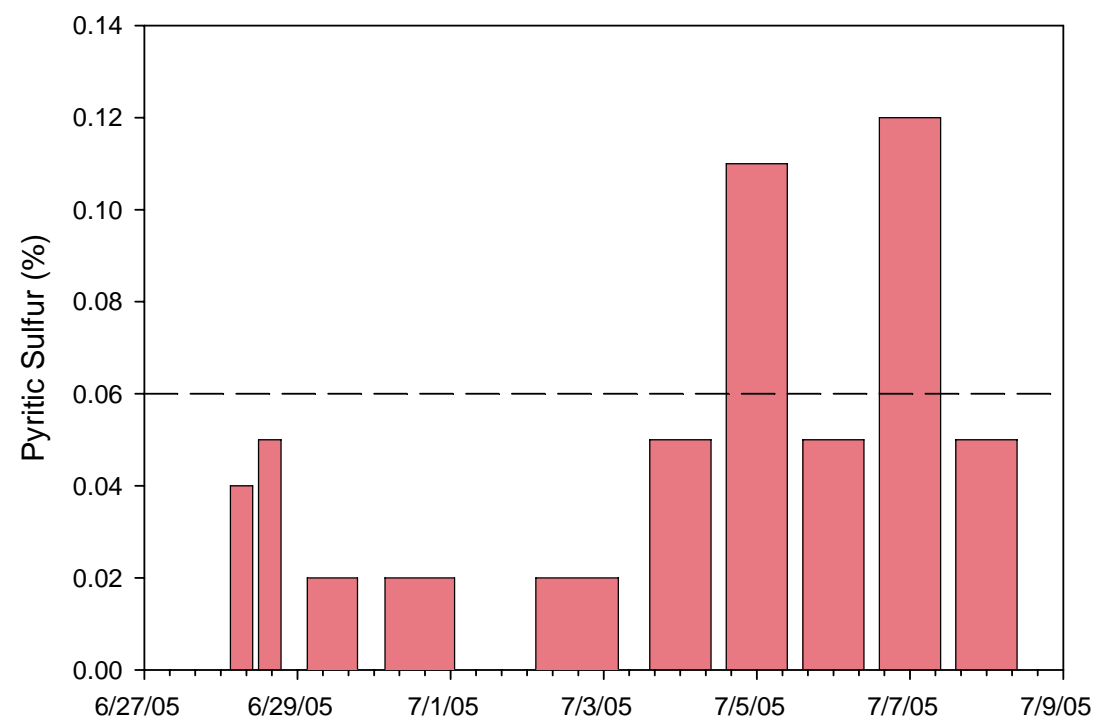

Figure 3.2.1.3 Pyritic sulfur variability of Hugo feed coal during inter-method comparison testing. (The line represents the value from the initial per-test evaluation)

Figure 3.2.1.4 shows the $\mathrm{Hg}$ content of the plant feed coal. Despite erratic $\mathrm{Hg}$ concentrations during the early testing, $\mathrm{Hg}$ concentrations in the coal seemed to stabilize during the days of the $\mathrm{Hg}$ mass balance testing (07/06 - 07/07/2005) with $\mathrm{Hg}$ concentrations similar to those found during the initial tests. The actual coal $\mathrm{Hg}$ concentration determined for each day was used to calculate the $\mathrm{Hg}$ mass balance. The average $\mathrm{Hg}$ concentration was $\mathbf{0 . 0 9 7} \mathbf{p p m} \pm$ 0.035ppm (1 ).

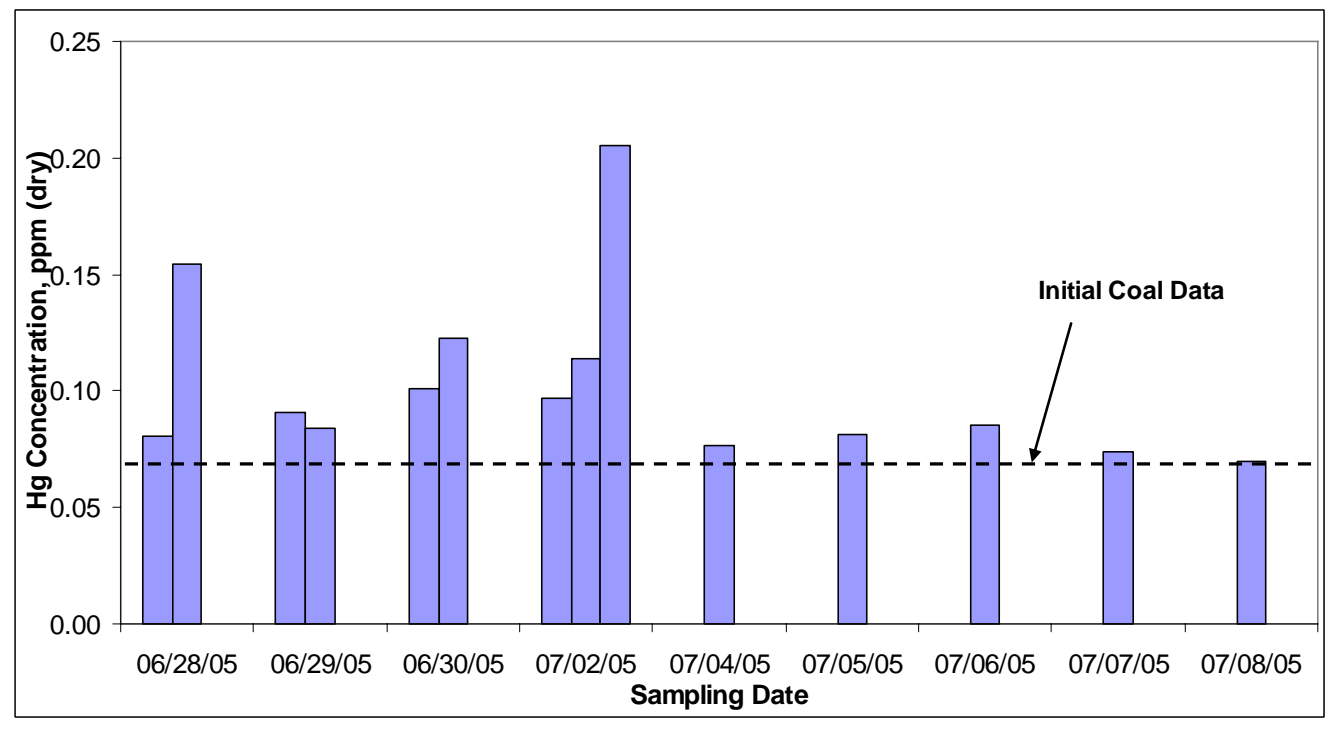

Figure 3.2.1.4 Coal Hg concentrations 


\subsubsection{Ash Analysis}

Analysis results for the fly ash removed from the ESP hoppers are shown in Figure 3.2.2.1. For the duration of the Hg mass balance testing (07/06 - 07/07/2005), fly ash samples from the corresponding hoppers were collected in the middle of each Ontario-Hydro sampling method run. As can be seen in Figure 3.2.2.1, the high coal $\mathrm{Hg}$ concentrations during the early testing period (06/29 - 06/30/2005) were reflected in the fly ash mercury concentrations. The fly ash $\mathrm{Hg}$ concentration in the fly ash was 0.040ppm $\pm \mathbf{0 . 0 3 4 p p m ~ ( 1 ) . ~}$

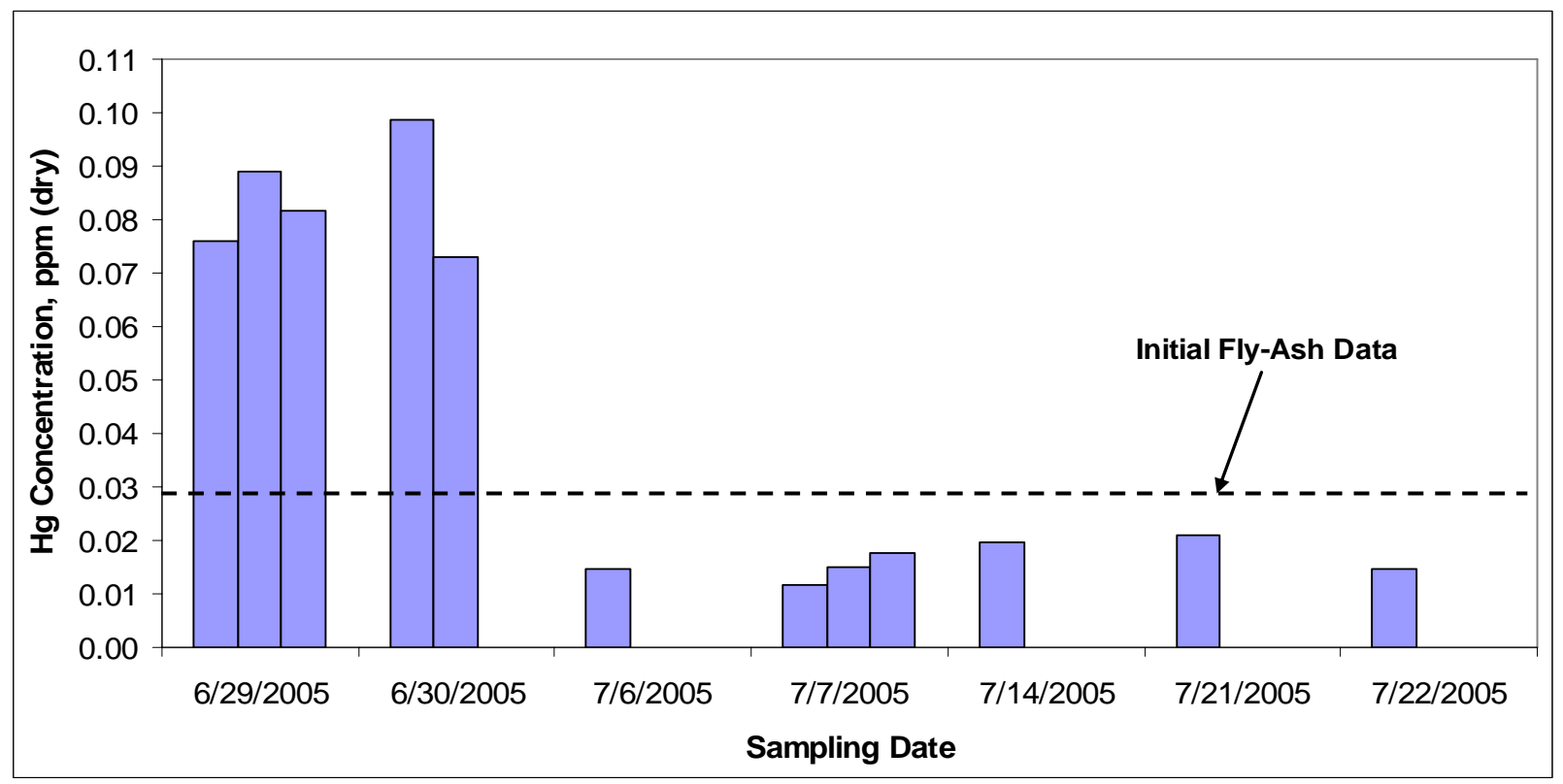

Figure 3.2.2.1 Ash sample analysis results

As for the bottom ash, sampling during mass balance testing yielded very little $\mathrm{Hg}$ concentrations: $4.5 \mathrm{ppb}$ and $2 \mathrm{ppb}$ (on a dry basis) for 07/06/2005 and 07/07/2005, respectively. $\mathrm{Hg}$ mass flow rates based on these results were insignificant and were therefore omitted in the $\mathrm{Hg}$ mass balance calculations. The average concentration in the bottom ash was $0.111 \mathrm{ppm} \pm$ $0.197 \mathrm{ppm}(1 \sigma)$.

\subsubsection{Mercury Emissions Results}

The Hg mass balances across the plant and ESP are presented in Table 3.2.3.1 and Table 3.2.3.2, respectively. The overall $\mathrm{Hg}$ mass balance closes to $95.6 \%$, while the $\mathrm{Hg}$ mass balance across the ESP is $93.8 \%$. A description of the details and calculations are presented in Appendix A. 
Table 3.2.3.1 Hg mass flow rate across Hugo facility

Hg Mass Flow Rate (g/hr)

\section{Inlet Hg}

$\mathrm{Hg}$ from coal

\section{Outlet Hg}

Hg exiting the stack

$\mathrm{Hg}$ in bottom ash

$\mathrm{Hg}$ in ESP hopper ash

Outlet/Inlet Balance

$95.6 \%$

Note that $\mathrm{Hg}$ mass flow at the ESP inlet $(16.1 \mathrm{~g} / \mathrm{hr})$ is slightly higher than the calculated $\mathrm{Hg}$ mass flow entering the plant via the coal $(15.8 \mathrm{~g} / \mathrm{hr})$. However, considering the variation in $\mathrm{Hg}$ entering the system via the coal during the three mass balance Ontario-Hydro sampling method runs $(15.8 \mathrm{~g} / \mathrm{hr} \pm 1.4 \mathrm{~g} / \mathrm{hr})$, these two values are essentially identical.

Table 3.2.3.2 Hg mass flow rate across ESP

\begin{tabular}{lc}
\hline & $\begin{array}{c}\text { Hg Mass Flow Rate } \\
\text { (g/hr) }\end{array}$ \\
\hline Hg at the ESP inlet & 16.1 \\
Hg at the Stack & 14.9 \\
Hg in ESP hopper ash & 0.2 \\
Outlet/Inlet Balance & $\mathbf{9 3 . 8 \%}$ \\
\hline
\end{tabular}

The mercury mass balance closures are presented in Figure 3.2.3.3 and yield closures of $100 \% \pm 25 \%$ except for sampling during week 7 . This low closure has been attributed to a twoday outage during which the monitoring system continued sampling at a constant rate, shifting the average mercury concentration for the sampling period to a lower value. In addition to above considerations, keep in mind that due to the nature of the coal sampling schedule, some of the mass balances were based on weekly coal sample composites, while others were based on monthly composites. Furthermore, considering the variability of the mercury content in coal, as evident from Figure 19, this variability alone could explain the mass balance discrepancy.

In Figure 3.2.3.3 values in the body of each column represent either the Relative Deviation (RD) or the field spike recovery (FS) in percent (\%). Units are on a dry basis. In addition, total gaseous mercury concentrations for each sorbent trap pair are superimposed with the mercury mass balance closures based on the results per sampling run. Note that the plant went offline from 08/19/05 - 08/21/05 (week 7). 


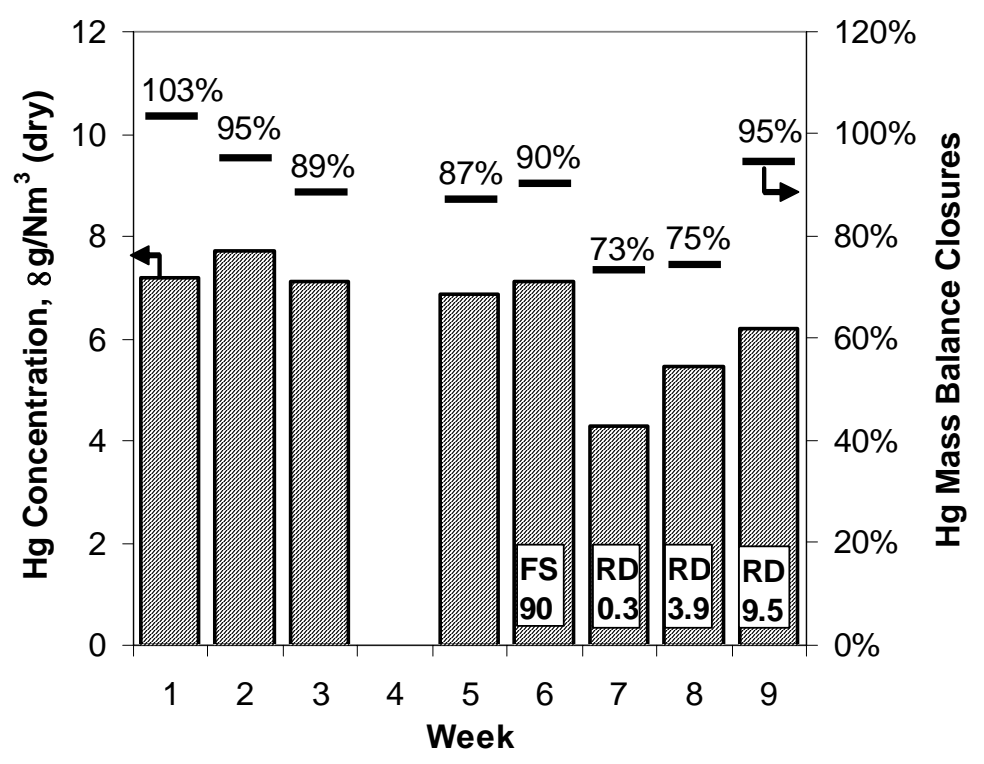

Figure 3.2.3.3 Average total mercury concentrations per sorbent trap sampling run

\subsection{Mercury Speciation}

A second objective of the project was to ascertain the speciation of the mercury in the Hugo plant. Specifically, the distribution between the elemental and the oxidized mercury exiting the boiler and exiting the stack. Ontario-Hydro is the method that allows for the determination of the species of mercury in the flue gas streams in the plant. This testing was conducted in order to confirm any changes in speciation as a result of the flue gas and mercury passing through the cold-side ESP.

The subbituminous coal burned at Hugo results in a high percentage of $\mathrm{Hg}^{0}$ in the flue gas. At the ESP inlet, $89.5 \%$ of the total $\mathrm{Hg}$ was measured in the form of $\mathrm{Hg}^{0}$, while only $8.0 \%$ were present as $\mathrm{Hg}^{2+}$. It should be noted that about $2.5 \%$ of the $\mathrm{Hg}$ at the ESP inlet was particulate-bound. Tables 3.3.1 and 3.3.2 detail the $\mathrm{Hg}$ speciation on a mass basis and concentration basis.

Table 3.3.1 Hg Speciation Mass Results

\begin{tabular}{lcccc}
\hline Hg Species & $\begin{array}{c}\text { ESP Inlet } \\
\text { (g/hr) }\end{array}$ & $\begin{array}{c}\text { Stack } \\
\text { (g/hr) }\end{array}$ & $\begin{array}{c}\text { ESP Inlet } \\
\text { (\% of Total) }\end{array}$ & $\begin{array}{c}\text { Stack } \\
\text { (\% of Total) }\end{array}$ \\
$\mathrm{Hg}^{0}$ & 14.42 & 11.28 & 89.5 & 75.7 \\
$\mathrm{Hg}^{2+}$ & 1.30 & 3.61 & 8.0 & 24.3 \\
$\mathrm{Hg}^{\mathrm{PB}}$ & 0.40 & 0.00 & 2.5 & 0.0 \\
\hline
\end{tabular}


Table 3.4.2 shows the concentrations of $\mathrm{Hg}$ in the flue gas for the two sample locations. All $\mathrm{Hg}$ mass flow rates were based on these results. Note that each value is the average of three paired Ontario-Hydro sampling runs.

Table 3.3.2 Flue gas $\mathrm{Hg}$ concentrations

\begin{tabular}{lcc}
\hline Hg Species & $\begin{array}{c}\text { ESP Inlet } \\
\left(\mathbf{g} / \mathbf{N m}^{3} @ \mathbf{9} \% \mathbf{O}_{\mathbf{2}}\right)\end{array}$ & $\begin{array}{c}\text { Stack } \\
\left(\mathbf{g} / \mathbf{N m}^{3} @ \mathbf{9} \% \mathbf{O}_{\mathbf{2}}\right)\end{array}$ \\
\hline $\mathrm{Hg}^{\mathrm{T}}$ & $8.08(0.28)$ & $7.97(0.40)$ \\
$\mathrm{Hg}^{0}$ & $7.23(0.19)$ & $6.03(0.09)$ \\
$\mathrm{Hg}^{2+}$ & $0.65(0.12)$ & $1.94(0.34)$ \\
$\mathrm{Hg}^{\mathrm{PB}}$ & $0.20(0.03)$ & $<0.01$ \\
\hline
\end{tabular}

(value) represents 1 standard deviation

The Hg speciation results across the ESP can be seen in Figure 3.3.1. As expected, nearly all of the $\mathrm{Hg}^{\mathrm{PB}}$ is removed across the ESP. Since $\mathrm{Hg}^{\mathrm{PB}}$ constitutes only a minor fraction of the $\mathrm{Hg}^{\mathrm{T}}$ present in the flue gas, there is little removal of $\mathrm{Hg}^{\mathrm{T}}$ across the ESP. Also evident is the oxidation of some of the $\mathrm{Hg}^{0}$ to $\mathrm{Hg}^{2+}$.

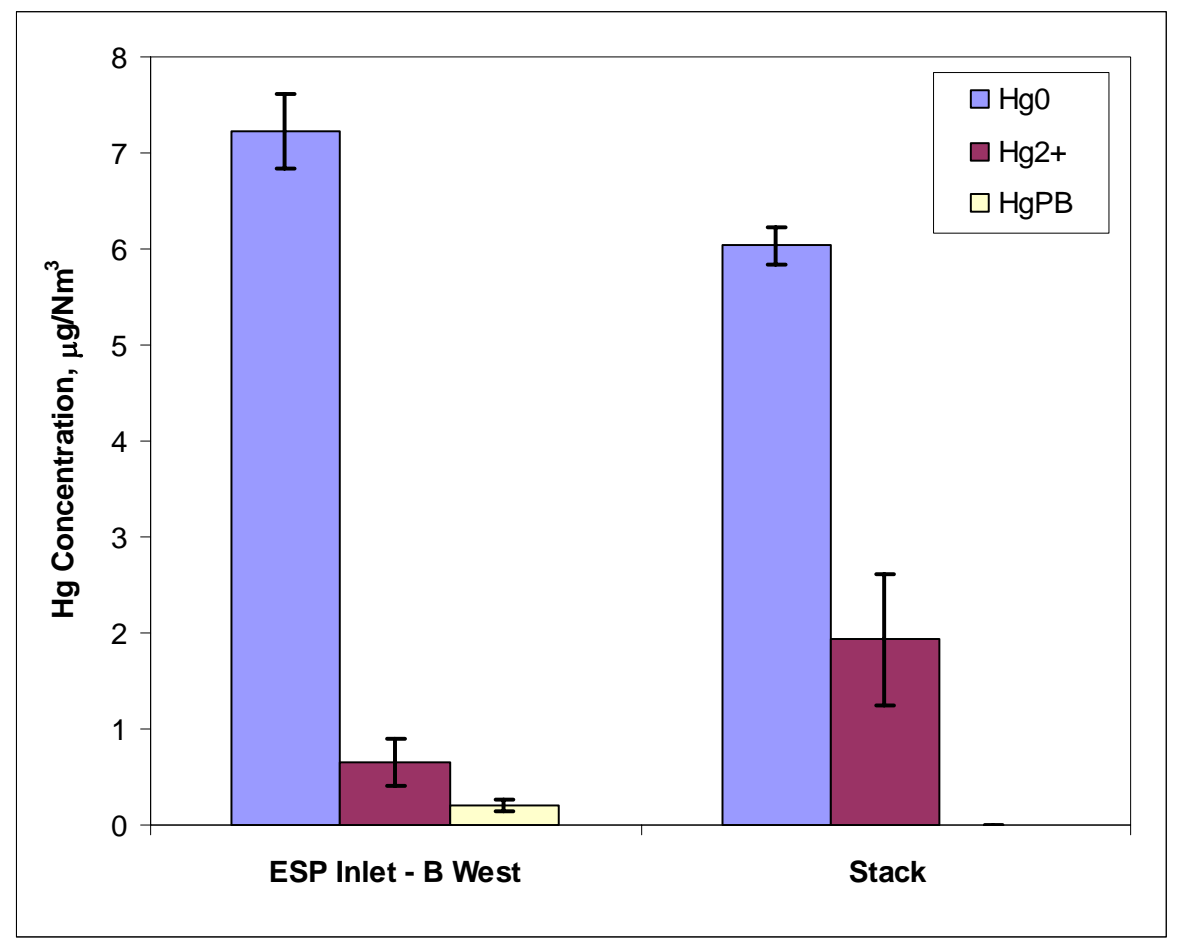

Figure 3.3.1 Hg speciation results 


\subsection{Inter-Method Comparison}

A third objective of the project was to conduct an inter-method comparison, emissions source sampling included a Performance Specification (PS) 12A Relative Accuracy Test Audit (RATA) consisting of nine (9) paired OH reference method (RM) runs at the exhaust stack. In addition, nine consecutive paired sorbent-based US EPA Method 324 runs were performed simultaneously at the stack, and the corresponding mercury CEMS data were recorded.

\subsubsection{PS12A Reference Method - Ontario Hydro}

The minimum performance criteria for paired RM tests according to Performance Specification 12A required Relative Deviation (RD) of less than $10 \%$ for total gaseous $\mathrm{Hg}$ concentrations greater than $1.0 \mathrm{~g} / \mathrm{m}^{3}$ ). In order to establish the Ontario Hydro as the reference method requires an evaluation of the paired data for relative

The results of the Ontario-Hydro testing for the elemenetal and the oxidized mercury are pressnted in Figures 3.4.1.1 and 3.4.1.2 for the elemental and Figures 3.4.1.3 and 3.4.1.4 for the oxidized mercury.

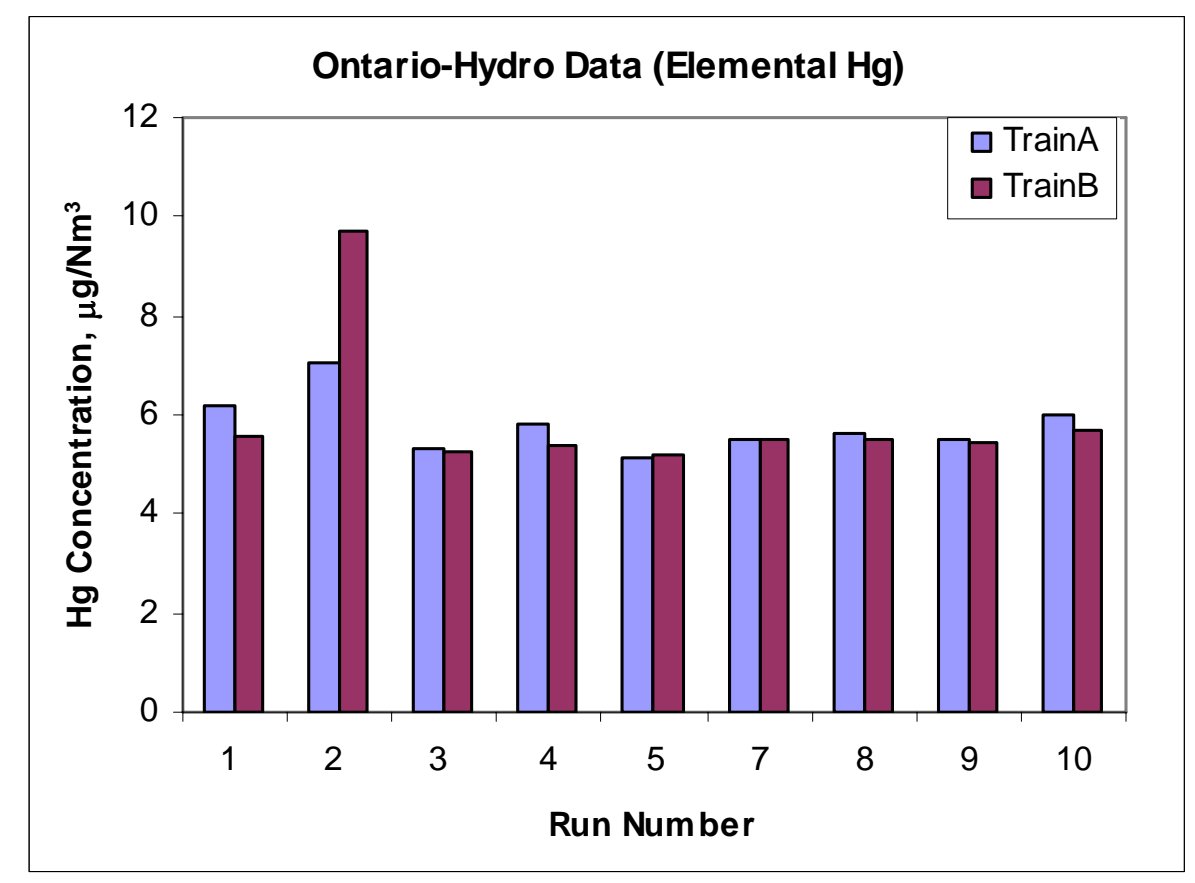

Figure 3.4.1.1 Ontario-Hydro- elemental Hg per train 


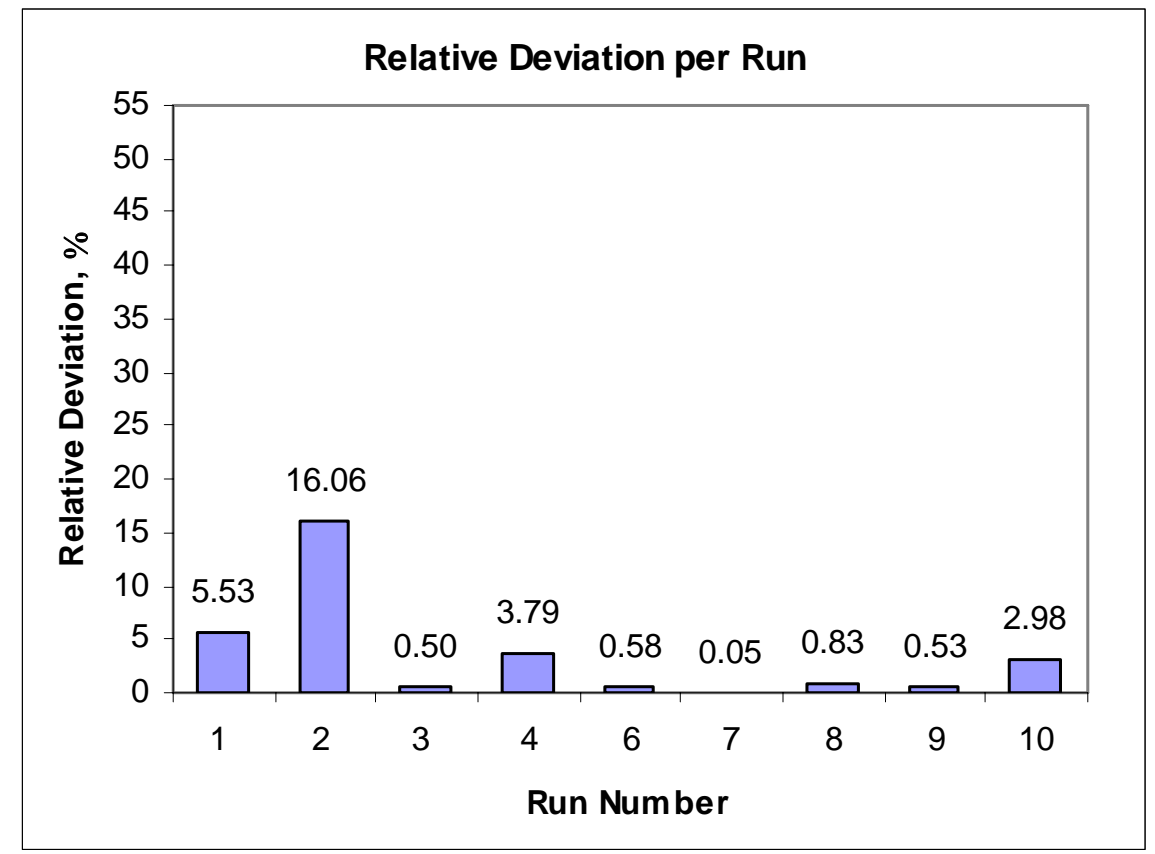

Figure 3.4.1.2 Ontario-Hydro - elemental Hg relative deviation per run

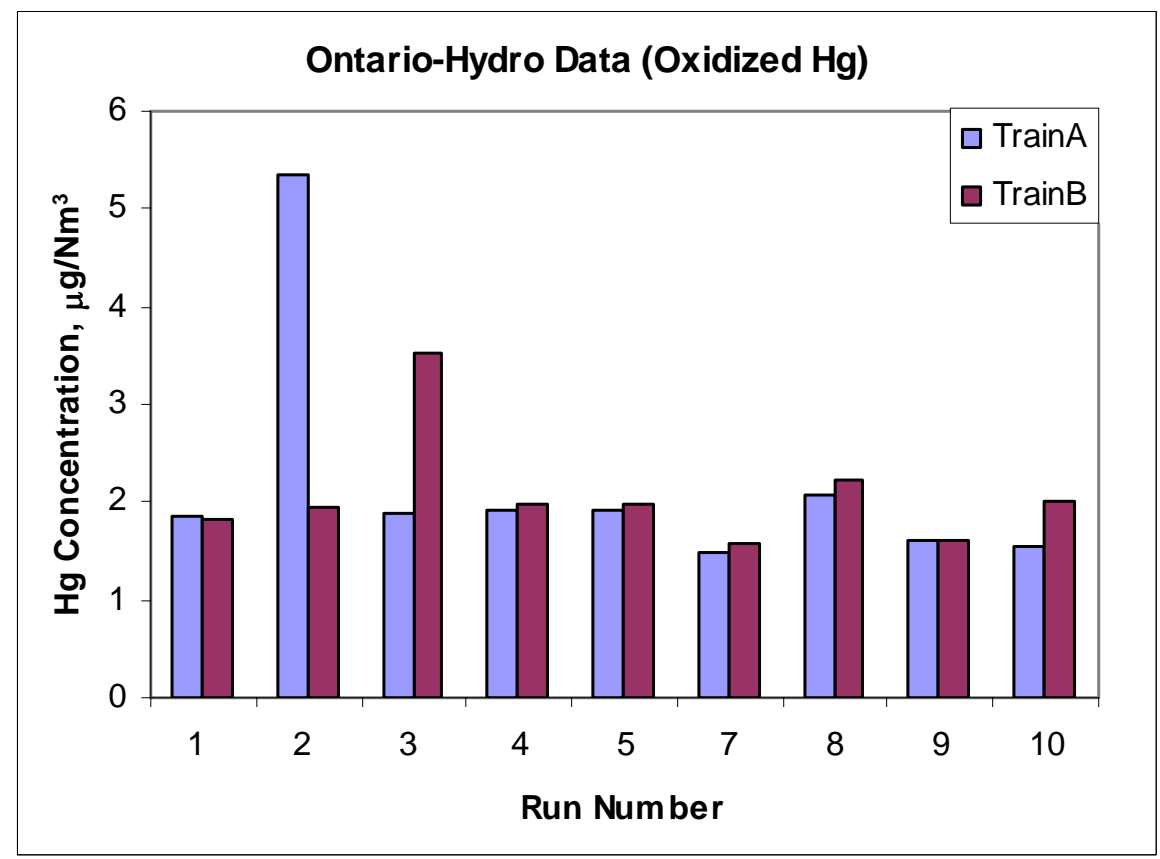

Figure 3.4.1.3 Ontario-Hydro- oxidized Hg per train 


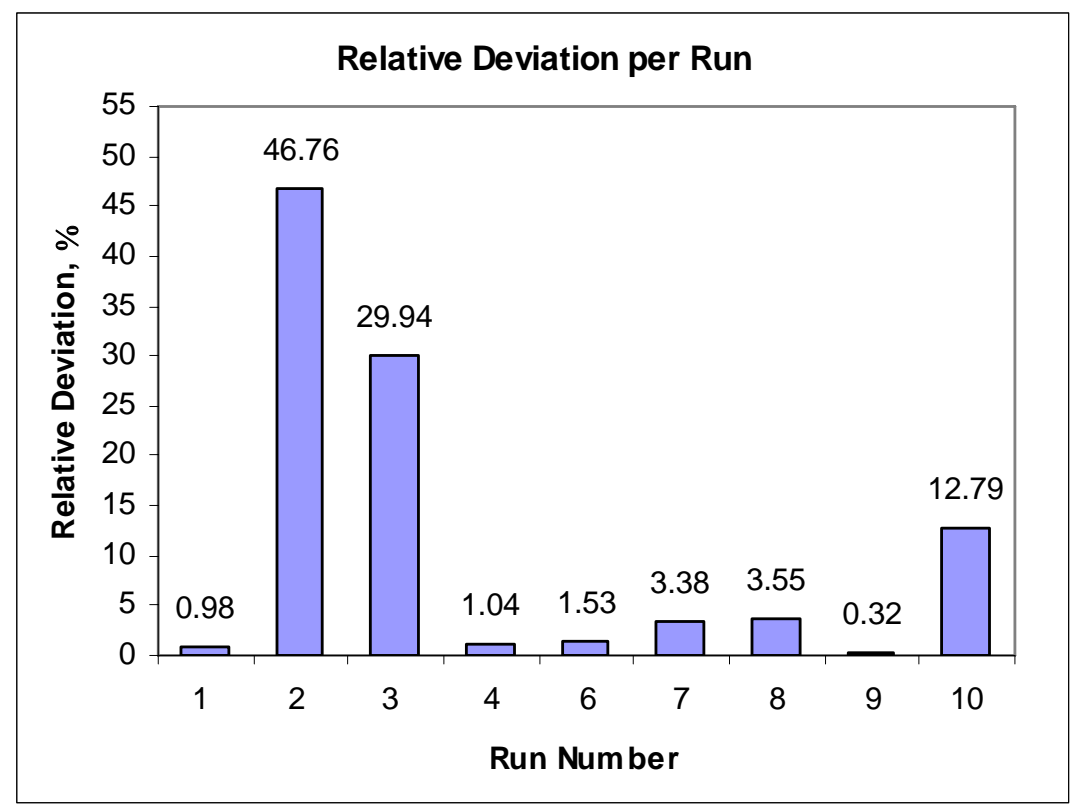

Figure 3.4.1.4 Ontario-Hydro - oxidized Hg relative deviation per run

The average total gaseous $\mathrm{Hg}$ results for each paired Ontario-Hydro test run are presented in Figure 3.4.1.5.

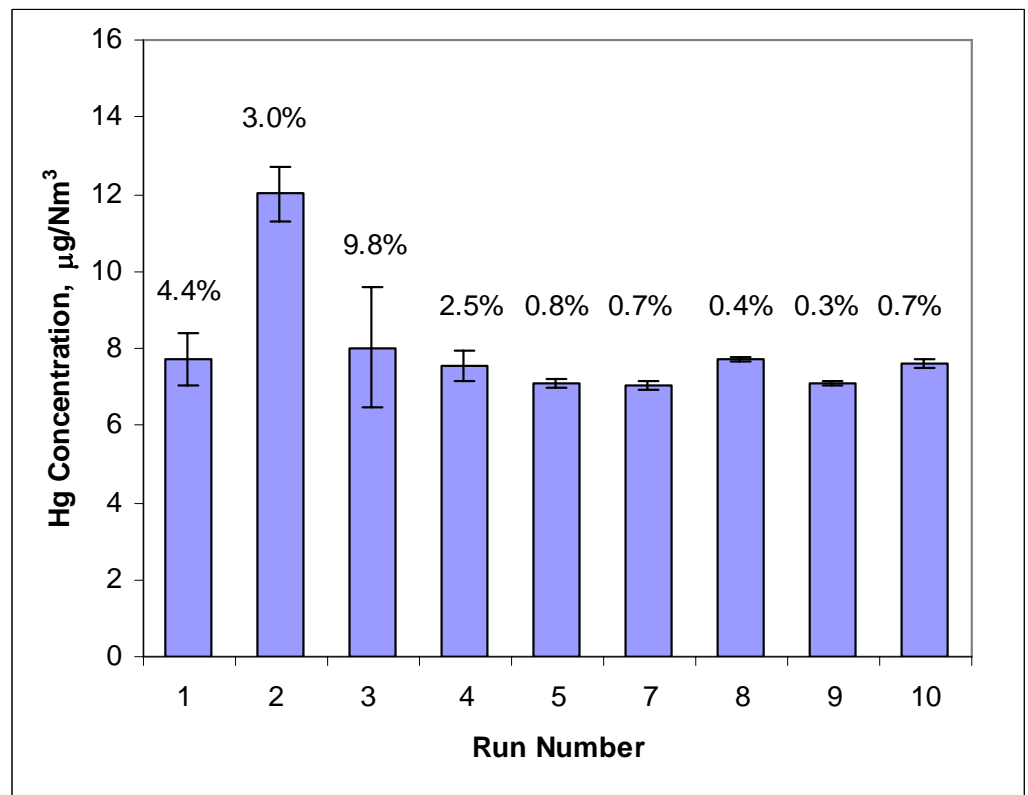

Figure 3.4.1.5 Average total gaseous $\mathrm{Hg}$ result for each paired Ontario-Hydro test run

All Ontario-Hydro sampling method runs satisfy the minimum performance criteria for paired reference method (RM) tests as specified in Performance Specification 12A. According to this criteria, the relative deviation (RD) for any data pair of the RM test runs must be less than $10 \%$ as long as the mean $\mathrm{Hg}$ concentration in the flue gas is greater than $1.0 \mathrm{~g} / \mathrm{m}^{3}$. Despite 
satisfying these criteria, it is evident from Figure 3.4.1.6 that Run 2 should be considered an outlier and omitted from subsequent data correlations.

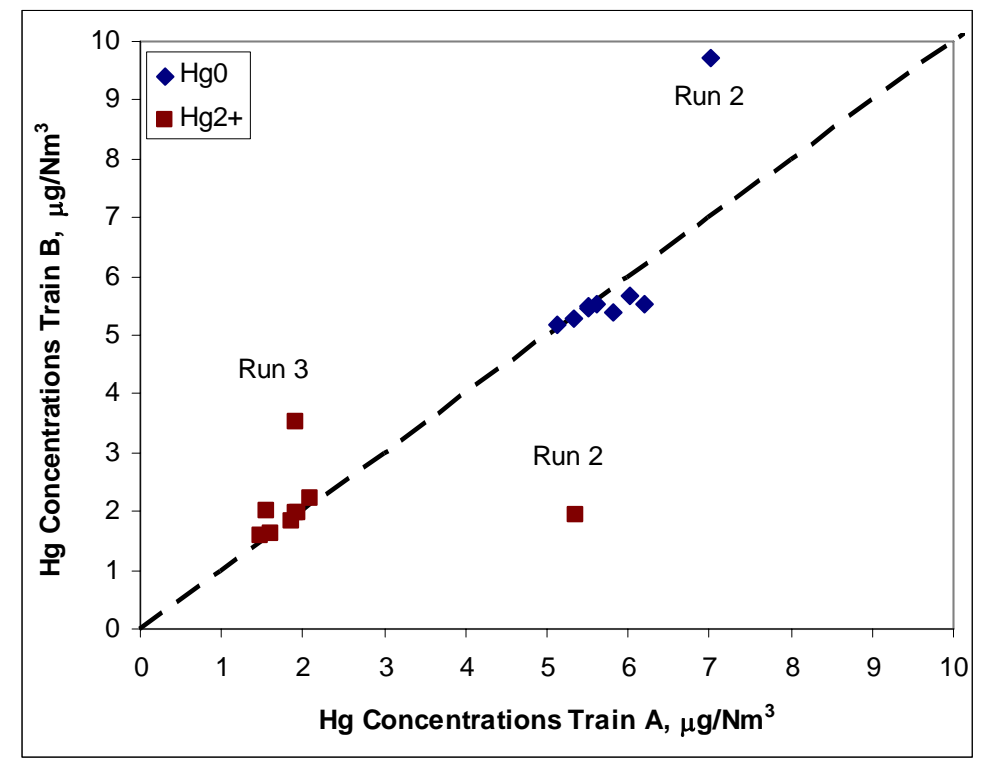

Figure 3.4.1.6 Hg results for each Ontario-Hydro train

The $\mathrm{Hg}^{2+}$ of Train A is almost three times the concentration of the results for Train $\mathrm{B}$, while the $\mathrm{Hg}^{0}$ of Train $\mathrm{B}$ is almost $40 \%$ higher than the corresponding result for Train A. The error bars represent the Relative Percent Difference (RPD) between the individual OntarioHydro method train results for each pair. The values on top of each column indicate the Relative Deviation (RD) for each data pair. The relative deviation for each run ranges from $0.03 \%$ to 9.8\% as presented in Figure 3.4.1.5. Run 6 was omitted from the data set since it was interrupted by an unplanned plant outage.

\subsubsection{Method 324 RATA}

Table 324-2 of 67 FR 4467 requires pre- and post-sampling leak rate of less than $2 \%$ of prevalent sampling rate and sorbent trap backup section mercury loading less than $2 \%$ or, alternatively, 5ng/trap of the main section mercury loading. Further details on each of these can be found in Appendix A. Relative Accuracy Test Audit (RATA) for the Method 324 data requires the following:

- Field Spike Recovery: Spiked sorbent trap section mercury mass equal to $80-120 \%$ of original elemental mercury spike amount, and

- Paired Trap Agreement: Relative deviation (RD) between results of paired traps less than or equal to $10 \%$.

Figures 3.4.2.1, 3.4.2.2 and 3.4.2.3 show the results for the corresponding sorbent-based Method 324 sampling. 


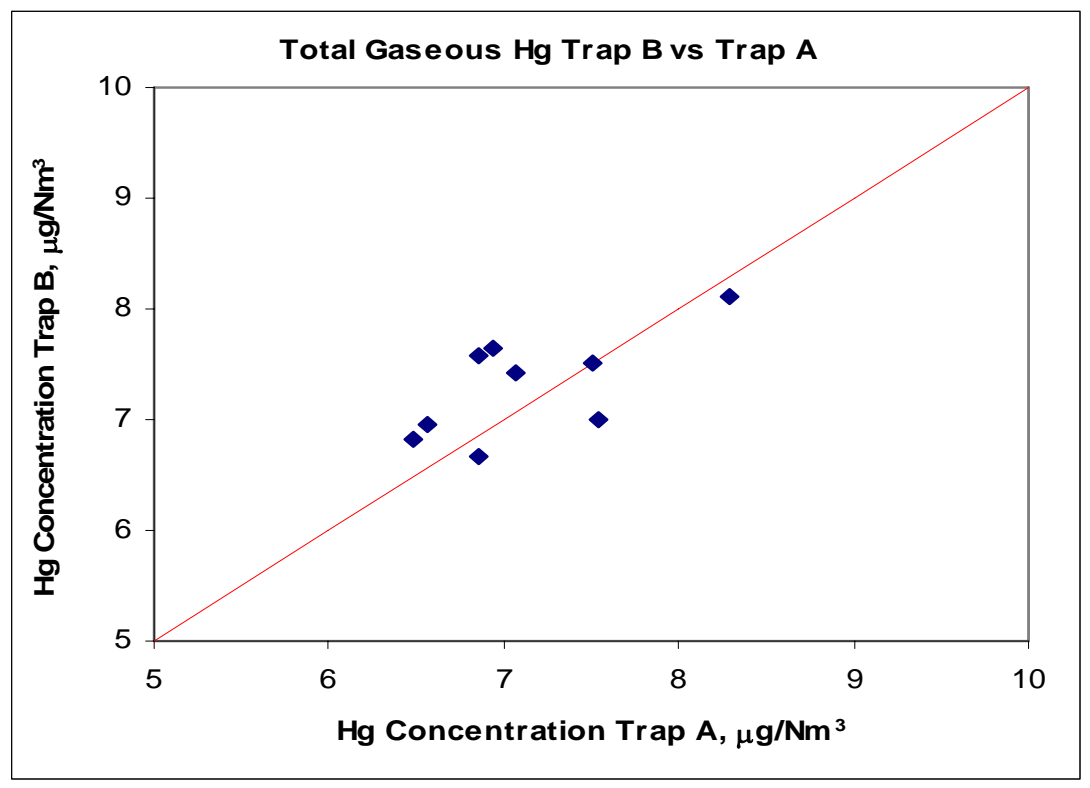

Figure 3.4.2.1 Hg results for each paired sorbent trap test

Included in the data set are the results for the field spike run. Field spike recovery was $90 \%$.

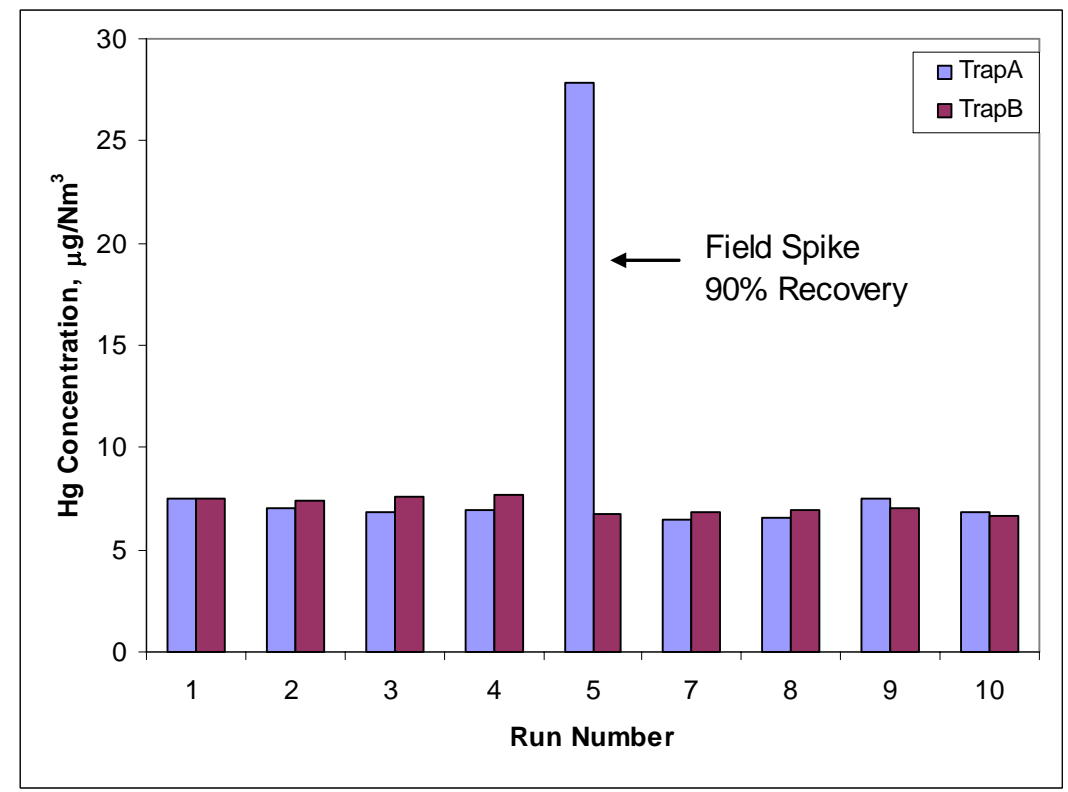

Figure 3.4.2.2 Hg results for each paired sorbent trap test run

The error bars represent the Relative Percent Difference (RPD) between the individual sorbent traps for each pair. The values on top of each column indicate the Relative Deviation (RD). Units are on a dry basis. 


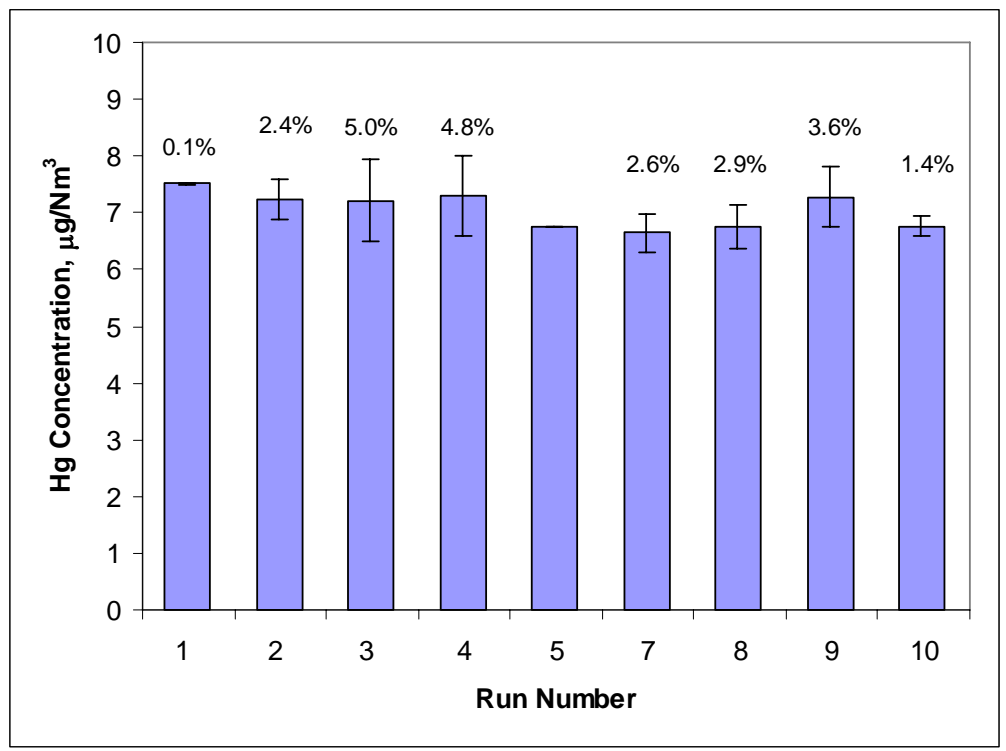

Figure 3.4.2.3 Average Hg result for each paired sorbent trap test run

For comparison of both method results, the total gaseous $\mathrm{Hg}$ concentrations obtained from the sorbent-based method were plotted against the total gaseous $\mathrm{Hg}$ concentrations of the Ontario-Hydro sampling method runs. Figure 3.4.2.4 indicates that results of both methods compare very favorably to each other except for Run 2.

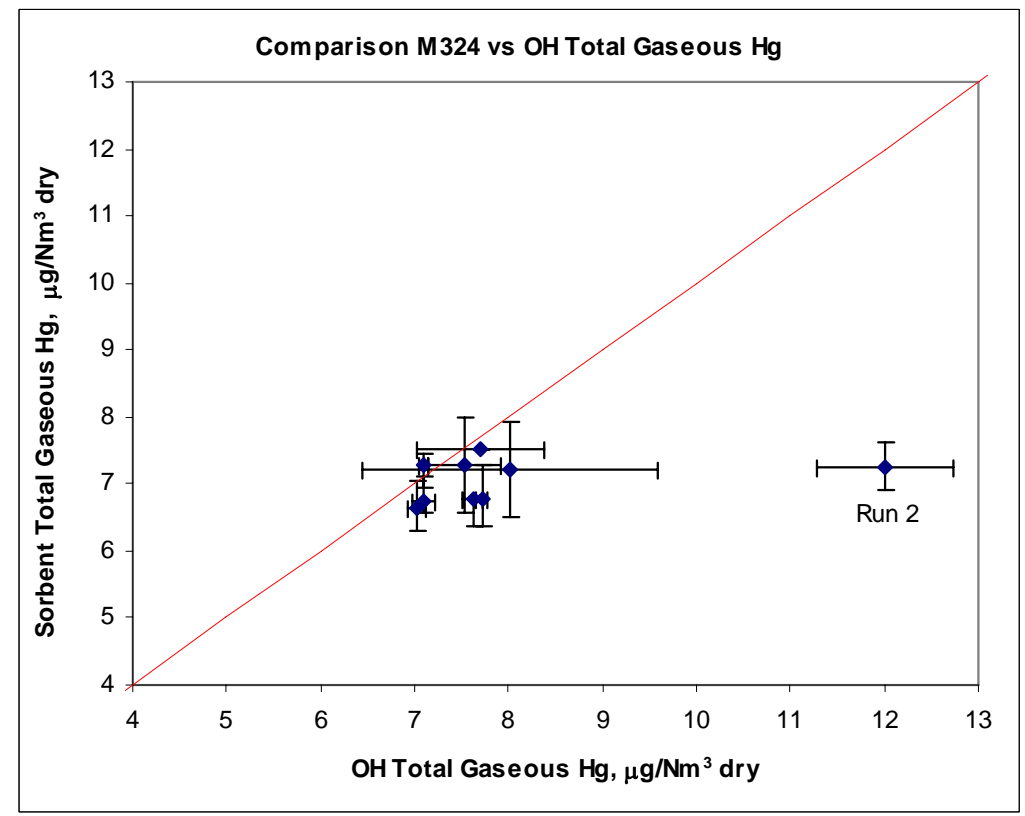

Figure 3.4.2.4 Sorbent trap results vs. Ontario-Hydro results

Using the Ontario-Hydro sampling method as the reference method (RM) and excluding Run 2 from the data set, a relative accuracy (RA) of $10.4 \%$ with respect to the RM is indicated. The error bars represent the RPD between both results of each data pair. All units are on a dry 
basis. In summary, the Method 324 RATA showed a relative accuracy as a percent of $\mathrm{OH}$ as reference method was $10.4 \%$ (limit of $20 \%$ ), and an absolute difference of $0.46 \mu \mathrm{g} / \mathrm{m}^{3}$ (limit of $\left.1 \mu \mathrm{g} / \mathrm{m}^{3}\right)$. As such, the Method 324 data passed the RATA.

\subsubsection{Horiba DM-6 CEMS}

In addition to the Ontario-Hydro and sorbent-based sampling method test runs, a Horiba DM-6 mercury CEMS was used to continuously monitor the total gaseous $\mathrm{Hg}$ concentrations at the stack. During the first week of testing, the mercury CEMS was generally reading 10-22\% lower than the corresponding RM during the same time period, as can be seen in Figures 3.4.3.1 and 3.4.3.2. However, after several unplanned plant outages during which steam was vented through the stack and the unit was fired using oil, $\mathrm{Hg}$ concentrations reported by the DM-6 never recovered and were consistently lower by more than $50 \%$ with respect to the RM for the remainder of the testing. Nevertheless, after exchanging the unit's reducing catalyst, reported $\mathrm{Hg}$ concentrations returned to the levels seen during the first week. The reasons for this behavior as well as the short-term drifts of the instrument are currently under investigation.

Figures 3.4.3.1 and 3.4.3.2 show the comparison of OH, Method 324 and the Horiba data during the test periods of June 29 and 30, 2005. With the exception of run 2, the $\mathrm{OH}$ and Method 324 correlate well as expected from the RATA. The Horiba DM-6 data was consistently biased low.

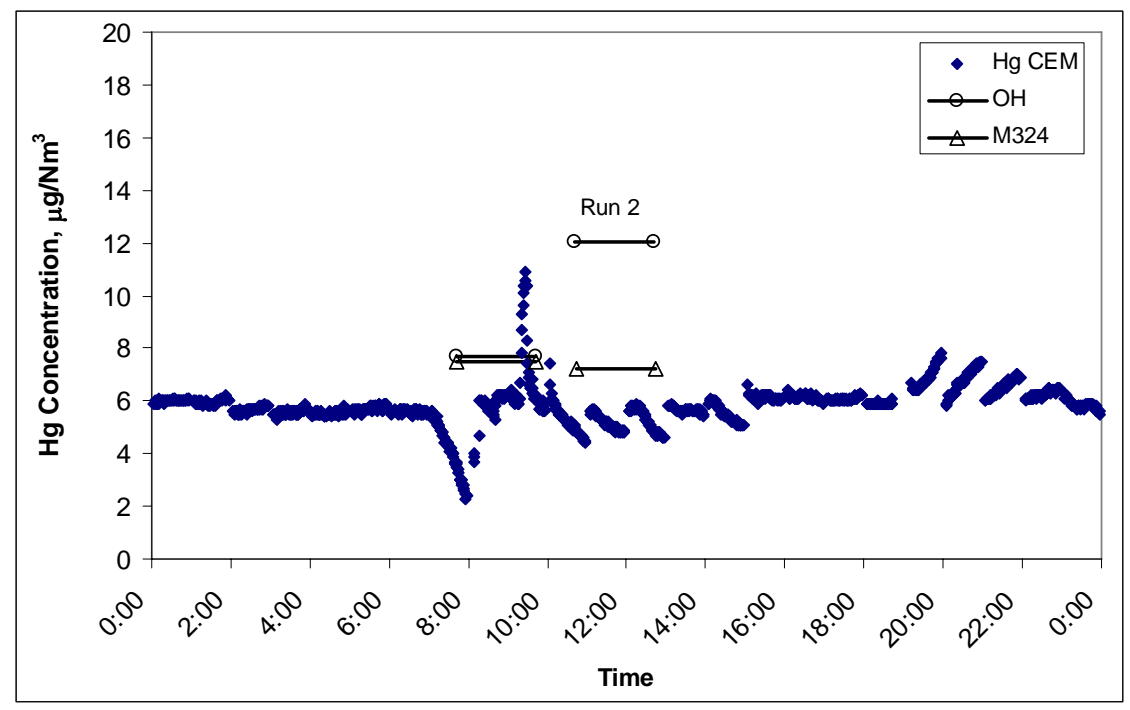

Figure 3.4.3.1 Hg-CEMS results vs. Ontario-Hydro results for June 29, 2005 


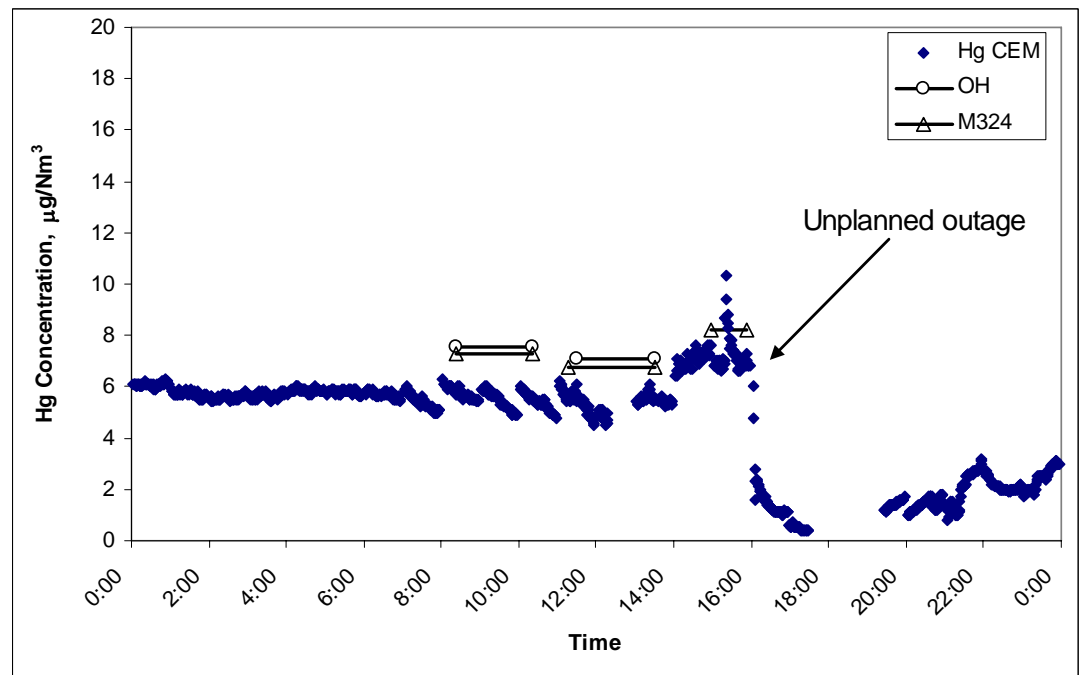

Figure 3.4.3.2 Hg-CEMS results vs. corresponding Ontario-Hydro results

for June 30, 2005

The sudden drop in Hg concentrations around 16:00 hours was due to an unplanned plant outage. All data are adjusted for CEMS response time. A similar RATA conducted using the data from the Horiba DM-6 CEMS showed a relative accuracy as a $\%$ of the $\mathrm{OH}$ as the reference method of $64.8 \%$ (limit of $20 \%$ ) and an absolute difference of $2.98 \mu \mathrm{g} / \mathrm{m}^{3}$ (limit of $1 \mu \mathrm{g} / \mathrm{m}^{3}$ ). As such, the Horiba DM-6 data does not pass the RATA.

The comparison of the three methods is shown graphically in Figure 3.4.3.3

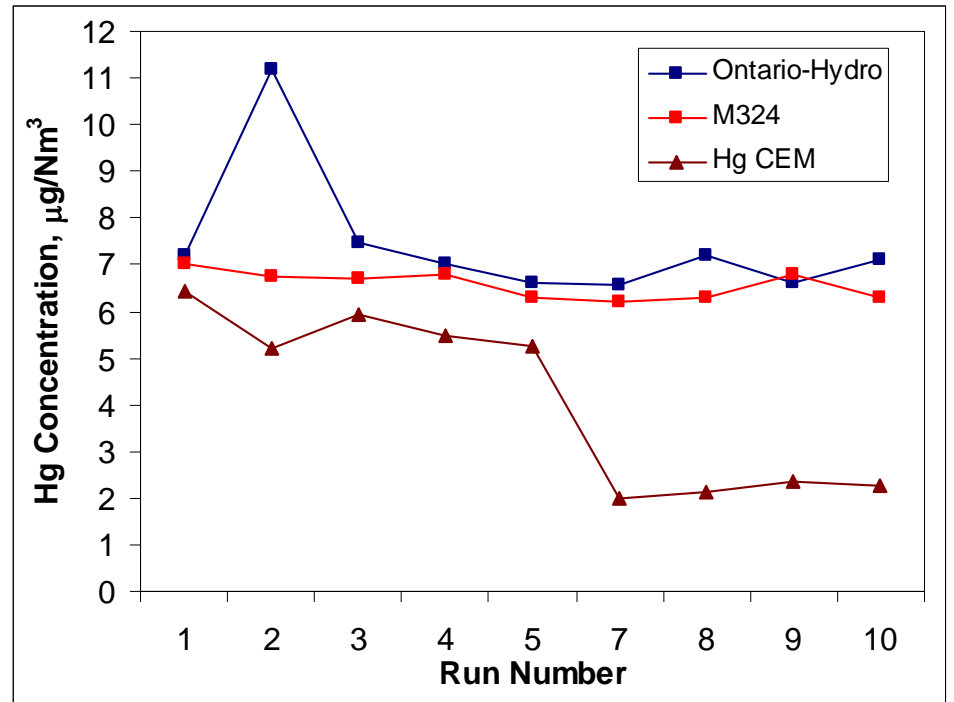

Figure 3.4.3.3 Ontario-Hydro vs. M324 (sorbent tube) vs. Hg-CEMS

In addition to the testing described above. inter-method comparison of the Method 324 and the Horiba CEMS continued through July and August 2005. Figures 3.4.4.1 and 3.4.4.2 shows the results of that testing. In general, the Horiba and M324 methods tracked each other, 
but the Horiba showed a bias for a lower concentration. In addition there was a slow decline in the Horiba as a result of the slow deactivation of the catalyst.

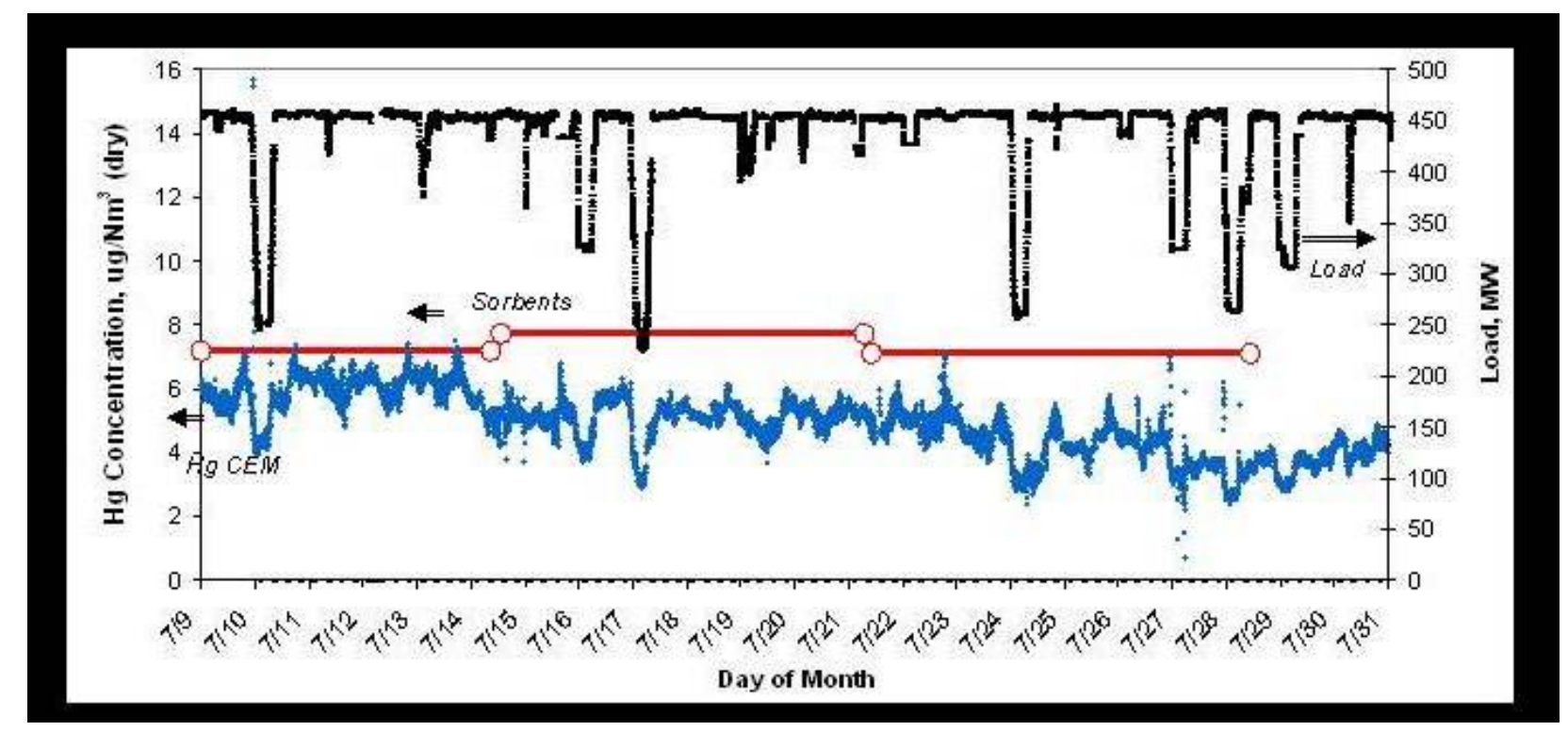

Figure 3.4.4.1 Mercury emissions and load for 7 July through 31 July 2005

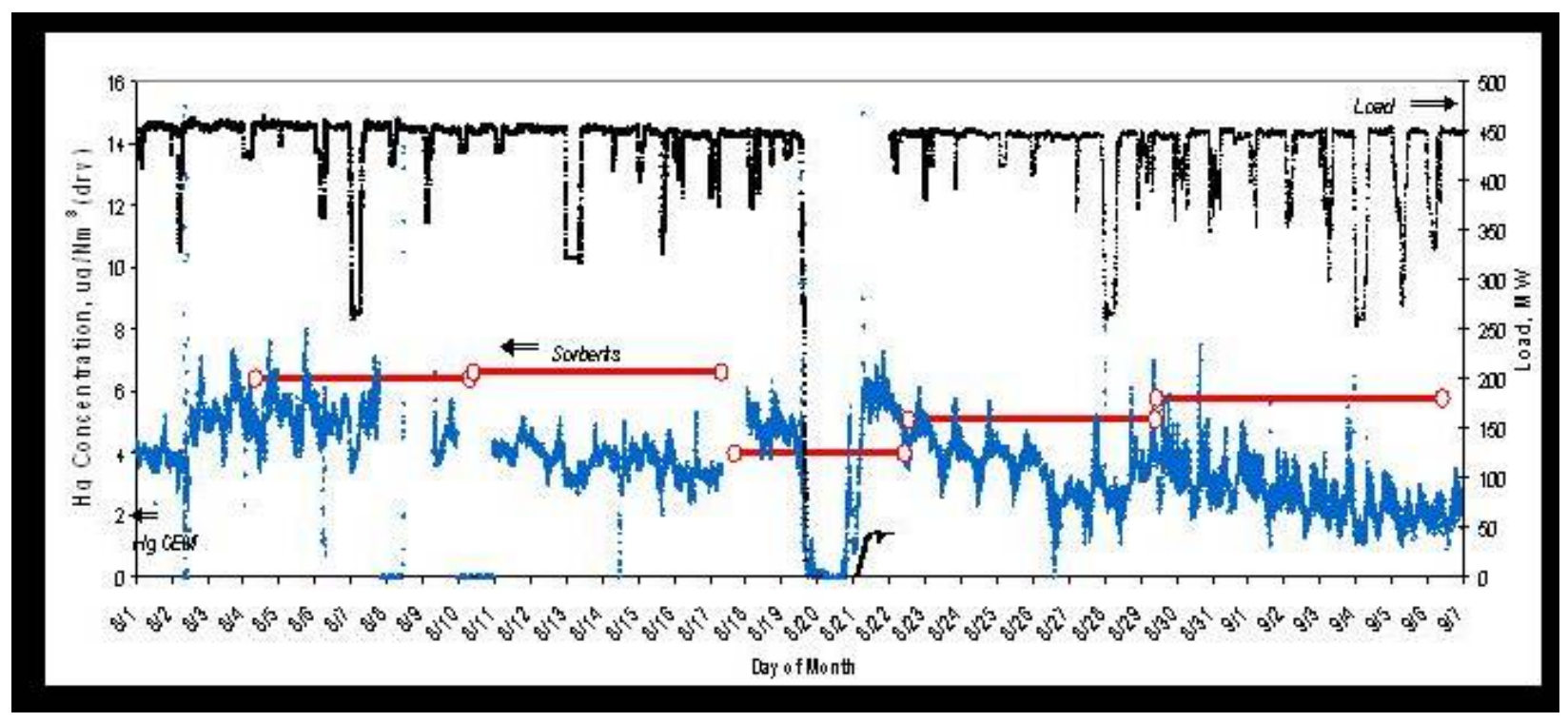

Figure 3.4.4.2 Mercury emissions and load for 1 August through 7 September 2005

The data shows a cyclic nature of the Horiba data with a continued decline in recorded concentration with time. This is considered to reflect the deactivation of the catalyst with time between replacement events. 


\subsubsection{Summary}

In summary,

- All paired Ontario-Hydro sampling method test runs passed the minimum performance criteria for paired RM tests according to Performance Specification 12A (RD less than $10 \%$ for total gaseous $\mathrm{Hg}$ concentrations greater than $1.0 \mu \mathrm{g} / \mathrm{m}^{3}$ ). Particulate-bound $\mathrm{Hg}$ was negligible (non-detected).

- All Method 324 data pairs had a relative deviation (RD) of less than 5\%. A field spike was recovered to $90 \%$ (80-120\% limit).

- The relative accuracy (RA) of Method 324 with respect to Ontario-Hydro as reference method result was $10.4 \%\left(20.00 \%\right.$ limit) with an absolute difference of $0.46 \mu \mathrm{g} / \mathrm{m}^{3}$ (limit of $1 \mu \mathrm{g} / \mathrm{m}^{3}$ ). As such, the Method 324 data passed the RATA.

- During the first week of testing, (June 29 and 30), the Horiba DM-6 Hg CEMS used at the stack provided data comparable to those obtained using the Ontario-Hydro and sorbent-based sampling method (10-22\% lower with Run 2 not included).

- The relative accuracy of the Horiba DM-6-6 CEMS data showed a relative accuracy of $64.8 \%$ (limit of $20 \%$ ) relative to the $\mathrm{OH}$ as the reference method and an absolute difference of $2.98 \mu \mathrm{g} / \mathrm{m}^{3}$ (limit of $1 \mu \mathrm{g} / \mathrm{m}^{3}$ ). As such, the Horiba DM-6 data does not pass the RATA.

\subsection{Long-Term Mercury Variability}

As part of this study, an evaluation of long-term mercury variability was conducted. This evaluation extended beyond the period of the initial Ontario-Hydro method testing and continued throughout the remainder of the 6-month program. The evaluation examined the variability of the feed coal throughout this period, evaluation of the variability of the mercury in the ash, and the resultant variability in the mercury emissions at the stack.

\subsubsection{Coal Analysis}

All coal samples were analyzed for moisture, ash, carbon, sulfur, hydrogen, nitrogen, oxygen and mercury content. See the appropriate Appendix for other results. Coal mercury was performed using ASTM Method D6722-01. Figures 3.5.1.1 and 3.5.1.2 show the long-term variability in the coal ash content and the heating value $(\mathrm{Btu} / \mathrm{lb})$ over the 6 -month period. It is clear that the coal quality parameters were very consistent. Average ash content was $6.40 \% \pm$ $1.76 \%(1 \sigma)$. 


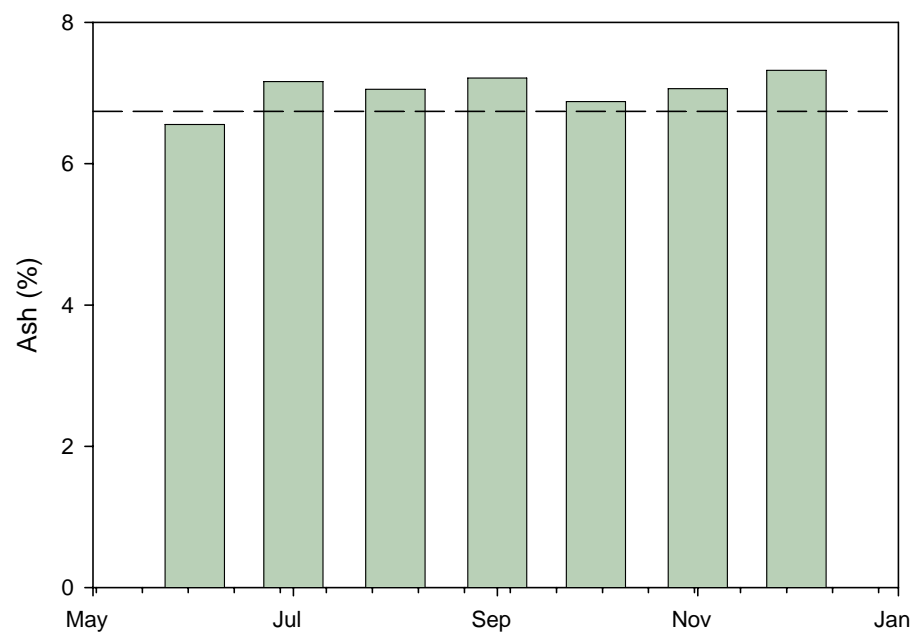

Figure 3.5.1.1 Ash content of the feed coals on a monthly basis over the 6-month monitoring period. (Line represents the values determined in the pre-test coals.)

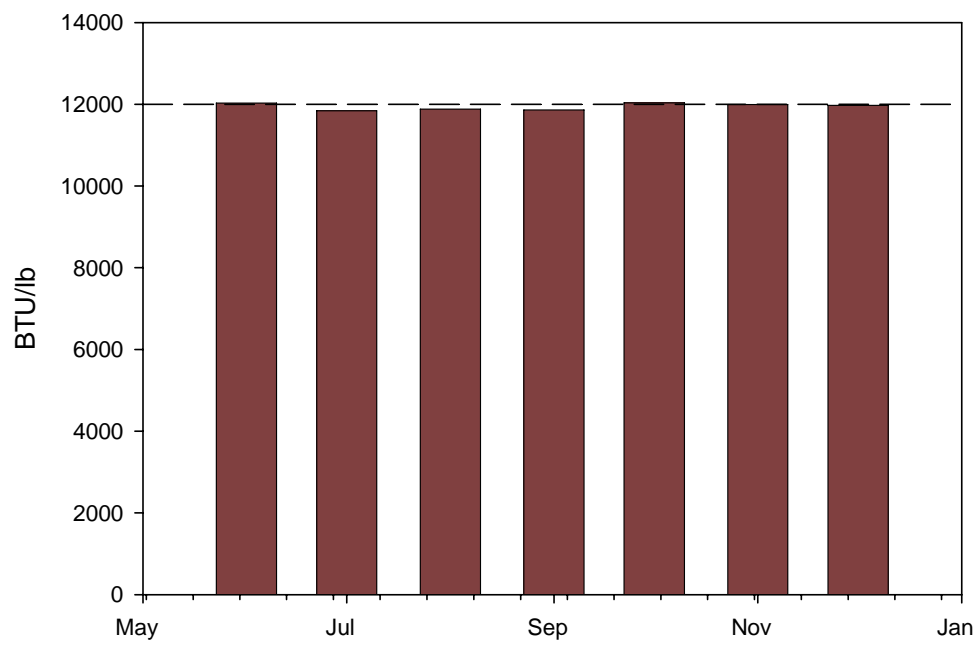

Figure 3.5.1.2 Heating value content of the feed coals on a monthly basis over the 6-month monitoring period. (Line represents the values determined in the pre-test coals.)

Figure 3.5.1.3 shows the $\mathrm{Hg}$ content as a monthly average of the feed coal for the 6month period. The line represents the value determined in the pre-test coals (see Section 3.1). Unlike the ash and heating values, the $\mathrm{Hg}$ concentration varies considerably from a high of 0.12 ppm to a low of $0.06 \mathrm{ppm}$ in September 2005. For comparison, Figure 3.5.1.4 shows the individual $\mathrm{Hg}$ variability for the same period. As one can determine, even within a particular month variability of $\mathrm{Hg}$ is high. The average coal mercury concentration for the entire project duration was $0.096 \mathrm{ppm} \pm 0.032 \mathrm{ppm}(1 \sigma)$ on a dry basis. 


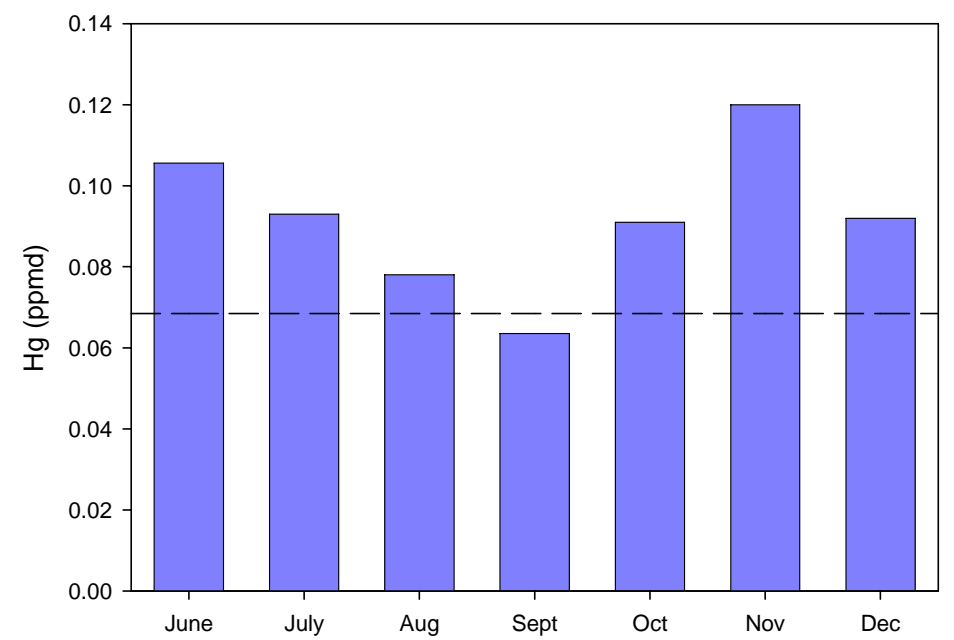

Figure 3.5.1.3 Monthly Hg averages for the Hugo feed coal over the 6-month evaluation

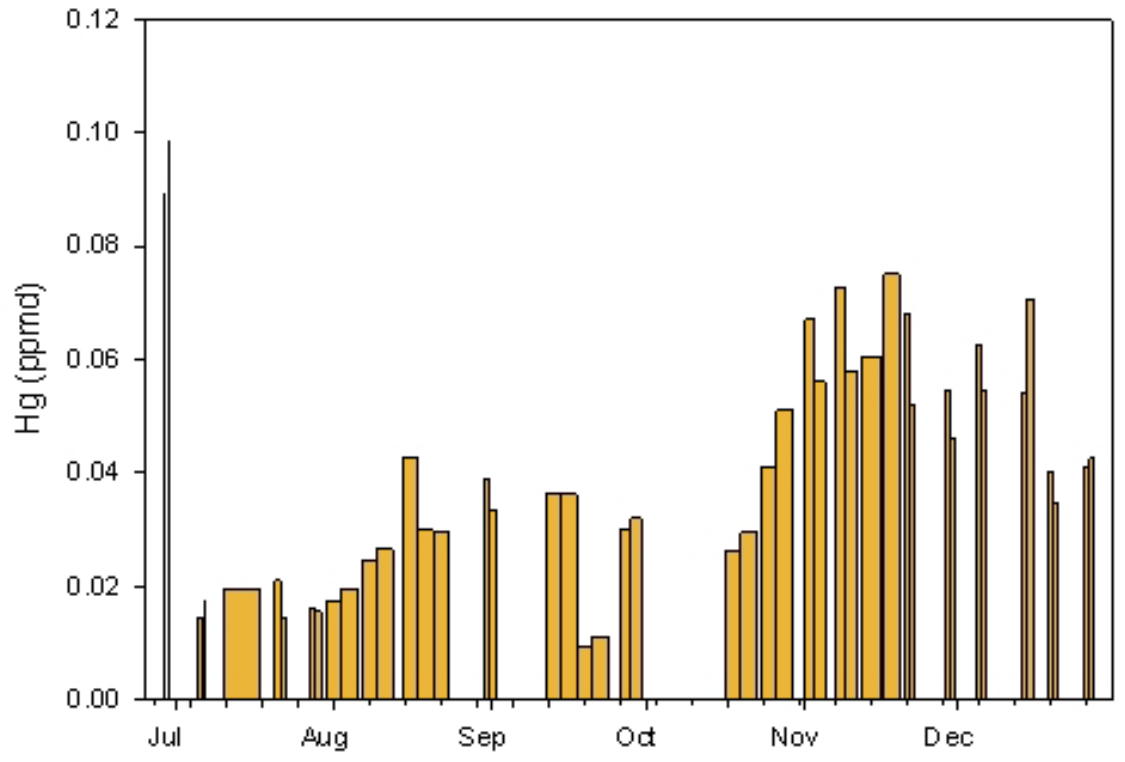

Figure 3.5.1.4 Individual Hg content in coal samples over the 6-month evaluation period 


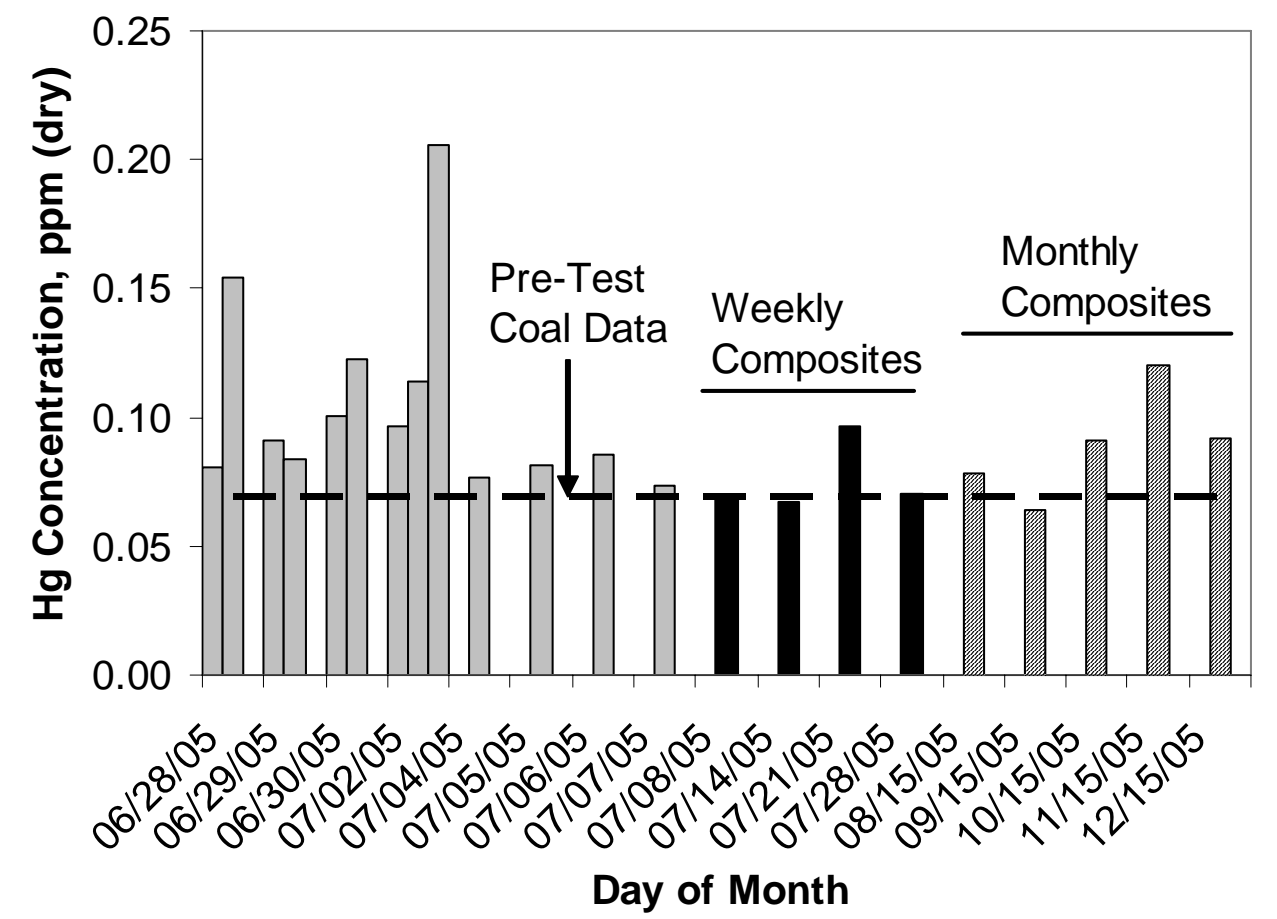

Figure 3.5.1.5 Coal $\mathrm{Hg}$ analysis results for the three testing period (daily, weekly and monthly)

Figure 3.5.1.5 summarizes the coal mercury over the 6-month period. Figure 3.5.1.6 shows the variability of pyritic sulfur content on the feed coal over the 6-month evaluation period. Like the $\mathrm{Hg}$ content the pyritic sulfur content ranging from $0.02 \%$ to $0.07 \%$-average $0.05 \% \pm 0.03 \%(1 \sigma)$. Both $\mathrm{Hg}$ and pyritic sulfur show a low in September 2005 and a high in the October-November timeframe. There is a correlation between the pyritic sulfur and the $\mathrm{Hg}$ contents in the feed coal. 


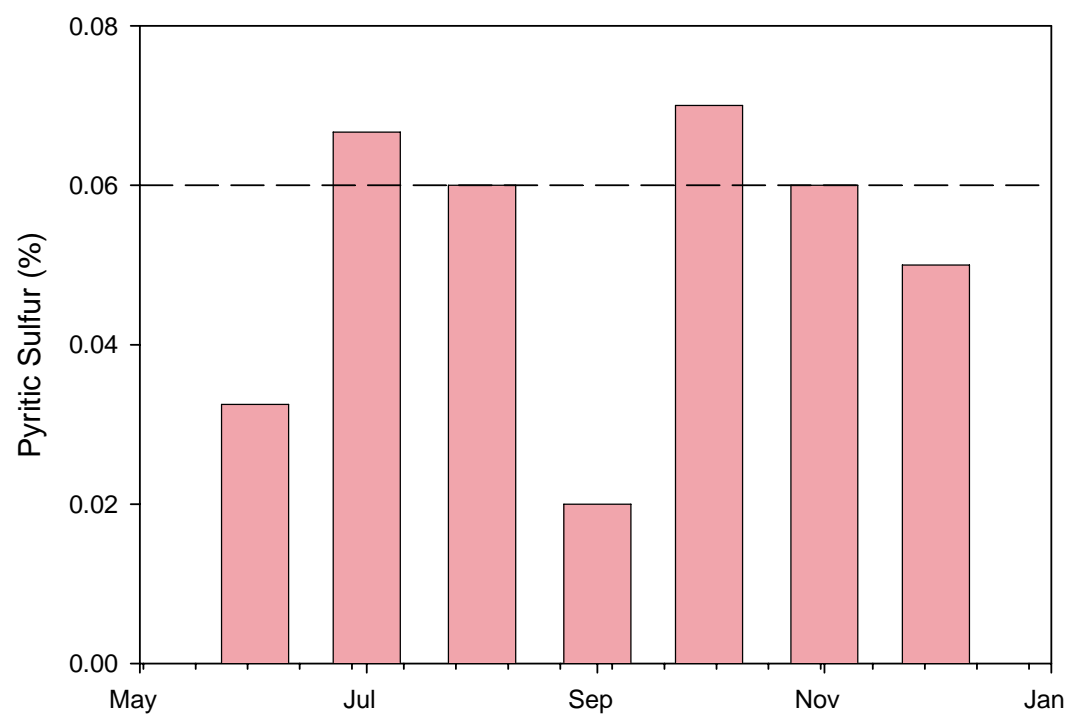

Figure 3.5.1.6 Pyritic sulfur content of the feed coals on a monthly basis over the 6-month monitoring period. (Line represents the values determined in the pre-test coals.)

One should keep in mind that there were coal shipment issues during the time of the testing resulting in the utility to go deeper into the coal pile and use some older stockpile coal. This could account for the feed coal variability shown in the data.

\subsubsection{Ash Analyses}

Mercury analysis results for the fly ash removed from the ESP hoppers are shown in Figure 3.5.2.1. For the initial part of the program (07/06 - 07/07/2005), fly ash samples from the corresponding ESP hoppers were collected in the middle of each Ontario-Hydro method sampling run. As can be seen in Figure 3.5.2.1, the high coal mercury concentrations during the early testing period (see results for dates 06/29 - 06/30/2005 in Figure 3.5.2.1 were reflected in the corresponding fly ash mercury concentrations. For the remainder of the project, fly ash samples were targeted to be collected daily and analyzed as a weekly composite. The average mercury content in the fly ash for the entire project duration was $0.042 \mathrm{ppm} \pm 0.023 \mathrm{ppm}(1 \sigma)$ on a dry basis. 


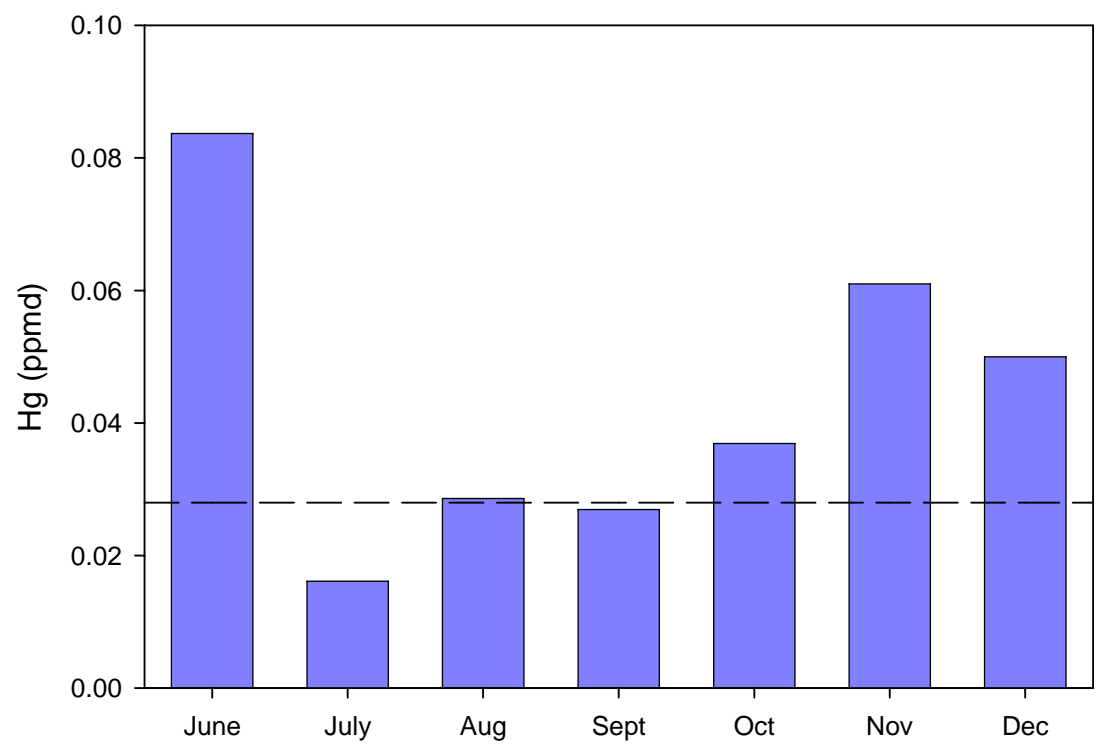

Figure 3.5.2.1 Monthly mercury results for the fly ash over the 6-month evaluation period. (Line represents the concentration determined from the pre-test samples.)

For the bottom ash, sampling during the actual mass balance testing yielded very low mercury concentrations: daily averages of $4.5 \mathrm{ppb}$ and $2 \mathrm{ppb}$ (on a dry basis) for the $07 / 06 / 2005$ and 07/07/2005, respectively. However, as is evident from Figure 3.5.2.2, mercury concentrations in the bottom ash seemed to vary greatly (by several orders of magnitude) over the course of the project, raising concerns about the collection of representative bottom ash samples. The average mercury content of the bottom ash for the 6-month project duration was $0.065 \mathrm{ppm} \pm 0.198 \mathrm{ppm}(1 \sigma)$.

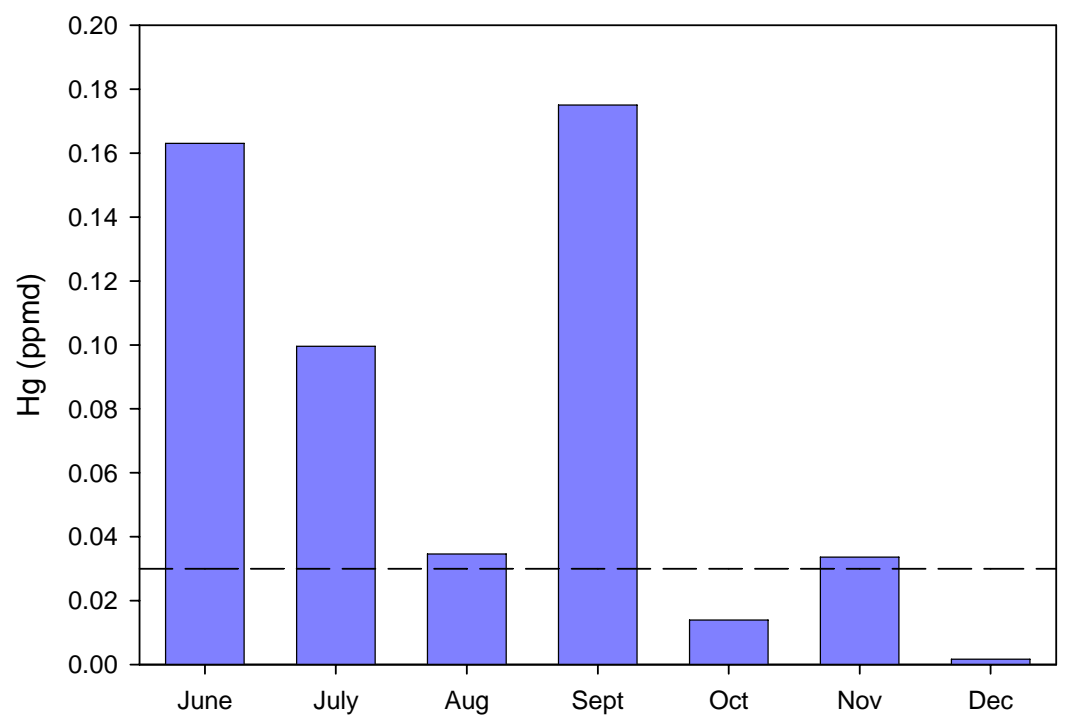

Figure 3.5.2.2 Monthly mercury content of the bottom ash samples 


\subsubsection{Mercury Emissions.}

Concurrent with the coal and ash samples, the Horiba DM-6 mercury continuous emissions monitoring system and Method 324 sorbent tubes were used to monitor the $\mathrm{Hg}$ emissions in the flue gas at Hugo's exhaust stack over the six month evaluation period. Sorbent tube Method 324 sampling was performed during the first two of those six months and Horiba DM-6 CEMS monitored the stack gas emissions over the entire 6-month period. The Hg in the stack gas as measured by both or one of these methods is shown in Figures 3.5.3.1 through 3.5.3.6.

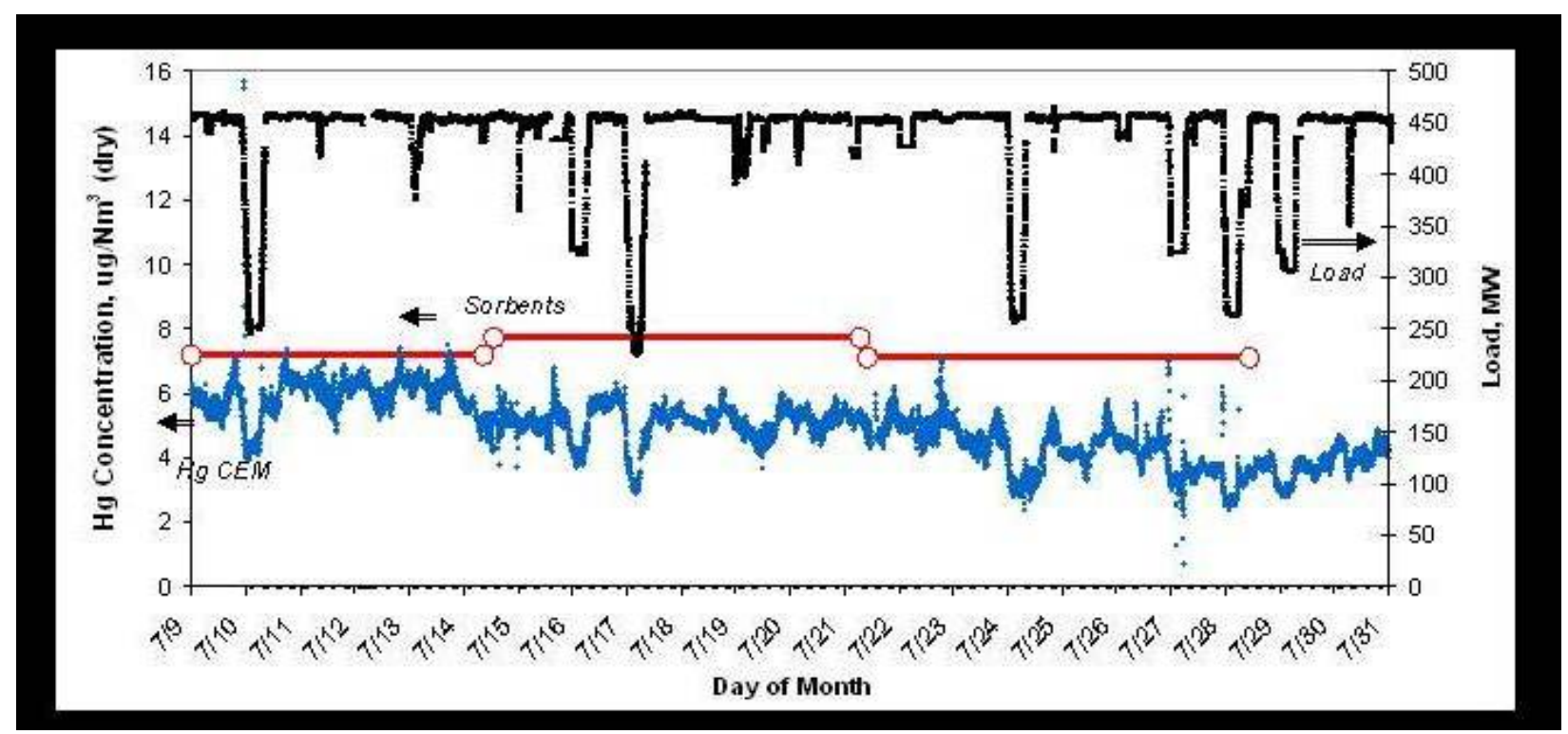

Figure 3.5.3.1 Mercury emissions and load for 7 July through 31 July 2005

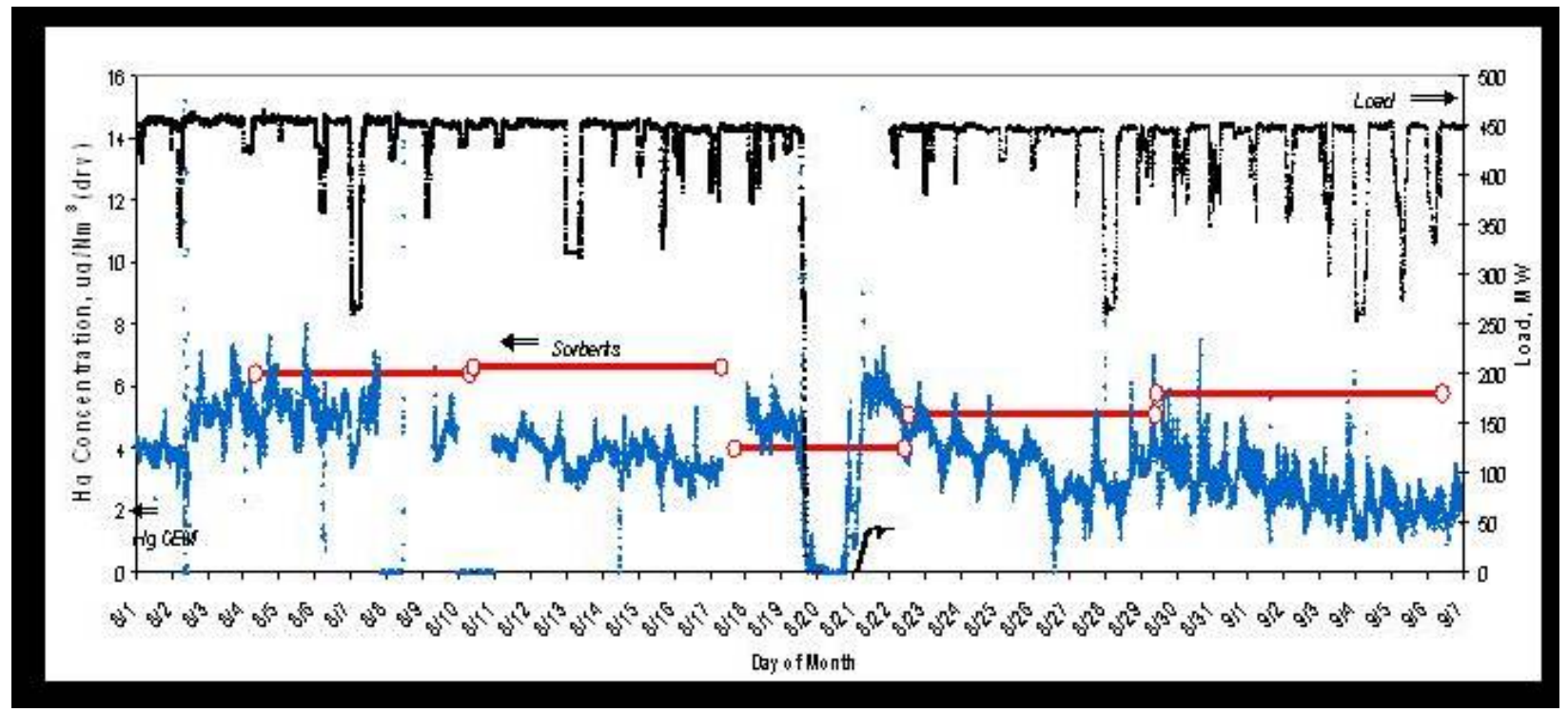

Figure 3.5.3.2 Mercury emissions and load for 1 August through 7 September 2005 


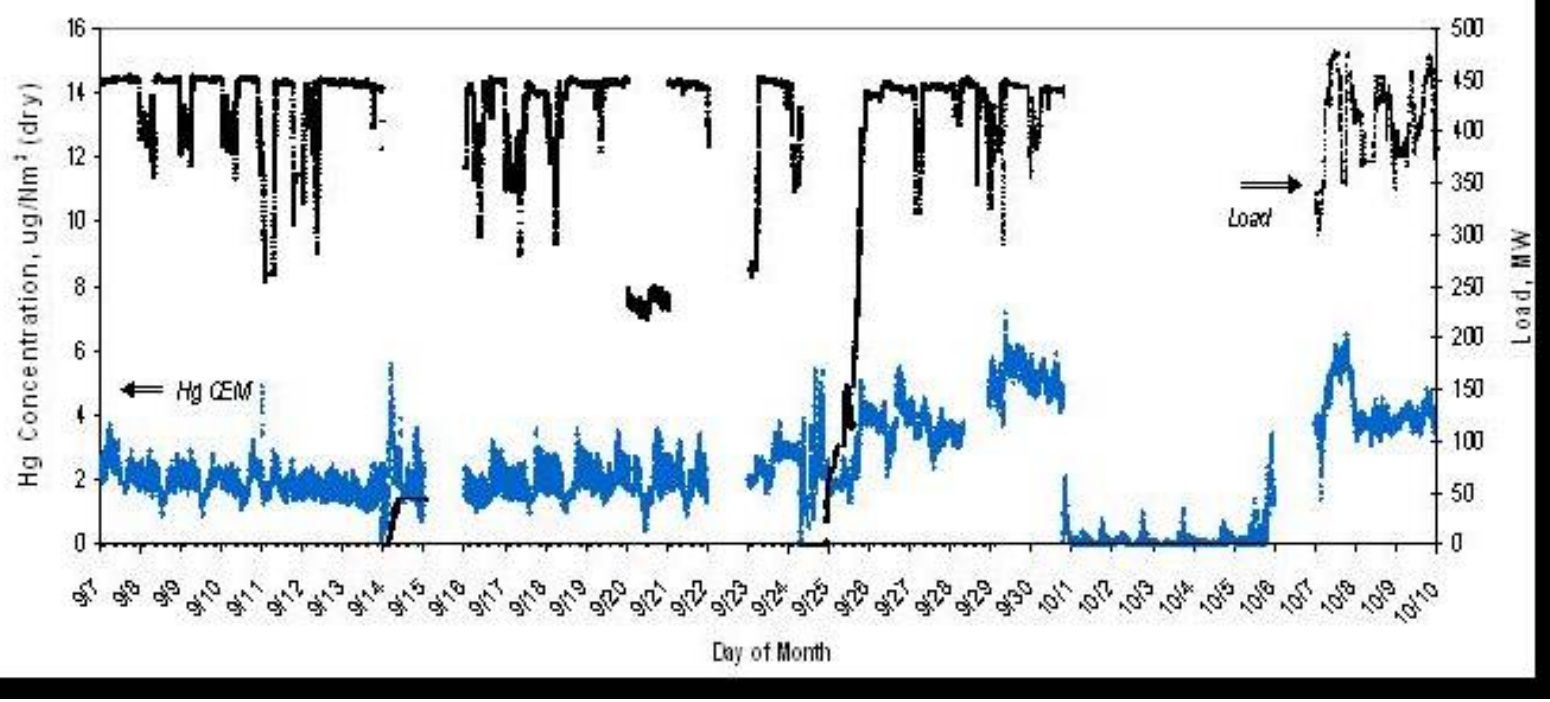

Figure 3.5.3.3 Mercury emissions and load for 8 September through 10 October 2005

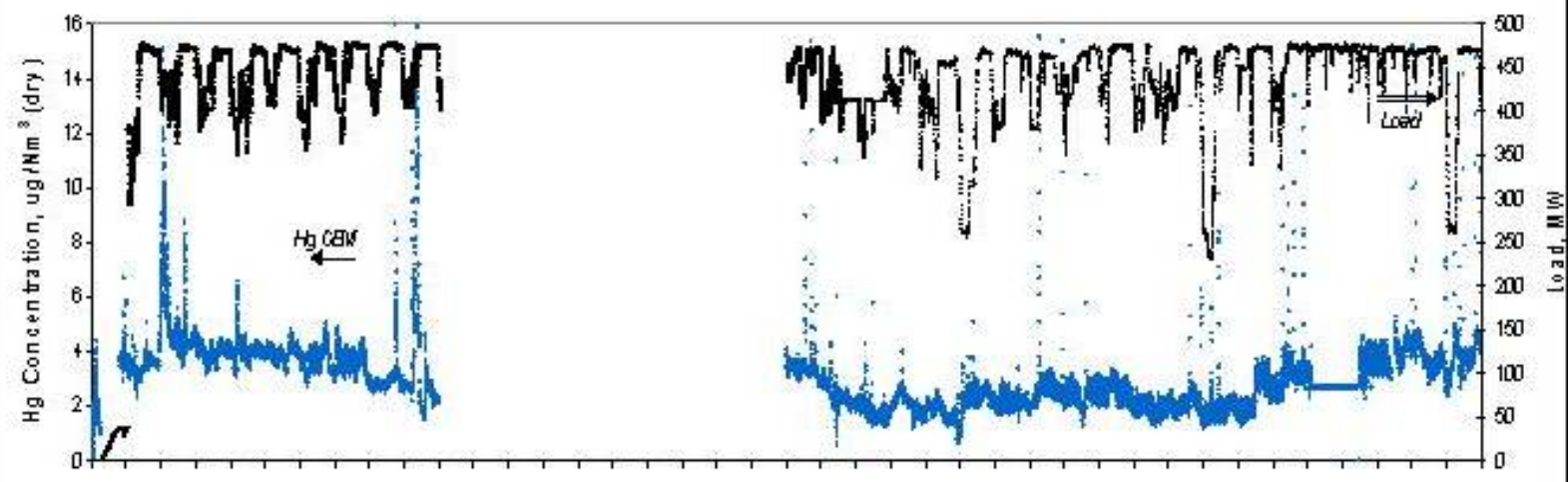

की

Day of Month

Figure 3.5.3.4 Mercury emissions and load for11 October through 21 November 2005 


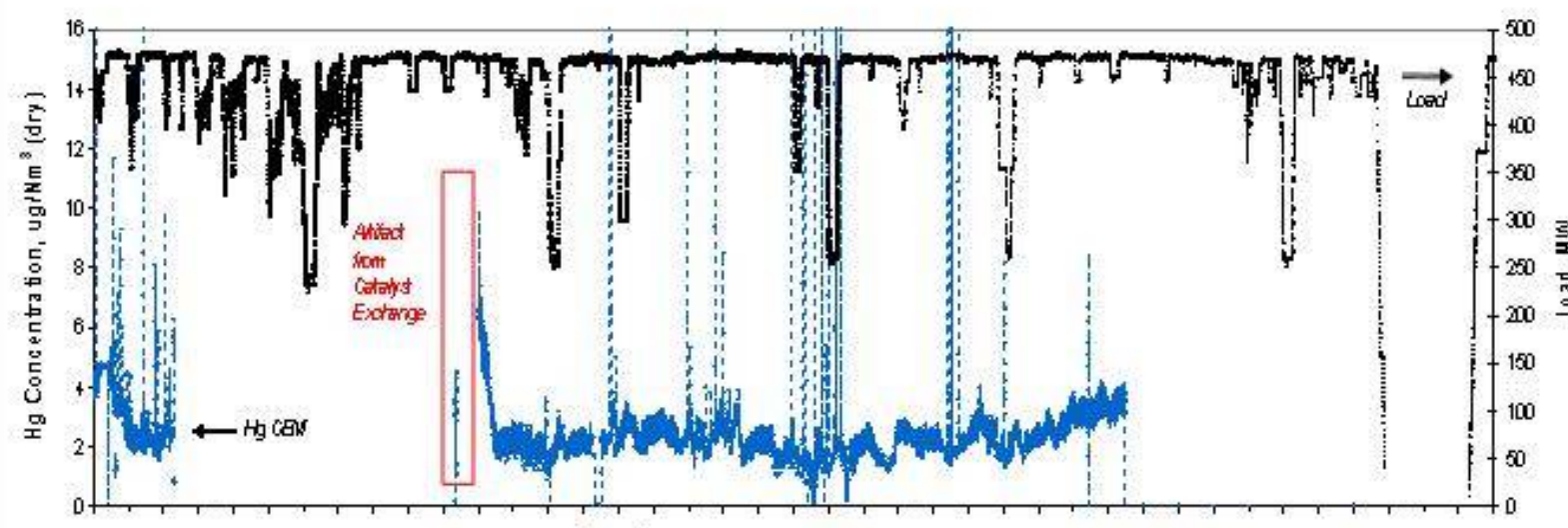

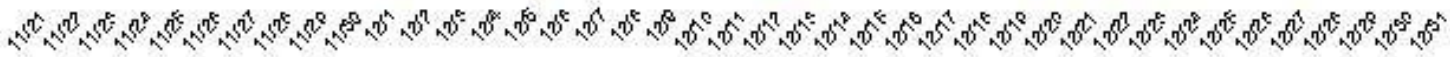

Day of Hon h

Figure 3.5.3.5 Mercury emissions and load for21 November through 31 December 2005

It can be seen that there is a downward trend in the emissions $\mathrm{Hg}$ concentration with time as determine by the Horiba CEMs system. It is unclear that this is real or a deterioration of performance with time (see levels in August compared with levels in November and December.

\subsection{Method 324 and Horiba CEMS Long-Term Operation and Maintenance Record}

Plant personnel were trained on site on the use, care and maintenance of the sorbent tube sampling equipment and Hg-CEMS. Phone and email support was provided when requested. Several site visits over the six-month period for maintenance was also performed. The Horiba Hg-CEMS and sorbent tube were maintained by plant personnel over this six month period. Horiba Hg-CEMS data files and facility boiler data was downloaded by plant personnel and emailed daily for data reduction and reporting. WFEC's CEMS and boiler data was provided for the six month period showing boiler load levels, coal consumption, as well as sulfur dioxide, nitrogen oxides, and flue gas flow rates. Maintenance of the Horiba Hg-CEMS included weekly calibration checks, as well as daily inspections to ensure continued sampling. The six-month period covered emissions from June 24, 2005 until December 20, 2005.

\subsubsection{Method 324 Operation and Maintenance.}

Table 3.6.1.1 shows the results of gaseous mercury emissions of measured during the program. As can be seen in Table 3.7.1.1, there were several hardware, software as well as sorbent trap recovery issues during the first five weeks of the program. As a result, only one sorbent trap of each pair could be recovered successfully for the first five weeks. In addition, the sorbent trap results for the $4^{\text {th }}$ week were deemed invalid for the same reason. The QA / QC for the sorbent trap method is presented in Appendix A. 
Table 3.6.1.1 Summary of Test Results for Long-Term Sorbent Trap Monitoring

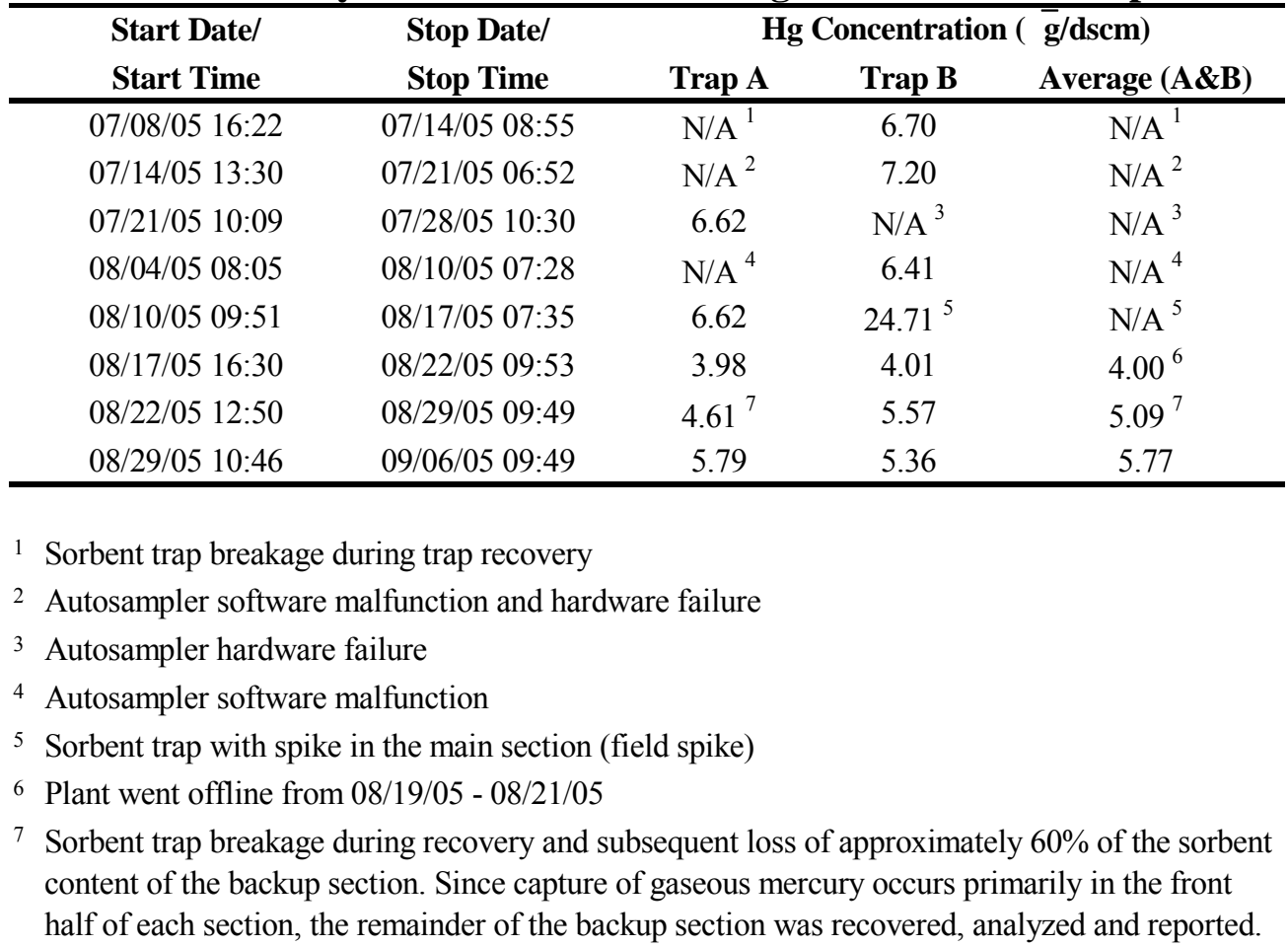

In addition to the sorbent trap breakage and autosampler malfunctions, the laboratory analysis of the sorbent faced issues as well. Table 3.6.1.2. shows the recoveries of the laboratory spikes and the certified reference materials (CRM). Recoveries of spikes range from 91\% to $103 \%$ which is within the acceptable limits. However, the recovery from the NIST 1641d CRM range only between 82 and 105\%. These percent recoveries fall outside of the allowed 90\% $110 \%$ range. 
Table 3.6.1.2 Summary of the Laboratory Spike and CRM Recoveries

\begin{tabular}{|c|c|c|c|c|c|c|}
\hline $\begin{array}{c}\text { Sorbent } \\
\text { Trap } \\
\text { ID }\end{array}$ & $\begin{array}{c}\text { Digestion } \\
\text { Blanks } \\
\text { ng/trap }\end{array}$ & $\begin{array}{l}\text { MDL }^{1} \\
\text { ng/trap }\end{array}$ & $\begin{array}{c}\text { CRM }^{2} \\
\text { (NIST 1641d) } \\
\text { \% Recovery }\end{array}$ & $\begin{array}{c}\text { Laboratory } \\
\text { Matrix Spike }^{3} \\
\text { \% Recovery }\end{array}$ & $\begin{array}{c}\text { Lab Matrix } \\
\text { Duplicate } \\
\text { RPD }^{4}\end{array}$ & $\begin{array}{c}\text { Lab Matrix } \\
\text { Spike Duplicate } \\
\text { RPD }\end{array}$ \\
\hline 830 & 0.50 & 3.35 & $82.2 \%$ & $101.6 \%$ & $1.3 \%$ & $0.4 \%$ \\
\hline 832,833 & 2.70 & 1.93 & $83.3 \%$ & $101.1 \%$ & $6.6 \%$ & $1.2 \%$ \\
\hline 838 & 0.14 & 0.42 & $96.7 \%$ & $99.1 \%$ & $0.6 \%$ & $1.5 \%$ \\
\hline 839 & 2.70 & 1.93 & $83.3 \%$ & $101.1 \%$ & $6.6 \%$ & $1.2 \%$ \\
\hline $828^{5}$ & 2.70 & 1.93 & $83.3 \%$ & $100.4 \%$ & $3.8 \%$ & $6.5 \%$ \\
\hline 840,841 & 0.10 & 0.09 & $103.0 \%$ & $102.9 \%$ & $7.1 \%$ & $6.0 \%$ \\
\hline $842,843,844,845$ & 0.39 & 2.42 & $104.6 \%$ & $91.4 \%$ & $2.1 \%$ & $10.6 \%$ \\
\hline
\end{tabular}

1 Estimated Method Detection Limit (three times the standard deviation of sucessive digestion blank results)

2 Certified Reference Material (CRM)

3 Average of duplicate analysis

${ }^{4}$ Relative Percent Deviation (RPD)

5 Sorbent trap with spike in the main section (field spike)

Table 3.6.1.3 Sorbent Trap Breakthrough Performance

\begin{tabular}{|c|c|c|c|c|c|c|c|}
\hline & \multirow{2}{*}{$\begin{array}{l}\text { Start Date/ } \\
\text { Start Time }\end{array}$} & \multirow{2}{*}{$\begin{array}{l}\text { Stop Date/ } \\
\text { Stop Time }\end{array}$} & \multicolumn{4}{|c|}{ Backup Section Analysis (Breakthrough) } & \multirow{2}{*}{$\begin{array}{c}\text { Paired Trap } \\
\text { Agreement } \\
\text { \%RD }\end{array}$} \\
\hline & & & $\begin{array}{c}\text { Trap A } \\
\text { ng }\end{array}$ & $\begin{array}{c}\text { Trap B } \\
\text { ng }\end{array}$ & $\begin{array}{c}\text { Trap A } \\
\%^{7}\end{array}$ & $\underset{\%^{7}}{\operatorname{Trap} B}$ & \\
\hline & 07/08/05 16:22 & 07/14/05 08:55 & $\mathrm{N} / \mathrm{A}^{1}$ & 1.94 & $\mathrm{~N} / \mathrm{A}^{1}$ & $0.02 \%$ & $\mathrm{~N} / \mathrm{A}^{1}$ \\
\hline & 07/14/05 13:30 & 07/21/05 06:52 & $\mathrm{N} / \mathrm{A}^{2}$ & 5.49 & $\mathrm{~N} / \mathrm{A}^{2}$ & $0.02 \%$ & $\mathrm{~N} / \mathrm{A}^{2}$ \\
\hline & 07/21/05 10:09 & 07/28/05 10:30 & 3.89 & $\mathrm{~N} / \mathrm{A}^{3}$ & $0.01 \%$ & $\mathrm{~N} / \mathrm{A}^{3}$ & $N / A^{3}$ \\
\hline & 08/04/05 08:05 & 08/10/05 07:28 & $\mathrm{N} / \mathrm{A}^{4}$ & 0.00 & $\mathrm{~N} / \mathrm{A}^{4}$ & $0.00 \%$ & $\mathrm{~N} / \mathrm{A}^{4}$ \\
\hline & 08/10/05 09:51 & 08/17/05 07:35 & 0.00 & 0.24 & $0.00 \%$ & $0.00 \%$ & $\mathrm{~N} / \mathrm{A}^{5}$ \\
\hline & 08/17/05 16:30 & 08/22/05 09:53 & 0.28 & 0.12 & $0.00 \%$ & $0.00 \%$ & 0.34 \\
\hline & 08/22/05 12:50 & 08/29/05 09:49 & $1.01^{6}$ & 0.03 & $0.01 \%{ }^{6}$ & $0.00 \%$ & 9.46 \\
\hline & 08/29/05 10:46 & 09/06/05 09:49 & 0.00 & 0.00 & $0.00 \%$ & $0.00 \%$ & 3.87 \\
\hline \multicolumn{8}{|c|}{ Sorbent trap breakage during trap recovery } \\
\hline 2 & \multicolumn{7}{|c|}{ Autosampler software malfunction and hardware failure } \\
\hline 3 & \multicolumn{7}{|c|}{ Autosampler hardware failure } \\
\hline \multicolumn{8}{|c|}{ Autosampler software malfunction } \\
\hline \multicolumn{8}{|c|}{ Sorbent trap with spike in the main section (field spike) } \\
\hline \multicolumn{8}{|c|}{$\begin{array}{l}\text { Sorbent trap breakage during recovery and subsequent loss of approximately } 60 \% \text { of the sorbent content of } \\
\text { the backup section. Remainder of the backup section was recovered, analyzed and reported. }\end{array}$} \\
\hline
\end{tabular}

Table 3.6.1.2 presents the analysis of the backup section of the sorbent traps as it relates to the comparison of the paired Method 324 sorbent traps. The high amount of trap breakage makes analysis difficult. However, where paired traps were available (August 17 through $8 / 29 / 2005$ showed paired trap agreement of $0.34 \%$ to $9.46 \%$ were used. 
The Method 324 plant personnel operations and maintenance summary contained herein includes only the major maintenance and operational events. The infrequent trips of the plant technicians up the stack in order to assess the system's state have not been included in this report, anticipating that future versions of sorbent trap-based monitoring equipment are enhanced with remote monitoring capabilities that make these trips redundant. In addition to the description and date of each major maintenance/operational event, Table 3.6.1.4 also includes an estimate of the duration of each event. Durations for logbook entries with missing time stamps were based on documented durations for similar tasks or time stamps of data files for subsequent sampling runs. Note that some time durations are not representative of the actual time spent to maintain or operate the system, since on several occasions plant personnel interrupted their tasks for several hours in order to devote their attention onto more pressing issues related to their daily duties.

Nevertheless, after working through most of the issues that plagued the sorbent trap monitoring system for the first five weeks of the program, the duration recorded for the operation and maintenance of the remainder of the program reflects the true effort for plant personnel. As such, when sampling sorbent traps on a weekly basis, the time spent on the sampling location is approximately 1-3 hours per week. 
Table 3.6.1.4 Summary Log of Major Sorbent Trap Maintenance Events

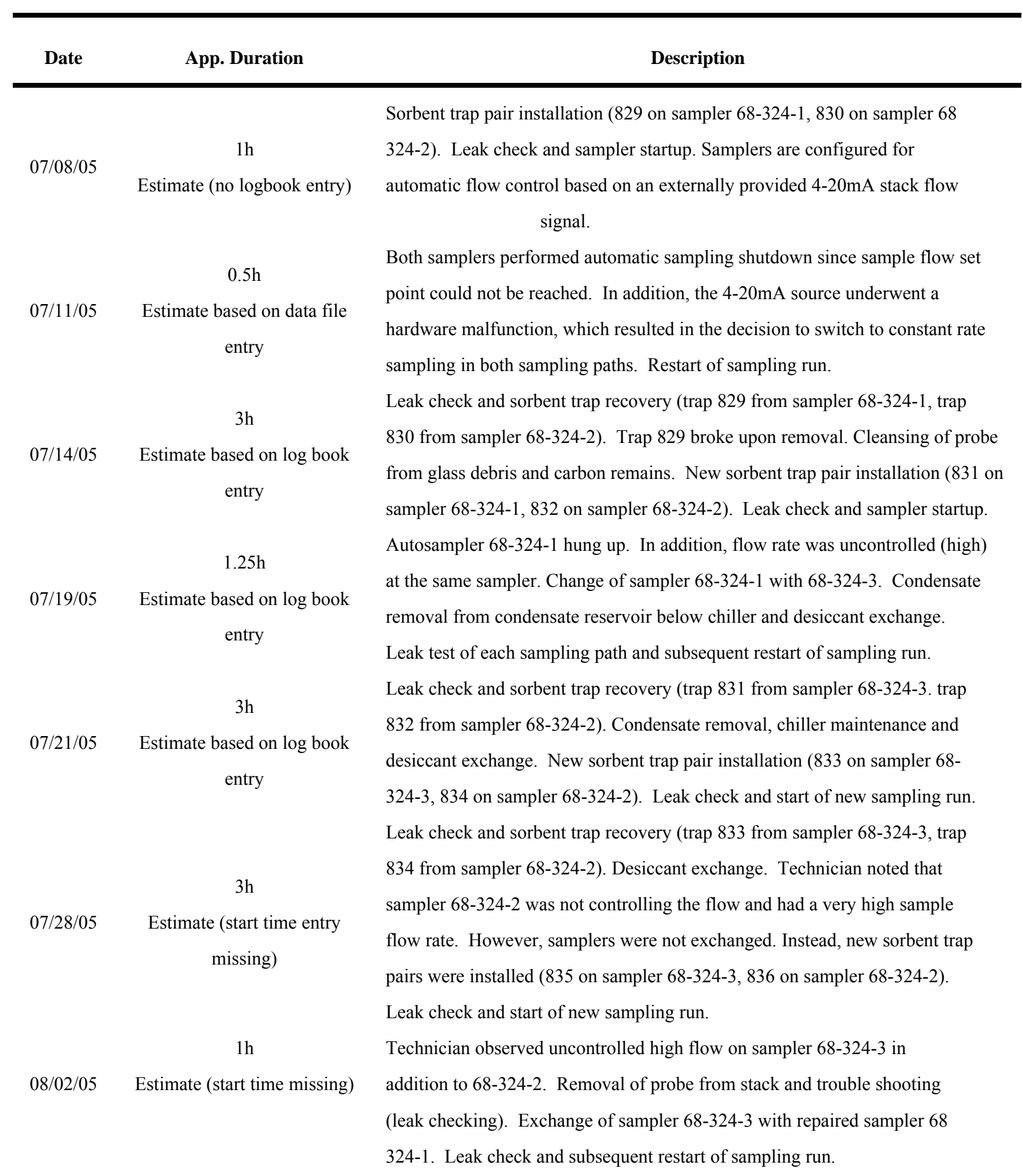


Table 3.6.1.4 Summary Log of Major Sorbent Trap Maintenance Events (continued)

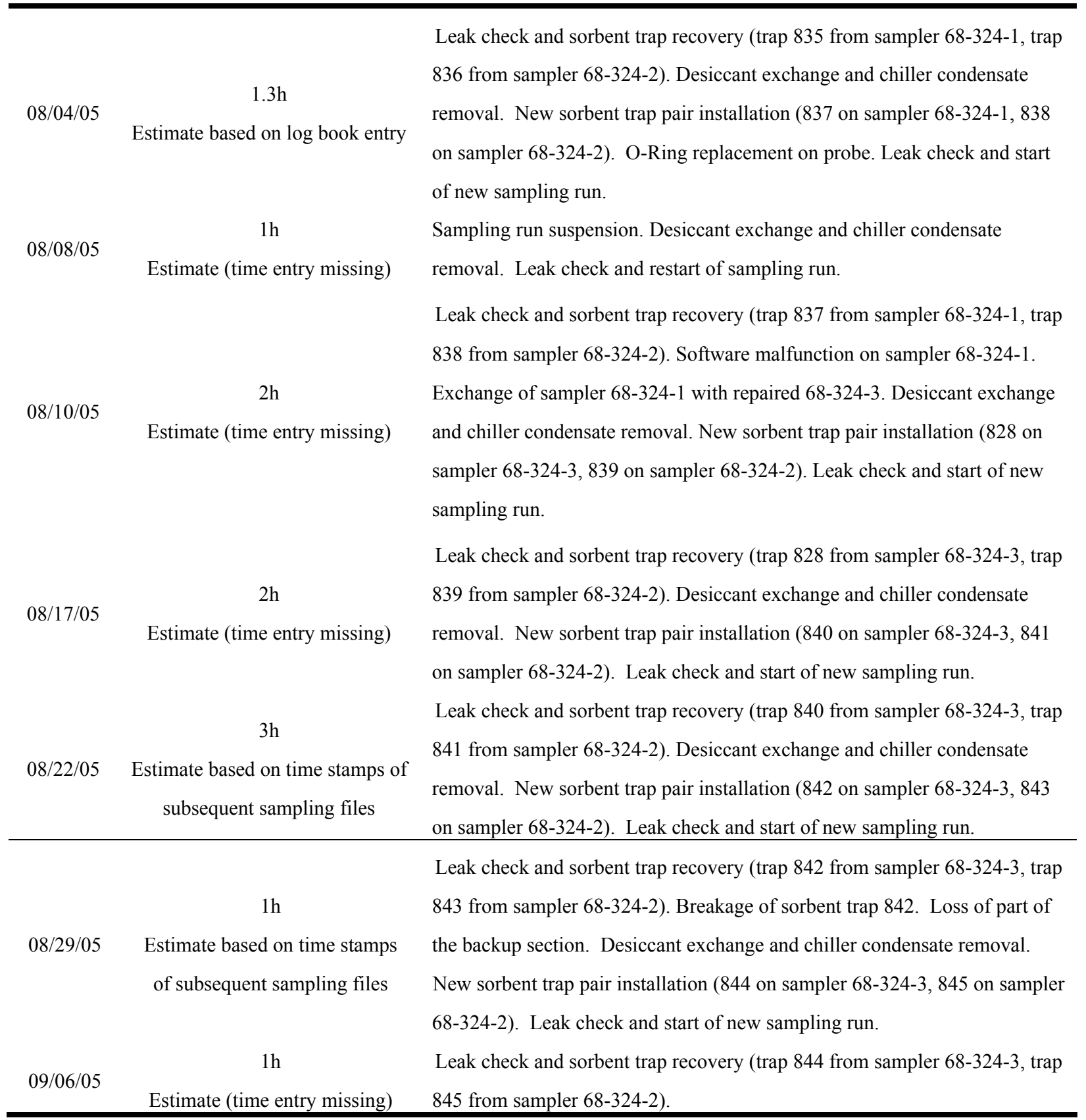

\subsubsection{Horiba DM-6 CEMS Operation and Maintenance}

Horiba CEMS maintenance report summary in Table 3.6.2.1 is based on the plant technician's logbook notes as well as service technician site visit reports. 
Table 3.6.2.1 Summary Log of Major Hg-CEMS Maintenance Events

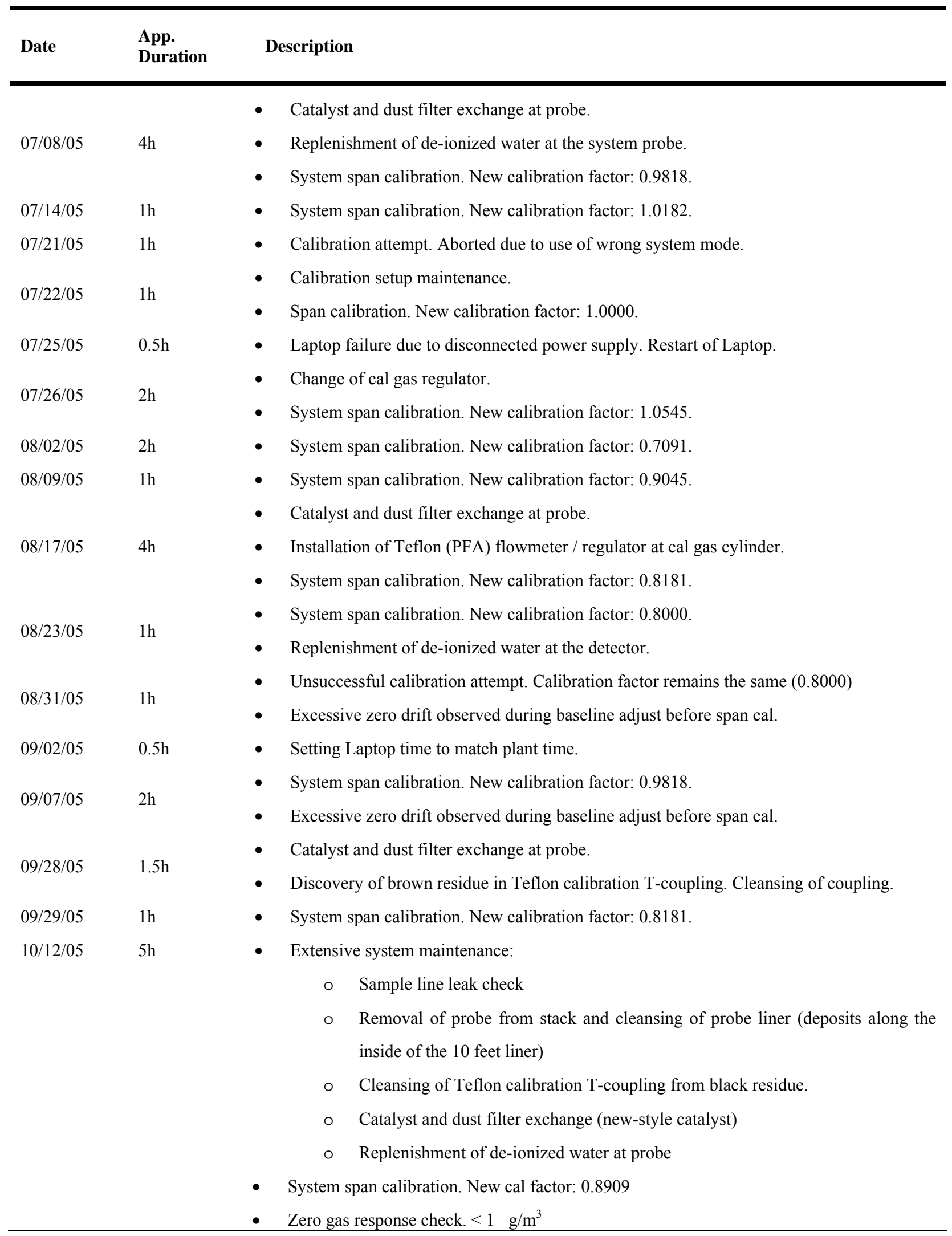


Table 3.6.2.1 Summary Log of Major Sorbent Trap Maintenance Events(continued)

\begin{tabular}{|c|c|c|c|}
\hline $10 / 27 / 05$ & $1 \mathrm{~h}$ & \multicolumn{2}{|c|}{ Catalyst (original-style catalyst) } \\
\hline $10 / 28 / 05$ & $1 \mathrm{~h}$ & \multicolumn{2}{|c|}{ - $\quad$ System span calibration. New cal factor: 1.2182} \\
\hline $11 / 01 / 05$ & $1.5 \mathrm{~h}$ & \multicolumn{2}{|c|}{ - $\quad$ System span calibration. New cal factor: 1.2727} \\
\hline $11 / 14 / 05$ & $1 \mathrm{~h}$ & \multicolumn{2}{|c|}{ - $\quad$ System span calibration. New cal factor: 0.9091} \\
\hline $11 / 17 / 05$ & $1.5 \mathrm{~h}$ & \multicolumn{2}{|c|}{$\begin{array}{l}\text { - Horiba stopped due to 'Probe Error' (possibly due to freezing of condensate in some part of } \\
\text { the probe). Restart and system span calibration. New cal factor: } 0.9091\end{array}$} \\
\hline $11 / 18 / 05$ & $3 \mathrm{~h}$ & \multirow{2}{*}{\multicolumn{2}{|c|}{$\begin{array}{l}\text { - Maintenance at probe to remove condensate from probe liner. } \\
\text { - Horiba stopped due to 'Probe Error' possibly due to freezing of condensate in } \\
\text { the probe, which is supported by a considerable vacuum pressure. } \\
\text { - Troubleshooting }\end{array}$}} \\
\hline $11 / 21 / 05$ & $1 \mathrm{~h}$ & & \\
\hline $11 / 23 / 05$ & $0.5 \mathrm{~h}$ & \multicolumn{2}{|c|}{$\begin{array}{l}\text { - } \quad \text { Erratic measurements with high vacuum pressure. } \\
\text { - } \quad \text { Shutdown of analyzer for preventive maintenance. } \\
\text { - } \quad \text { Preventive maintenance }\end{array}$} \\
\hline \multirow{4}{*}{$12 / 01 / 05$} & \multirow{4}{*}{$4 \mathrm{~h}$} & 0 & $\begin{array}{l}\text { Inspection and cleansing of probe liner and Teflon cal T-coupling from brown } \\
\text { deposits and condensate. }\end{array}$ \\
\hline & & 0 & Disassembly of dust filter (noticing water stains) \\
\hline & & 0 & Maintenance of heated sample line \\
\hline & & 0 & $\begin{array}{l}\text { Additional insulation of probe penetrating the stack annulus as well as unheated } \\
\text { sample line portion within the probe housing in order to prevent further formation } \\
\text { and freezing of condensate. }\end{array}$ \\
\hline $12 / 02 / 05$ & $0.5 \mathrm{~h}$ & - $\quad$ Systen & span calibration. New cal factor: 1.0727 \\
\hline $12 / 09 / 05$ & $0.5 \mathrm{~h}$ & - $\quad$ Systen & span calibration. New cal factor: 1.1273 \\
\hline $12 / 16 / 05$ & $0.5 \mathrm{~h}$ & Systen & span calibration. New cal factor: 1.0000 \\
\hline
\end{tabular}

Once again, only major maintenance and operational events are listed here. The infrequent trips of the plant technician up the stack and to the CEM shelter to visually assess state of the system components have not been included in this report. In addition to the description and date of each major maintenance/operational event, Table 3.6.2.1 also includes an estimate of the duration of each maintenance event. Durations for logbook entries with missing time stamps were based on documented durations for similar tasks as well as the judgment of the authors aiming to be as conservative as possible in the time estimate.

For reference to the reader, typical maintenance duties included the changing of the catalyst (Figure 3.6.2.1) and the changing of the filters depicted in Figure 3.6.2.2). 

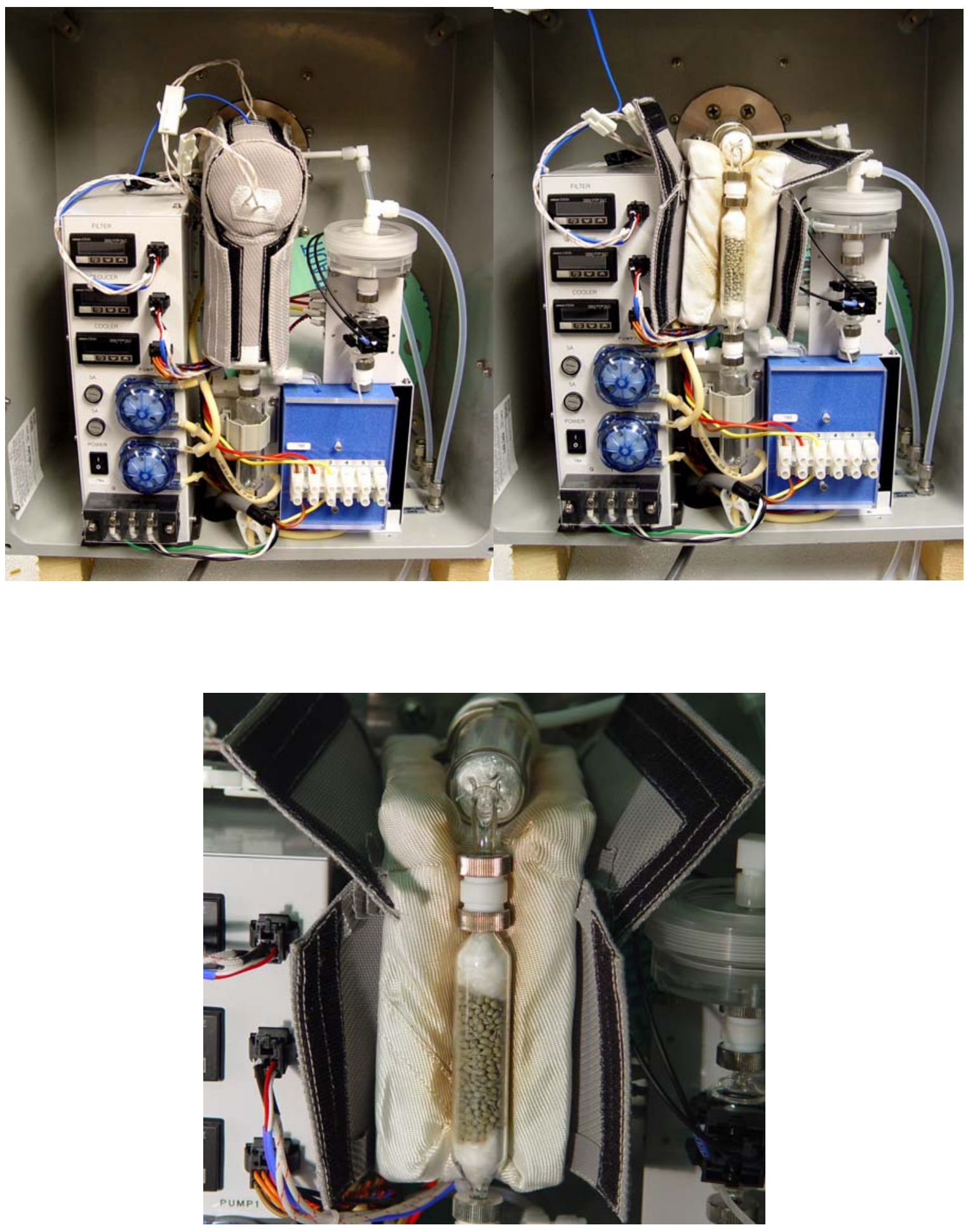

Figure 3.6.2.1 Photograph sequence of the changing of Horiba CEM catalysts 


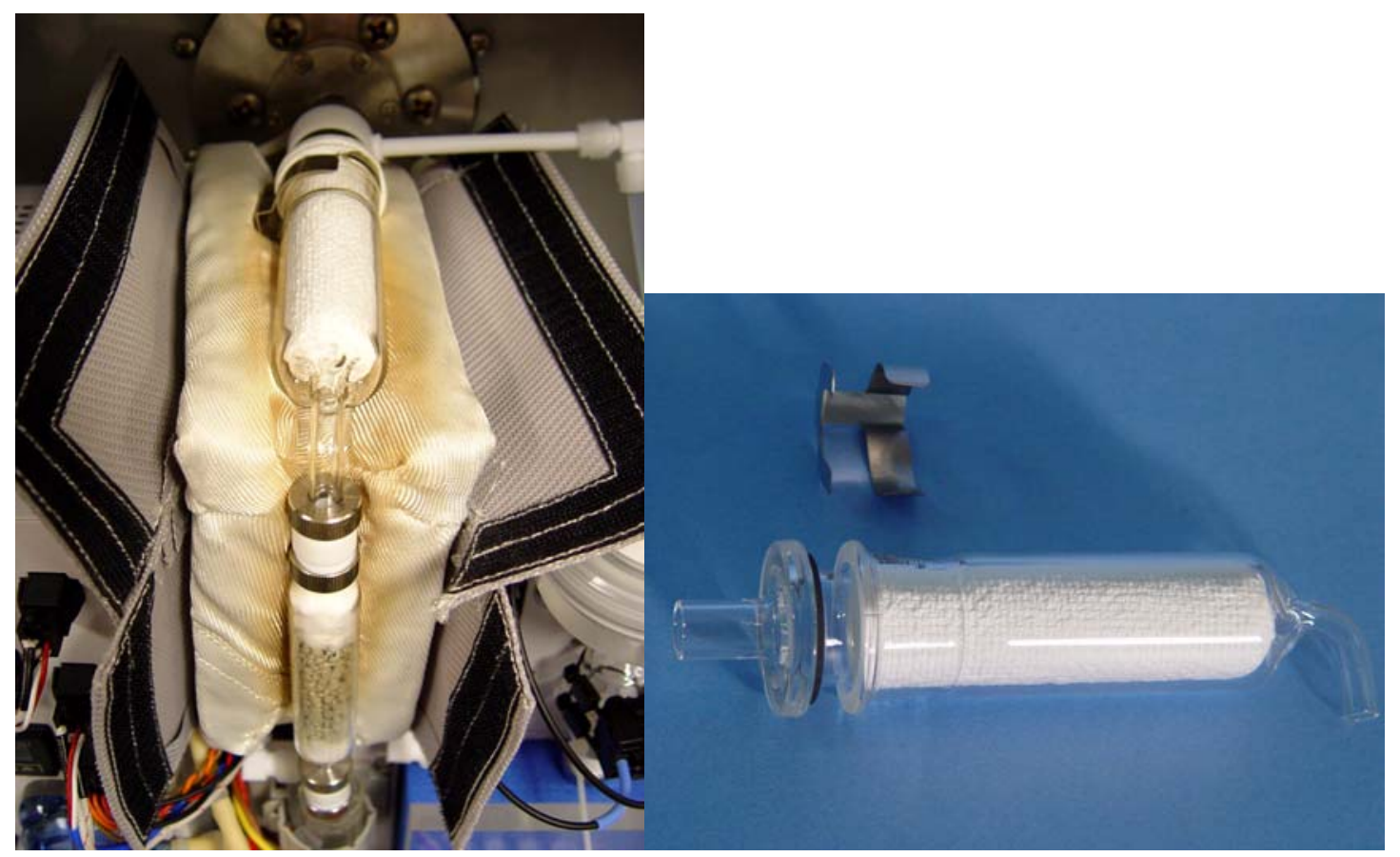

Figure 3.6.2.2 Photographs of changing of the filter

As can be seen earlier in Tables 3.6.2.1. the mercury Horiba CEM suffered from several shortcomings affecting the Horiba CEMS performance in various ways.

Buildup of fly ash / particulate matter in the probe and filter.

The stack platform geometry required the use of a rather long (10 feet) probe with large internal diameter of the probe stinger. It is conceivable that particulate buildup along the stinger wall as well as in the particulate filter adsorbed mercury contained in the flue gas causing a consistently low bias of the Horiba CEM readings.

\section{Catalyst deactivation.}

The catalyst in use to convert all oxidized forms of mercury to their elemental state underwent a rather rapid deactivation with an average life expectancy of approximately $2-3$ weeks per catalyst. The reasons for this rapid deactivation are unknown. As a result, the CEM mercury readings dropped slowly over the course of $2-3$ weeks subsequent to its installation. This can be seen in particular during the use of the first catalyst (07/08/05 - 08/17/05), which was kept installed over a longer period of time in order to assess the lifetime of a catalyst for the subsequent monitoring part of the program.

Cold spots / condensation in the probe.

As can be seen in the maintenance record, at several instances condensation was observed in several parts of the probe, in particular in the initially unheated / not-insulated calibration tee 
coupling. This became of particular concern during the colder months of the monitoring part of the project and may have resulted in the scrubbing of mercury from the sample gas stream. Eventually, the probe penetrating the annulus as well as the unheated calibration tee coupling was insulated to prevent further condensation.

\section{Freezing of condensate in probe.}

On several occasions during the colder months of the year the condensate originating from the Peltier cooler removing moisture from the sample gas froze in the cooler. This led to blockage of the sampling path and eventually to an automatic suspension of the sampling activity via the Horiba CEM controller.

\subsection{SUMMARY AND CONCLUSIONS}

Western Research Institute (WRI), in conjunction with Western Farmers Electric Cooperative (WFEC, has teamed with Clean Air Engineering of Pittsburgh, PA to conduct a mercury monitoring program at the WEFC Hugo plant in Oklahoma. This research effort had five objectives: (1) determine the mass balance of mercury for subbituminous coal-fired power plant; (2) assess the distribution of mercury species in the flue gas (3) perform a comparison of three different $\mathrm{Hg}$ test methods; (4) investigate the long-term (six months) mercury variability at a subbituminous coal-fired power plant; and (5) assess operation and maintenance of the Method 324 and Horiba CEMS utilizing plant personnel.

\subsection{Mercury Mass Balance}

In order to establish the $\mathrm{Hg}$ mass balance across the plant, the rate of $\mathrm{Hg}$ entering the plant was compared to the rate of $\mathrm{Hg}$ leaving the plant. Mercury testing and analysis was performed on process samples, (coal, coal pyrite rejects, fly ash, and bottom ash), as well as the flue gas at the facility's boiler exhaust stack and electrostatic precipitator (ESP) inlet (1 of 4 inlets) over a two day period of July 6 and 7, 2005. Flue gas sampling was performed using colocated, Ontario-Hydro or OH, (ASTM D6784-02) test trains at the facilities boiler exhaust stack as well as paired $\mathrm{OH}$ trains at one of the four inlets to the ESP. Hg concentrations and other flue gas characteristics were assumed the same for each ESP inlet. The three 2-hour Ontario-Hydro test runs indicated $93.8 \%$ total mercury closure across the ESP and $95.6 \%$ overall mass balance closure.

\subsection{Mercury Species Distribution.}

Mercury speciation testing of showed $89.5 \%$ elemental $\mathrm{Hg}, 8.0 \%$ oxidized $\mathrm{Hg}$ and $2.5 \%$ particulate bound $\mathrm{Hg}$ at the inlet of the ESP and $75.7 \%$ elemental $\mathrm{Hg}$, and $23.3 \%$ oxidized $\mathrm{Hg}$ at the stack. The Hg speciation results across the ESP can be seen in Figure 3.4.5. As expected, nearly all of the $\mathrm{Hg}^{\mathrm{PB}}$ is removed across the ESP. Since $\mathrm{Hg}^{\mathrm{PB}}$ constitutes only a minor fraction 
of the $\mathrm{Hg}^{\mathrm{T}}$ present in the flue gas, there is little removal of $\mathrm{Hg}^{\mathrm{T}}$ across the ESP. Also evident is the oxidation of some of the $\mathrm{Hg}^{0}$ to $\mathrm{Hg}^{2+}$.

\subsection{Inter-Methods Comparison}

Three different mercury test methods were concurrently performed and compared, including: Hg continuous emissions monitoring system (Horiba Hg-CEMS), former dry sorbenttube based USEPA Method 324, and Ontario Hydro (OH) test method (ASTM D6784-02). In order to compare the results of different methods of measuring $\mathrm{Hg}$ concentrations in the flue gas, nine consecutive co-located Ontario-Hydro runs and Method 324 runs (with co-located sorbent tubes) were performed simultaneously at the stack, while corresponding Horiba DM-6 mercury continuous emissions monitoring system using a vapor phase mercury monitor was used to monitor the $\mathrm{Hg}$ emissions in the flue gas at Hugo's exhaust stack. Testing was performed over the period of June 29-30 and July 6-7, 2005. In summary, the results include:

- All paired Ontario-Hydro sampling method test runs passed the minimum performance criteria for paired RM tests according to Performance Specification 12A (RD less than $10 \%$ for total gaseous $\mathrm{Hg}$ concentrations greater than $1.0 \mathrm{~g} / \mathrm{m}^{3}$ ). Particulate-bound $\mathrm{Hg}$ was negligible (non-detected).

- All Method 324 data pairs had a relative deviation (RD) of less than 5\%. A field spike was recovered to $90 \%(80-120 \%$ limit $)$.

- The relative accuracy (RA) of Method 324 with respect to Ontario-Hydro as reference method result was $10.4 \%\left(20.00 \%\right.$ limit) with an absolute difference of $0.46 \mu \mathrm{g} / \mathrm{m}^{3}$ (limit of $1 \mu \mathrm{g} / \mathrm{m}^{3}$ ). As such, the Method 324 data passed the RATA.

- During the first week of testing, (June 29 and 30), the Horiba DM-6 Hg CEMS used at the stack provided data comparable to those obtained using the Ontario-Hydro and sorbent-based sampling method (10-22\% lower with Run 2 not included).

- The relative accuracy of the Horiba DM-6-6 CEMS data showed a relative accuracy of $64.8 \%$ (limit of $20 \%$ ) relative to the $\mathrm{OH}$ as the reference method and an absolute difference of $2.98 \mu \mathrm{g} / \mathrm{m}^{3}$ (limit of $1 \mu \mathrm{g} / \mathrm{m}^{3}$ ). As such, the Horiba DM-6 data does not pass the RATA.

Additional method comparisons continued over the first two months of the program using both Method 324 sorbent tubes and the Horiba Hg-CEMS. The sorbent tubes continued with weekly switch out of sorbent tubes. The mercury content of the coal, fly ash and bottom ash was also monitored over this period. 


\subsection{Long-Term Hg Monitoring Method Operation and Maintenance Record}

Plant personnel were trained on site on the use, care and maintenance of the sorbent tube sampling equipment and Hg-CEMS. The Horiba DM-6 Hg-CEMS and Method 324 sorbent tubes were maintained by plant personnel over a six month period.

There were several Method 324 auto-sampler hardware and software, as well as sorbent trap recovery issues during the program. As a result, only one sorbent trap of each pair could be recovered successfully for the first five weeks. Nevertheless, after working through most of the issues that plagued the sorbent trap monitoring system for the first five weeks of the program, the operation and maintenance of the Method 324 sorbent traps when sampling sorbent traps on a weekly basis, required approximately 1-3 hours per week.

Maintenance of the Hg-CEMS included weekly calibration checks as well as daily inspections to ensure continued sampling. The six-month period covered emissions from June 24, 2005 until December 20, 2005. This included calibration checks and routine catalyst and filter replacements. The following Horiba DM-6 CEMS maintenance issues were observed.

- Buildup of fly ash / particulate matter in the probe and filter. The stack platform geometry required the use of a rather long (10 feet) probe with large internal diameter of the probe stinger. It is conceivable that particulate buildup along the stinger wall as well as in the particulate filter adsorbed mercury contained in the flue gas causing a consistently low bias of the Horiba CEM readings.

- Catalyst deactivation. The catalyst used to convert all oxidized forms of mercury to their elemental state underwent a rather rapid deactivation with an average life expectancy of approximately 2-3 weeks per catalyst. As a result, the CEM mercury readings dropped slowly over the course of 2-3 weeks subsequent to its installation.

- Cold spots / condensation in the probe. Condensation was observed in several parts of the probe, in particular in the initially unheated / not-insulated calibration tee coupling. This became of particular concern during the colder months of the monitoring part of the project and may have resulted in the scrubbing of mercury from the sample gas stream.

- Freezing of condensate in probe. On several occasions during the colder months of the year the condensate originating from the Peltier cooler removing moisture from the sample gas froze in the cooler. This led to blockage of the sampling path and eventually to an automatic suspension of the sampling activity via the Horiba CEM controller.

In summary, although mercury emissions monitoring techniques are progressing to be able to meet the regulatory needs of the promulgated CAMR rules, there is room for improvement of Hg CEMS both in performance and in maintenance and operation by plant personnel. 
APPENDIX A

Ontario Hydro Run Data 


\section{APPENDIX A CONTENTS}

\section{A-1 Ontario-Hydro Data}

\section{A-2 Ontario Hydro Mercury Species Balance}

A-3 Ontario Hydro Mass Balance Calculations

A-4 Method 324 Data

A-5 Method 324 RATA

A-6 Method 324 QA/QC Description

A-7 Horiba DM-6 CEMS RATA 


\section{A-1-1}

Unit 1 ESP Inlet (B-West duct) - Ontario-Hydro, Runs 2A-4A

\begin{tabular}{|c|c|c|c|c|c|}
\hline \multicolumn{2}{|c|}{ Run No. } & $2 A$ & $3 A$ & 4A & Average \\
\hline \multicolumn{2}{|c|}{ Date (2005) } & Jul 6 & Jul 7 & Jul 7 & \\
\hline \multicolumn{2}{|c|}{ Start Time (approx.) } & $13: 30$ & 09:32 & $12: 40$ & \\
\hline \multicolumn{2}{|c|}{ Stop Time (approx.) } & $16: 07$ & $11: 56$ & $15: 37$ & \\
\hline \multicolumn{6}{|c|}{ Process Conditions } \\
\hline $\mathrm{R}_{\mathrm{P}}$ & Coal Flow - (Ton/hour) & 286 & 286 & 286 & 286 \\
\hline $\mathrm{P}_{1}$ & Load Level - (MW) & 459 & 459 & 458 & 458 \\
\hline$F_{c}$ & Carbon dioxide-based F-factor (dscf/MMBtu) & 1,800 & 1,800 & 1,800 & 1,800 \\
\hline \multicolumn{6}{|c|}{ Gas Conditions } \\
\hline $\mathrm{O}_{2}$ & Oxygen (dry volume \%) & 7.6 & 7.8 & 7.4 & 7.6 \\
\hline $\mathrm{CO}_{2}$ & Carbon dioxide (dry volume \%) & 12.2 & 11.8 & 12.0 & 12.0 \\
\hline $\mathrm{T}_{\mathrm{s}}$ & Sample temperature $\left({ }^{\circ} \mathrm{F}\right)$ & 331 & 324 & 328 & 328 \\
\hline $\mathrm{B}_{\mathrm{w}}$ & Actual water vapor in gas ( $\%$ by volume) & 11.94 & 12.15 & 11.33 & 11.80 \\
\hline \multicolumn{6}{|c|}{ Gas Flow Rate } \\
\hline $\mathrm{Q}_{\mathrm{s}}$ & Volumetric flow rate, standard (scfm) & 374,271 & 371,863 & 371,753 & 372,629 \\
\hline$Q_{\text {std }}$ & Volumetric flow rate, dry standard (dscfm) & 329,586 & 326,693 & 329,647 & 328,642 \\
\hline \multicolumn{6}{|c|}{ Total Mercury Results } \\
\hline $\mathrm{C}_{\mathrm{sd}}$ & Concentration $(\mu \mathrm{g} / \mathrm{dscm})$ & 7.22 & 6.98 & 7.55 & 7.25 \\
\hline$E_{\mid b / y r}$ & Rate (lb/yr) & 78.11 & 74.86 & 81.67 & 78.22 \\
\hline $\mathrm{E}_{\mathrm{Fc}}$ & Rate - Fc-based (lb/TBtu) & 6.65 & 6.65 & 7.07 & 6.79 \\
\hline \multicolumn{6}{|c|}{ Particulate Bound Mercury Results } \\
\hline $\mathrm{C}_{\mathrm{sd}}$ & Concentration $(\mu \mathrm{g} / \mathrm{dscm})$ & 0.181 & 0.206 & 0.212 & 0.199 \\
\hline$E_{\mid b / y r}$ & Rate (lb/yr) & 1.95 & 2.21 & 2.29 & 2.15 \\
\hline $\mathrm{E}_{\mathrm{Fc}}$ & Rate - Fc-based (Ib/TBtu) & 0.166 & 0.196 & 0.198 & 0.187 \\
\hline \multicolumn{6}{|c|}{ Oxidized Mercury Results } \\
\hline $\mathrm{C}_{\mathrm{sd}}$ & Concentration $(\mu \mathrm{g} / \mathrm{dscm})$ & 0.579 & 0.574 & 0.535 & 0.563 \\
\hline$E_{\mid b / y r}$ & Rate (lb/yr) & 6.27 & 6.15 & 5.79 & 6.07 \\
\hline $\mathrm{E}_{\mathrm{Fc}}$ & Rate - Fc-based (Ib/TBtu) & 0.534 & 0.547 & 0.502 & 0.527 \\
\hline \multicolumn{6}{|c|}{ Elemental Mercury Results } \\
\hline $\mathrm{C}_{\mathrm{sd}}$ & Concentration $(\mu \mathrm{g} / \mathrm{dscm})$ & 6.46 & 6.20 & 6.80 & 6.49 \\
\hline$E_{\mid b / y r}$ & Rate (lb/yr) & 69.89 & 66.50 & 73.59 & 69.99 \\
\hline $\mathrm{E}_{\mathrm{Fc}}$ & Rate - Fc-based (lb/TBtu) & 5.95 & 5.91 & 6.37 & 6.08 \\
\hline \multicolumn{6}{|c|}{ Total Gaseous Results } \\
\hline $\mathrm{C}_{\mathrm{sd}}$ & Concentration $(\mu \mathrm{g} / \mathrm{dscm})$ & 7.04 & 6.78 & 7.34 & 7.05 \\
\hline$E_{\mid b / y r}$ & Rate (lb/yr) & 76.16 & 72.65 & 79.38 & 76.06 \\
\hline $\mathrm{E}_{\mathrm{Fc}}$ & Rate - Fc-based (lb/TBtu) & 6.49 & 6.45 & 6.87 & 6.60 \\
\hline
\end{tabular}




\section{A-1-2}

Unit 1 ESP Inlet (B-West duct) - Ontario-Hydro, Runs 2B-4B

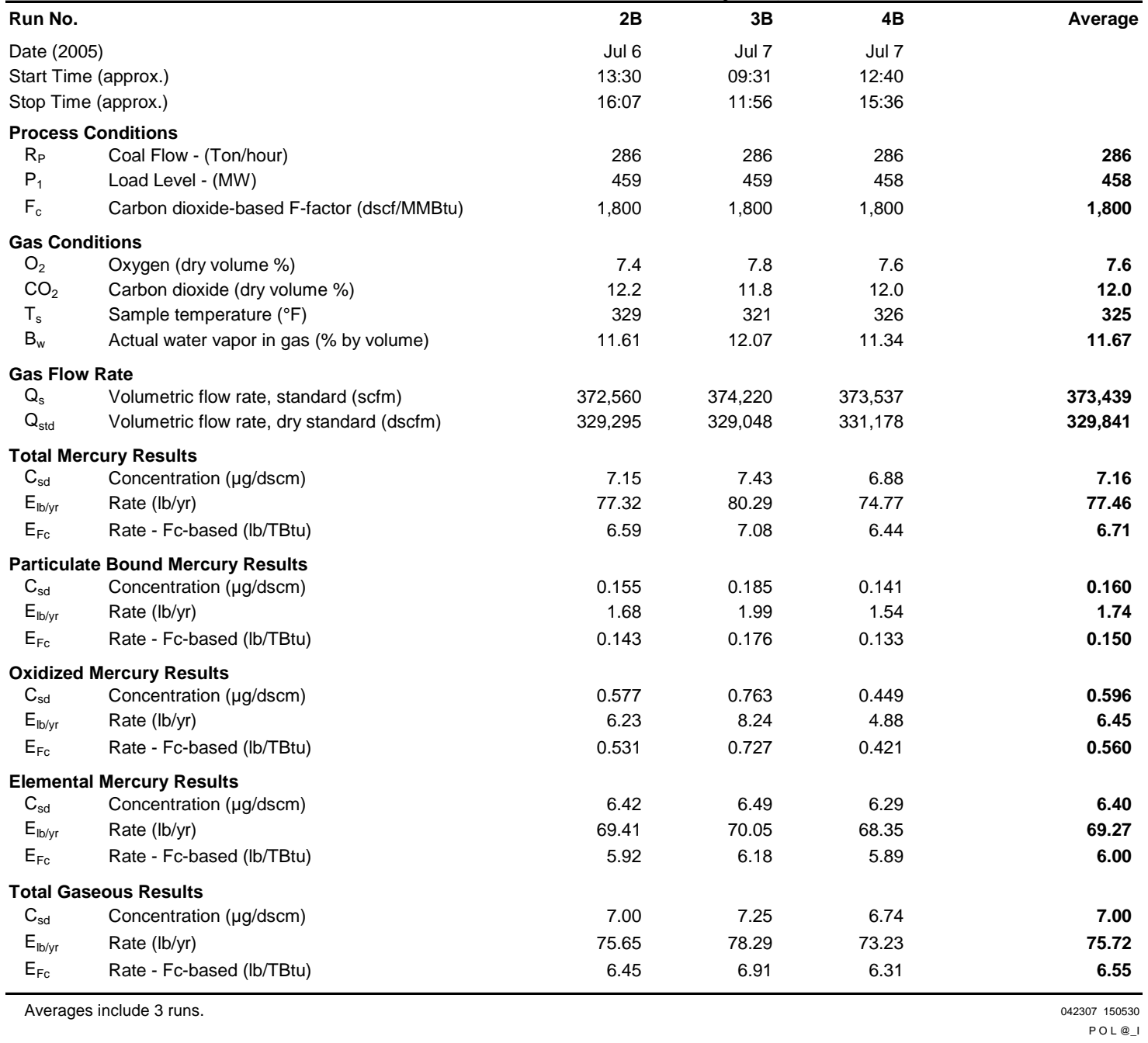




\section{A-1-3}

Unit 1 Stack - Ontario-Hydro, Runs 1A-3A

\begin{tabular}{|c|c|c|c|c|c|}
\hline \multicolumn{2}{|c|}{ Run No. } & $1 \mathrm{~A}$ & $2 A$ & 3A & Average \\
\hline \multicolumn{2}{|c|}{ Date (2005) } & Jun 29 & Jun 29 & Jun 29 & \\
\hline \multicolumn{2}{|c|}{ Start Time (approx.) } & 08:51 & 11:51 & $15: 26$ & \\
\hline \multicolumn{2}{|c|}{ Stop Time (approx.) } & $10: 51$ & $13: 51$ & $17: 26$ & \\
\hline \multicolumn{6}{|c|}{ Process Conditions } \\
\hline $\mathrm{R}_{\mathrm{P}}$ & Coal Flow - (Ton/hour) & 217 & 215 & 219 & 217 \\
\hline $\mathrm{P}_{1}$ & Load Level - (MW) & 355 & 355 & 359 & 356 \\
\hline $\mathrm{F}_{\mathrm{c}}$ & Carbon dioxide-based F-factor (dscf/MMBtu) & 1,800 & 1,800 & 1,800 & 1,800 \\
\hline \multicolumn{6}{|c|}{ Gas Conditions } \\
\hline $\mathrm{O}_{2}$ & Oxygen (dry volume \%) & 7.8000 & 7.6000 & 8.2000 & 7.8667 \\
\hline $\mathrm{CO}_{2}$ & Carbon dioxide (dry volume \%) & 11.8000 & 11.7000 & 11.2000 & 11.5667 \\
\hline $\mathrm{T}_{\mathrm{s}}$ & Sample temperature $\left({ }^{\circ} \mathrm{F}\right)$ & 292.8750 & 295.9167 & 299.3750 & 296.0556 \\
\hline $\mathrm{B}_{\mathrm{w}}$ & Actual water vapor in gas (\% by volume) & 11.3566 & 10.7201 & 10.8852 & 10.9873 \\
\hline \multicolumn{6}{|c|}{ Gas Flow Rate } \\
\hline $\mathrm{Q}_{\mathrm{s}}$ & Volumetric flow rate, standard (scfm) & $1,296,884$ & $1,296,468$ & $1,318,327$ & $1,303,893$ \\
\hline $\mathrm{Q}_{\text {std }}$ & Volumetric flow rate, dry standard (dscfm) & $1,149,602$ & $1,157,485$ & $1,174,825$ & $1,160,637$ \\
\hline $\mathrm{Q}_{\mathrm{std} 7}$ & Volumetric flow rate, dry std@ $7 \% \mathrm{O}_{2}$ (dscfm) & $1,083,438$ & $1,107,522$ & $1,073,401$ & $1,088,120$ \\
\hline \multicolumn{6}{|c|}{ Total Mercury Results } \\
\hline $\mathrm{C}_{\mathrm{sd}}$ & Concentration $(\mu \mathrm{g} / \mathrm{dscm})$ & 7.4990 & 11.5312 & 6.7407 & 8.5903 \\
\hline $\mathrm{E}_{\mathrm{T} / \mathrm{yr}}$ & Rate (lb/yr) & 282.9535 & 438.0830 & 259.9213 & 326.9859 \\
\hline $\mathrm{E}_{\mathrm{Rp}}$ & Rate - Production-based (Ib/Ton-coal) & $1.485 \mathrm{E}-04$ & $2.321 \mathrm{E}-04$ & $1.355 \mathrm{E}-04$ & $1.720 \mathrm{E}-04$ \\
\hline $\mathrm{E}_{\mathrm{Fc}}$ & Rate - Fc-based (Ib/TBtu) & 7.1434 & 11.0783 & 6.7650 & 8.3289 \\
\hline \multicolumn{6}{|c|}{ Particulate Bound Mercury Results } \\
\hline $\mathrm{C}_{\mathrm{sd}}$ & Concentration $(\mu \mathrm{g} / \mathrm{dscm})$ & $<4.645 \mathrm{E}-03$ & $<4.619 \mathrm{E}-03$ & $<4.600 \mathrm{E}-03$ & $<4.621 \mathrm{E}-03$ \\
\hline $\mathrm{E}_{\mathrm{T} / \mathrm{yr}}$ & Rate $(\mathrm{lb} / \mathrm{yr})$ & $<1.753 E-01$ & $<1.755 \mathrm{E}-01$ & $<1.774 \mathrm{E}-01$ & $<1.760 \mathrm{E}-01$ \\
\hline $\mathrm{E}_{\mathrm{Rp}}$ & Rate - Production-based (Ib/Ton-coal) & $<9.200 \mathrm{E}-08$ & $<9.299 \mathrm{E}-08$ & $<9.245 E-08$ & $<9.248 E-08$ \\
\hline $\mathrm{E}_{\mathrm{Fc}}$ & Rate - Fc-based (Ib/TBtu) & $<4.425 \mathrm{E}-03$ & $<4.438 \mathrm{E}-03$ & $<4.617 \mathrm{E}-03$ & $<4.493 E-03$ \\
\hline \multicolumn{6}{|c|}{ Oxidized Mercury Results } \\
\hline $\mathrm{C}_{\mathrm{sd}}$ & Concentration $(\mu \mathrm{g} / \mathrm{dscm})$ & 1.7326 & 4.9887 & 1.7710 & 2.8308 \\
\hline $\mathrm{E}_{\mathrm{T} / \mathrm{yr}}$ & Rate $(\mathrm{lb} / \mathrm{yr})$ & 65.3758 & 189.5259 & 68.2890 & 107.7303 \\
\hline $\mathrm{E}_{\mathrm{Rp}}$ & Rate - Production-based (Ib/Ton-coal) & $3.431 \mathrm{E}-05$ & $1.004 \mathrm{E}-04$ & 3.559E-05 & $5.678 \mathrm{E}-05$ \\
\hline $\mathrm{E}_{\mathrm{Fc}}$ & Rate - Fc-based (Ib/TBtu) & 1.6505 & 4.7927 & 1.7774 & 2.7402 \\
\hline \multicolumn{6}{|c|}{ Elemental Mercury Results } \\
\hline $\mathrm{C}_{\mathrm{sd}}$ & Concentration $(\mu \mathrm{g} / \mathrm{dscm})$ & 5.7663 & 6.5425 & 4.9697 & 5.7595 \\
\hline $\mathrm{E}_{\mathrm{T} / \mathrm{yr}}$ & Rate (lb/yr) & 217.5778 & 248.5571 & 191.6322 & 219.2557 \\
\hline $\mathrm{E}_{\mathrm{Rp}}$ & Rate - Production-based (Ib/Ton-coal) & $1.142 \mathrm{E}-04$ & $1.317 \mathrm{E}-04$ & $9.988 \mathrm{E}-05$ & 1.153E-04 \\
\hline $\mathrm{E}_{\mathrm{Fc}}$ & Rate - Fc-based (Ib/TBtu) & 5.4929 & 6.2855 & 4.9876 & 5.5887 \\
\hline
\end{tabular}




\section{A-1-4}

Unit 1 Stack - Ontario-Hydro, Runs 4A-7A

\begin{tabular}{|c|c|c|c|c|c|}
\hline \multicolumn{2}{|c|}{ Run No. } & 4A & $5 A$ & $7 \mathrm{~A}$ & Average \\
\hline \multicolumn{2}{|c|}{ Date (2005) } & Jun 30 & Jun 30 & Jul 6 & \\
\hline \multicolumn{2}{|c|}{ Start Time (approx.) } & 09:30 & $12: 40$ & $13: 30$ & \\
\hline \multicolumn{2}{|c|}{ Stop Time (approx.) } & $11: 30$ & $14: 40$ & $16: 03$ & \\
\hline \multicolumn{6}{|c|}{ Process Conditions } \\
\hline $\mathrm{R}_{\mathrm{P}}$ & Coal Flow - (Ton/hour) & N/A & N/A & 286 & 286 \\
\hline$P_{1}$ & Load Level - (MW) & N/A & $\mathrm{N} / \mathrm{A}$ & 459 & 459 \\
\hline $\mathrm{F}_{\mathrm{c}}$ & Carbon dioxide-based F-factor (dscf/MMBtu) & 1,800 & 1,800 & 1,800 & 1,800 \\
\hline \multicolumn{6}{|c|}{ Gas Conditions } \\
\hline $\mathrm{O}_{2}$ & Oxygen (dry volume \%) & 7.9333 & 8.0000 & 8.0000 & 7.9778 \\
\hline $\mathrm{CO}_{2}$ & Carbon dioxide (dry volume \%) & 11.2333 & 11.4000 & 11.6000 & 11.4111 \\
\hline $\mathrm{T}_{\mathrm{s}}$ & Sample temperature $\left({ }^{\circ} \mathrm{F}\right)$ & 294.8750 & 318.6250 & 331.7083 & 315.0694 \\
\hline $\mathrm{B}_{\mathrm{w}}$ & Actual water vapor in gas (\% by volume) & 11.0605 & 11.4806 & 11.6553 & 11.3988 \\
\hline \multicolumn{6}{|c|}{ Gas Flow Rate } \\
\hline $\mathrm{Q}_{\mathrm{s}}$ & Volumetric flow rate, standard (scfm) & $1,351,935$ & $1,505,688$ & $1,473,871$ & $1,443,832$ \\
\hline $\mathrm{Q}_{\text {std }}$ & Volumetric flow rate, dry standard (dscfm) & $1,202,404$ & $1,332,827$ & $1,302,088$ & $1,279,106$ \\
\hline $\mathrm{Q}_{\mathrm{std} 7}$ & Volumetric flow rate, dry std@ $7 \% \mathrm{O}_{2}$ (dscfm) & $1,121,667$ & $1,236,940$ & $1,208,412$ & $1,189,006$ \\
\hline \multicolumn{6}{|c|}{ Total Mercury Results } \\
\hline $\mathrm{C}_{\mathrm{sd}}$ & Concentration $(\mu \mathrm{g} / \mathrm{dscm})$ & 7.2038 & 6.5638 & 6.5017 & 6.7564 \\
\hline $\mathrm{E}_{\mathrm{T} / \mathrm{yr}}$ & Rate (lb/yr) & 284.3018 & 287.1413 & 277.8634 & 283.1021 \\
\hline $\mathrm{E}_{\mathrm{Rp}}$ & Rate - Production-based (Ib/Ton-coal) & N/A & N/A & 1.109E-04 & 1.109E-04 \\
\hline $\mathrm{E}_{\mathrm{Fc}}$ & Rate - Fc-based (Ib/TBtu) & 7.2084 & 6.4719 & 6.3001 & 6.6602 \\
\hline \multicolumn{6}{|c|}{ Particulate Bound Mercury Results } \\
\hline $\mathrm{C}_{\mathrm{sd}}$ & Concentration $(\mu \mathrm{g} / \mathrm{dscm})$ & $<4.440 \mathrm{E}-03$ & $<4.467 \mathrm{E}-03$ & $<4.666 \mathrm{E}-03$ & $<4.524 \mathrm{E}-03$ \\
\hline $\mathrm{E}_{\mathrm{T} / \mathrm{yr}}$ & Rate $(\mathrm{lb} / \mathrm{yr})$ & $<1.752 \mathrm{E}-01$ & $<1.954 \mathrm{E}-01$ & $<1.994 \mathrm{E}-01$ & $<1.900 \mathrm{E}-01$ \\
\hline $\mathrm{E}_{\mathrm{Rp}}$ & Rate - Production-based (Ib/Ton-coal) & N/A & N/A & $<7.956 \mathrm{E}-08$ & $<7.956 \mathrm{E}-08$ \\
\hline $\mathrm{E}_{\mathrm{Fc}}$ & Rate - Fc-based (Ib/TBtu) & $<4.443 \mathrm{E}-03$ & $<4.405 \mathrm{E}-03$ & $<4.521 \mathrm{E}-03$ & $<4.456 \mathrm{E}-03$ \\
\hline \multicolumn{6}{|c|}{ Oxidized Mercury Results } \\
\hline $\mathrm{C}_{\mathrm{sd}}$ & Concentration $(\mu \mathrm{g} / \mathrm{dscm})$ & 1.7939 & 1.7958 & 1.3765 & 1.6554 \\
\hline $\mathrm{E}_{\mathrm{T} / \mathrm{yr}}$ & Rate $(\mathrm{lb} / \mathrm{yr})$ & 70.7957 & 78.5572 & 58.8278 & 69.3936 \\
\hline $\mathrm{E}_{\mathrm{Rp}}$ & Rate - Production-based (Ib/Ton-coal) & N/A & N/A & 2.347E-05 & 2.347E-05 \\
\hline $\mathrm{E}_{\mathrm{Fc}}$ & Rate - Fc-based (Ib/TBtu) & 1.7950 & 1.7706 & 1.3338 & 1.6332 \\
\hline \multicolumn{6}{|c|}{ Elemental Mercury Results } \\
\hline $\mathrm{C}_{\mathrm{sd}}$ & Concentration $(\mu \mathrm{g} / \mathrm{dscm})$ & 5.4100 & 4.7681 & 5.1252 & 5.1011 \\
\hline $\mathrm{E}_{\mathrm{T} / \mathrm{yr}}$ & Rate $(\mathrm{lb} / \mathrm{yr})$ & 213.5060 & 208.5840 & 219.0356 & 213.7086 \\
\hline $\mathrm{E}_{\mathrm{Rp}}$ & Rate - Production-based (Ib/Ton-coal) & N/A & N/A & 8.739E-05 & 8.739E-05 \\
\hline $\mathrm{E}_{\mathrm{Fc}}$ & Rate - Fc-based (lb/TBtu) & 5.4134 & 4.7013 & 4.9663 & 5.0270 \\
\hline
\end{tabular}




\section{A-1-5}

Unit 1 Stack - Ontario-Hydro, Runs 8A-10A

\begin{tabular}{|c|c|c|c|c|c|}
\hline \multicolumn{2}{|c|}{ Run No. } & $8 \mathrm{~A}$ & $9 A$ & $10 \mathrm{~A}$ & Average \\
\hline \multicolumn{2}{|c|}{ Date (2005) } & Jul 7 & Jul 7 & Jul 7 & \\
\hline \multicolumn{2}{|c|}{ Start Time (approx.) } & 09:31 & $12: 40$ & $16: 52$ & \\
\hline \multicolumn{2}{|c|}{ Stop Time (approx.) } & $11: 52$ & $15: 34$ & 18:52 & \\
\hline \multicolumn{6}{|c|}{ Process Conditions } \\
\hline $\mathrm{R}_{\mathrm{P}}$ & Coal Flow - (Ton/hour) & 286 & 286 & 285 & 286 \\
\hline $\mathrm{P}_{1}$ & Load Level - (MW) & 458 & 458 & 456 & 458 \\
\hline $\mathrm{O}_{2}$ & Oxygen (dry volume \%) & 8.2000 & 8.4000 & 8.0000 & 8.2000 \\
\hline $\mathrm{CO}_{2}$ & Carbon dioxide (dry volume \%) & 11.2000 & 11.4000 & 11.2000 & 11.2667 \\
\hline$T_{s}$ & Sample temperature $\left({ }^{\circ} \mathrm{F}\right)$ & 323.6250 & 330.2083 & 334.2917 & 329.3750 \\
\hline $\mathrm{B}_{\mathrm{w}}$ & Actual water vapor in gas ( $\%$ by volume) & 12.0935 & 12.0237 & 11.5306 & 11.8826 \\
\hline \multicolumn{6}{|c|}{ Gas Flow Rate } \\
\hline $\mathrm{C}_{\mathrm{sd}}$ & Concentration $(\mu \mathrm{g} / \mathrm{dscm})$ & 7.1638 & 6.6338 & 7.0491 & 6.9489 \\
\hline$E_{T / y r}$ & Rate (lb/yr) & 301.2631 & 281.5918 & 316.5947 & 299.8165 \\
\hline$E_{R p}$ & Rate - Production-based (Ib/Ton-coal) & $1.201 \mathrm{E}-04$ & $1.125 \mathrm{E}-04$ & $1.269 \mathrm{E}-04$ & 1.198E-04 \\
\hline $\mathrm{E}_{\mathrm{Fc}}$ & Rate - Fc-based (Ib/TBtu) & 7.1897 & 6.5409 & 7.0746 & 6.9351 \\
\hline \multicolumn{6}{|c|}{ Particulate Bound Mercury Results } \\
\hline $\mathrm{C}_{\mathrm{sd}}$ & Concentration $(\mu \mathrm{g} / \mathrm{dscm})$ & $<4.778 \mathrm{E}-03$ & $<4.720 \mathrm{E}-03$ & $<4.460 \mathrm{E}-03$ & $<4.653 \mathrm{E}-03$ \\
\hline $\mathrm{E}_{\mathrm{T} / \mathrm{r}}$ & Rate (lb/yr) & $<2.009 \mathrm{E}-01$ & $<2.004 \mathrm{E}-01$ & $<2.003 E-01$ & $<2.005 \mathrm{E}-01$ \\
\hline$E_{R p}$ & Rate - Production-based (lb/Ton-coal) & $<8.008 \mathrm{E}-08$ & $<8.007 \mathrm{E}-08$ & $<8.027 \mathrm{E}-08$ & $<8.014 \mathrm{E}-08$ \\
\hline $\mathrm{E}_{\mathrm{Fc}}$ & Rate - Fc-based (lb/TBtu) & $<4.795 \mathrm{E}-03$ & $<4.654 \mathrm{E}-03$ & $<4.477 \mathrm{E}-03$ & $<4.642 \mathrm{E}-03$ \\
\hline \multicolumn{6}{|c|}{ Oxidized Mercury Results } \\
\hline $\mathrm{C}_{\mathrm{sd}}$ & Concentration $(\mu \mathrm{g} / \mathrm{dscm})$ & 1.9398 & 1.5010 & 1.4496 & 1.6302 \\
\hline $\mathrm{E}_{\mathrm{Fc}}$ & Rate - Fc-based (Ib/TBtu) & 5.2429 & 5.0609 & 5.6197 & 5.3078 \\
\hline
\end{tabular}




\section{A-1-6}

Unit 1 Stack - Ontario-Hydro, Runs 1B-3B

Run No.

Date (2005)

Start Time (approx.)

Stop Time (approx.)

\section{Process Conditions}

$\mathrm{R}_{\mathrm{P}} \quad$ Coal Flow - (Ton/hour)

$\mathrm{P}_{3} \quad$ Load Level - (MW)

$\mathrm{F}_{\mathrm{c}} \quad$ Carbon dioxide-based F-factor (dscf/MMBtu)

Gas Conditions

$\mathrm{O}_{2} \quad$ Oxygen (dry volume \%)

$\mathrm{CO}_{2} \quad$ Carbon dioxide (dry volume \%)

$\mathrm{T}_{\mathrm{s}} \quad$ Sample temperature $\left({ }^{\circ} \mathrm{F}\right)$

$B_{w} \quad$ Actual water vapor in gas (\% by volume)

Gas Flow Rate

$\mathrm{Q}_{\mathrm{s}} \quad$ Volumetric flow rate, standard (scfm)

$\mathrm{Q}_{\text {std }} \quad$ Volumetric flow rate, dry standard (dscfm)

$\mathrm{Q}_{\text {std7 }} \quad$ Volumetric flow rate, dry std@ $07 \% \mathrm{O}_{2}$ (dscfm)

Total Mercury Results

$\mathrm{C}_{\mathrm{sd}} \quad$ Concentration $(\mu \mathrm{g} / \mathrm{dscm})$

$\mathrm{E}_{\mathrm{T} / \mathrm{yr}} \quad$ Rate $(\mathrm{lb} / \mathrm{yr})$

$\mathrm{E}_{\mathrm{Rp}} \quad$ Rate - Production-based (Ib/Ton-coal)

$\mathrm{E}_{\mathrm{Fc}} \quad$ Rate - Fc-based (Ib/TBtu)

Particulate Bound Mercury Results

$\mathrm{C}_{\mathrm{sd}} \quad$ Concentration $(\mu \mathrm{g} / \mathrm{dscm})$

$\mathrm{E}_{\mathrm{T} / \mathrm{yr}} \quad$ Rate (lb/yr)

$E_{R p} \quad$ Rate - Production-based (Ib/Ton-coal)

$\mathrm{E}_{\mathrm{Fc}} \quad$ Rate - Fc-based (Ib/TBtu)

Oxidized Mercury Results

$\mathrm{C}_{\mathrm{sd}} \quad$ Concentration $(\mu \mathrm{g} / \mathrm{dscm})$

$\mathrm{E}_{\mathrm{T} / \mathrm{yr}} \quad$ Rate (lb/yr)

$E_{R p} \quad$ Rate - Production-based (Ib/Ton-coal)

$\mathrm{E}_{\mathrm{Fc}} \quad$ Rate - Fc-based (Ib/TBtu)

Elemental Mercury Results

$\mathrm{C}_{\mathrm{sd}} \quad$ Concentration $(\mu \mathrm{g} / \mathrm{dscm})$

$E_{T / y r} \quad$ Rate (lb/yr)

$\mathrm{E}_{\mathrm{Rp}} \quad$ Rate - Production-based (lb/Ton-coal)

$\mathrm{E}_{\mathrm{Fc}} \quad$ Rate - Fc-based (Ib/TBtu)

\begin{tabular}{|c|c|c|c|}
\hline 1B & $2 B$ & 3B & Average \\
\hline Jun 29 & Jun 29 & Jun 29 & \\
\hline 08:51 & 11:51 & $15: 26$ & \\
\hline $10: 51$ & $13: 51$ & $17: 26$ & \\
\hline 217 & 215 & 219 & 217 \\
\hline 355 & 355 & 359 & 356 \\
\hline 1,800 & 1,800 & 1,800 & 1,800 \\
\hline 7.6000 & 7.6667 & 8.0000 & 7.7556 \\
\hline 12.0000 & 11.6333 & 11.4000 & 11.6778 \\
\hline 293.0417 & 296.2500 & 300.0000 & 296.4306 \\
\hline 10.9849 & 10.7215 & 10.7846 & 10.8303 \\
\hline $1,295,242$ & $1,296,346$ & $1,317,017$ & $1,302,868$ \\
\hline $1,152,961$ & $1,157,358$ & $1,174,982$ & $1,161,767$ \\
\hline $1,103,193$ & $1,101,849$ & $1,090,451$ & $1,098,498$ \\
\hline 6.8606 & 10.8564 & 8.2047 & 8.6406 \\
\hline 259.6245 & 412.4023 & 316.4174 & 329.4814 \\
\hline 1.363E-04 & 2.185E-04 & $1.649 \mathrm{E}-04$ & 1.732E-04 \\
\hline 6.4264 & 10.4898 & 8.0899 & 8.3353 \\
\hline$<4.483 E-03$ & $<4.513 \mathrm{E}-03$ & $<4.627 \mathrm{E}-03$ & $<4.541 \mathrm{E}-03$ \\
\hline$<1.696$ E-01 & $<1.714 \mathrm{E}-01$ & $<1.784 \mathrm{E}-01$ & $<1.732 \mathrm{E}-01$ \\
\hline$<8.904 \mathrm{E}-08$ & $<9.085 E-08$ & $<9.299 \mathrm{E}-08$ & $<9.096 \mathrm{E}-08$ \\
\hline$<4.199$ E-03 & $<4.361 \mathrm{E}-03$ & $<4.562 \mathrm{E}-03$ & $<4.374 \mathrm{E}-03$ \\
\hline 1.6990 & 1.8099 & 3.2849 & 2.2646 \\
\hline 64.2961 & 68.7513 & 126.6822 & 86.5765 \\
\hline 3.375E-05 & 3.643E-05 & 6.603E-05 & 4.540E-05 \\
\hline 1.5915 & 1.7487 & 3.2389 & 2.1930 \\
\hline 5.1616 & 9.0466 & 4.9198 & 6.3760 \\
\hline 195.3285 & 343.6510 & 189.7351 & 242.9049 \\
\hline $1.025 \mathrm{E}-04$ & $1.821 \mathrm{E}-04$ & $9.889 \mathrm{E}-05$ & 1.278E-04 \\
\hline 4.8349 & 8.7410 & 4.8510 & 6.1423 \\
\hline
\end{tabular}




\section{A-1-7}

Unit 1 Stack - Ontario-Hydro, Runs 4B-7B

\begin{tabular}{|c|c|c|c|c|c|}
\hline \multicolumn{2}{|c|}{ Run No. } & 4B & 5B & 7B & Average \\
\hline \multicolumn{2}{|c|}{ Date (2005) } & Jun 30 & Jun 30 & Jul 6 & \\
\hline \multicolumn{2}{|c|}{ Start Time (approx.) } & 09:30 & $12: 40$ & $13: 30$ & \\
\hline \multicolumn{2}{|c|}{ Stop Time (approx.) } & $11: 30$ & $14: 40$ & $16: 03$ & \\
\hline \multicolumn{6}{|c|}{ Process Conditions } \\
\hline $\mathrm{R}_{\mathrm{P}}$ & Coal Flow - (Ton/hour) & N/A & $N / A$ & 286 & 286 \\
\hline $\mathrm{P}_{1}$ & Load Level - (MW) & $\mathrm{N} / \mathrm{A}$ & $\mathrm{N} / \mathrm{A}$ & 459 & 459 \\
\hline$F_{c}$ & Carbon dioxide-based F-factor (dscf/MMBtu) & 1,800 & 1,800 & 1,800 & 1,800 \\
\hline \multicolumn{6}{|c|}{ Gas Conditions } \\
\hline $\mathrm{O}_{2}$ & Oxygen (dry volume \%) & 8.0000 & 8.0000 & 8.0000 & 8.0000 \\
\hline $\mathrm{CO}_{2}$ & Carbon dioxide (dry volume \%) & 11.0667 & 11.4000 & 11.6000 & 11.3556 \\
\hline $\mathrm{T}_{\mathrm{s}}$ & Sample temperature $\left({ }^{\circ} \mathrm{F}\right)$ & 294.7917 & 319.1250 & 331.8333 & 315.2500 \\
\hline $\mathrm{B}_{\mathrm{w}}$ & Actual water vapor in gas (\% by volume) & 10.9586 & 11.4339 & 11.7754 & 11.3893 \\
\hline \multicolumn{6}{|c|}{ Gas Flow Rate } \\
\hline $\mathrm{Q}_{\mathrm{s}}$ & Volumetric flow rate, standard (scfm) & $1,352,222$ & $1,505,057$ & $1,474,512$ & $1,443,930$ \\
\hline $\mathrm{Q}_{\mathrm{std}}$ & Volumetric flow rate, dry standard (dscfm) & $1,204,037$ & $1,332,969$ & $1,300,882$ & $1,279,296$ \\
\hline $\mathrm{Q}_{\text {std7 }}$ & Volumetric flow rate, dry std@7\% $\mathrm{O}_{2}$ (dscfm) & $1,117,416$ & $1,237,072$ & $1,207,293$ & $1,187,260$ \\
\hline \multicolumn{6}{|c|}{ Total Mercury Results } \\
\hline $\mathrm{C}_{\mathrm{sd}}$ & Concentration $(\mu \mathrm{g} / \mathrm{dscm})$ & 6.8466 & 6.6756 & 6.5956 & 6.7059 \\
\hline $\mathrm{E}_{\mathrm{T} / \mathrm{r} \mathrm{r}}$ & Rate (Ton/yr) & 270.5707 & 292.0620 & 281.6162 & 281.4163 \\
\hline$E_{R p}$ & Rate - Production-based (lb/Ton-coal) & $\mathrm{N} / \mathrm{A}$ & N/A & 1.124E-04 & 1.124E-04 \\
\hline $\mathrm{E}_{\mathrm{Fc}}$ & Rate - Fc-based (Ib/TBtu) & 6.9541 & 6.5821 & 6.3911 & 6.6425 \\
\hline \multicolumn{6}{|c|}{ Particulate Bound Mercury Results } \\
\hline $\mathrm{C}_{\mathrm{sd}}$ & Concentration $(\mu \mathrm{g} / \mathrm{dscm})$ & $<4.413 \mathrm{E}-03$ & $<4.408 \mathrm{E}-03$ & 0.0027 & $<3.838 E-03$ \\
\hline $\mathrm{E}_{\mathrm{T} / \mathrm{rr}}$ & Rate (Ib/yr) & $<1.744 \mathrm{E}-01$ & $<1.929 \mathrm{E}-01$ & 0.1150 & $<1.608 \mathrm{E}-01$ \\
\hline$E_{R p}$ & Rate - Production-based (Ib/Ton-coal) & N/A & N/A & $4.589 \mathrm{E}-08$ & 4.589E-08 \\
\hline $\mathrm{E}_{\mathrm{Fc}}$ & Rate - Fc-based (lb/TBtu) & $<4.483 \mathrm{E}-03$ & $<4.346 \mathrm{E}-03$ & 0.0026 & $<2.073 E-03$ \\
\hline \multicolumn{6}{|c|}{ Oxidized Mercury Results } \\
\hline $\mathrm{C}_{\mathrm{sd}}$ & Concentration $(\mu \mathrm{g} / \mathrm{dscm})$ & 1.8315 & 1.8514 & 1.4727 & 1.7185 \\
\hline $\mathrm{E}_{\mathrm{T} / \mathrm{yr}}$ & Rate (lb/yr) & 72.3785 & 81.0006 & 62.8802 & 72.0864 \\
\hline $\mathrm{E}_{\mathrm{Rp}}$ & Rate - Production-based (lb/Ton-coal) & $N / A$ & $N / A$ & 2.509E-05 & 2.509E-05 \\
\hline $\mathrm{E}_{\mathrm{Fc}}$ & Rate - Fc-based (Ib/TBtu) & 1.8602 & 1.8255 & 1.4270 & 1.7043 \\
\hline \multicolumn{6}{|c|}{ Elemental Mercury Results } \\
\hline $\mathrm{C}_{\mathrm{sd}}$ & Concentration $(\mu \mathrm{g} / \mathrm{dscm})$ & 5.0151 & 4.8242 & 5.1202 & 4.9865 \\
\hline $\mathrm{E}_{\mathrm{T} / \mathrm{rr}}$ & Rate (lb/yr) & 198.1922 & 211.0614 & 218.6209 & 209.2915 \\
\hline $\mathrm{E}_{\mathrm{Rp}}$ & Rate - Production-based (lb/Ton-coal) & N/A & $\mathrm{N} / \mathrm{A}$ & 8.722E-05 & 8.722E-05 \\
\hline $\mathrm{E}_{\mathrm{Fc}}$ & Rate - Fc-based (Ib/TBtu) & 5.0939 & 4.7566 & 4.9615 & 4.9373 \\
\hline
\end{tabular}




\section{A-1-8}

Unit 1 Stack - Ontario-Hydro, Runs 8B-10B

\begin{tabular}{|c|c|c|c|c|c|}
\hline \multicolumn{2}{|c|}{ Run No. } & 8B & $9 \mathrm{~B}$ & 10B & Average \\
\hline \multicolumn{2}{|c|}{ Date (2005) } & Jul 7 & Jul 7 & Jul 7 & \\
\hline \multicolumn{2}{|c|}{ Start Time (approx.) } & 09:31 & $12: 40$ & $16: 52$ & \\
\hline \multicolumn{2}{|c|}{ Stop Time (approx.) } & $11: 52$ & $15: 34$ & $18: 52$ & \\
\hline \multicolumn{6}{|c|}{ Process Conditions } \\
\hline $\mathrm{R}_{\mathrm{P}}$ & Coal Flow - (Ton/hour) & 286 & 286 & 285 & 286 \\
\hline $\mathrm{P}_{1}$ & Load Level - (MW) & 458 & 458 & 456 & 458 \\
\hline $\mathrm{F}_{\mathrm{c}}$ & Carbon dioxide-based F-factor (dscf/MMBtu) & 1,800 & 1,800 & 1,800 & 1,800 \\
\hline \multicolumn{6}{|c|}{ Gas Conditions } \\
\hline $\mathrm{O}_{2}$ & Oxygen (dry volume \%) & 8.2000 & 8.4000 & 8.0000 & 8.2000 \\
\hline $\mathrm{CO}_{2}$ & Carbon dioxide (dry volume \%) & 11.0000 & 11.4000 & 11.2000 & 11.2000 \\
\hline $\mathrm{T}_{\mathrm{s}}$ & Sample temperature $\left({ }^{\circ} \mathrm{F}\right)$ & 323.6667 & 329.5417 & 334.5417 & 329.2500 \\
\hline $\mathrm{B}_{\mathrm{w}}$ & Actual water vapor in gas (\% by volume) & 12.1190 & 11.9846 & 11.2546 & 11.7861 \\
\hline \multicolumn{6}{|c|}{ Gas Flow Rate } \\
\hline $\mathrm{Q}_{\mathrm{s}}$ & Volumetric flow rate, standard (scfm) & $1,458,281$ & $1,470,528$ & $1,545,564$ & $1,491,458$ \\
\hline $\mathrm{Q}_{\text {std }}$ & Volumetric flow rate, dry standard (dscfm) & $1,281,552$ & $1,294,291$ & $1,371,617$ & $1,315,820$ \\
\hline $\mathrm{Q}_{\text {std7 }}$ & Volumetric flow rate, dry std@ $@ 7 \% \mathrm{O}_{2}$ (dscfm) & $1,170,914$ & $1,163,931$ & $1,272,940$ & $1,202,595$ \\
\hline \multicolumn{6}{|c|}{ Total Mercury Results } \\
\hline $\mathrm{C}_{\mathrm{sd}}$ & Concentration $(\mu \mathrm{g} / \mathrm{dscm})$ & 7.2207 & 6.5889 & 7.1503 & 6.9866 \\
\hline $\mathrm{E}_{\mathrm{T} / \mathrm{yr}}$ & Rate (Ton/yr) & 0.1519 & 0.1400 & 0.1610 & 0.1509 \\
\hline $\mathrm{E}_{\mathrm{Rp}}$ & Rate - Production-based (lb/Ton-coal) & $1.211 \mathrm{E}-04$ & 1.119E-04 & 1.290E-04 & 1.206E-04 \\
\hline $\mathrm{E}_{\mathrm{Fc}}$ & Rate - Fc-based (Ib/TBtu) & 7.3785 & 6.4967 & 7.1761 & 7.0171 \\
\hline \multicolumn{6}{|c|}{ Particulate Bound Mercury Results } \\
\hline $\mathrm{C}_{\mathrm{sd}}$ & Concentration ( $\mu \mathrm{g} / \mathrm{dscm})$ & $<4.809 \mathrm{E}-03$ & $<4.736 \mathrm{E}-03$ & $<4.496 \mathrm{E}-03$ & $<4.680 \mathrm{E}-03$ \\
\hline $\mathrm{E}_{\mathrm{T} / \mathrm{yr}}$ & Rate (Ton/yr) & $<1.011 \mathrm{E}-04$ & $<1.006 \mathrm{E}-04$ & $<1.012 \mathrm{E}-04$ & $<1.010 \mathrm{E}-04$ \\
\hline $\mathrm{E}_{\mathrm{Rp}}$ & Rate - Production-based (lb/Ton-coal) & $<8.063 E-08$ & $<8.039 \mathrm{E}-08$ & $<8.110 \mathrm{E}-08$ & $<8.071 \mathrm{E}-08$ \\
\hline $\mathrm{E}_{\mathrm{Fc}}$ & Rate - Fc-based (Ib/TBtu) & $<4.914 \mathrm{E}-03$ & $<4.669 \mathrm{E}-03$ & $<4.512 \mathrm{E}-03$ & $<4.699 \mathrm{E}-03$ \\
\hline \multicolumn{6}{|c|}{ Oxidized Mercury Results } \\
\hline $\mathrm{C}_{\mathrm{sd}}$ & Concentration $(\mu \mathrm{g} / \mathrm{dscm})$ & 2.0824 & 1.5106 & 1.8748 & 1.8226 \\
\hline $\mathrm{E}_{\mathrm{T} / \mathrm{yr}}$ & Rate (Ton/yr) & 0.0438 & 0.0321 & 0.0422 & 0.0394 \\
\hline $\mathrm{E}_{\mathrm{Rp}}$ & Rate - Production-based (lb/Ton-coal) & 3.491E-05 & 2.564E-05 & 3.382E-05 & 3.146E-05 \\
\hline $\mathrm{E}_{\mathrm{Fc}}$ & Rate - Fc-based (Ib/TBtu) & 2.1280 & 1.4895 & 1.8816 & 1.8330 \\
\hline \multicolumn{6}{|c|}{ Elemental Mercury Results } \\
\hline $\mathrm{C}_{\mathrm{sd}}$ & Concentration $(\mu \mathrm{g} / \mathrm{dscm})$ & 5.1382 & 5.0783 & 5.2755 & 5.1640 \\
\hline $\mathrm{E}_{\mathrm{T} / \mathrm{yr}}$ & Rate (Ton/yr) & 0.1081 & 0.1079 & 0.1187 & 0.1116 \\
\hline$E_{R p}$ & Rate - Production-based (Ib/Ton-coal) & 8.615E-05 & 8.621E-05 & 9.516E-05 & 8.917E-05 \\
\hline $\mathrm{E}_{\mathrm{Fc}}$ & Rate - Fc-based (Ib/TBtu) & 5.2505 & 5.0072 & 5.2945 & 5.1841 \\
\hline
\end{tabular}


A-2

Ontario Hydro Mercury Species Distribution

Ontario-Hydro $-\mathrm{Hg}^{\mathrm{PB}}$ Comparison \& Balance

\begin{tabular}{|c|c|c|c|c|c|c|c|c|c|}
\hline & \multirow[b]{3}{*}{ Test Time } & \multicolumn{6}{|c|}{ Mass Flow } & \multicolumn{2}{|c|}{ Process Conditions } \\
\hline & & \multicolumn{3}{|c|}{ ESP Inlet - B West } & \multicolumn{3}{|c|}{ Stack } & \multirow{2}{*}{$\begin{array}{c}\text { Coal } \\
\text { Flow } \\
\text { (Ton/hr) }\end{array}$} & \multirow{2}{*}{$\begin{array}{l}\text { Load } \\
\text { Level } \\
\text { (MW) }\end{array}$} \\
\hline & & $\begin{array}{c}\text { A } \\
(\mathrm{g} / \mathrm{hr})\end{array}$ & $\begin{array}{c}\text { B } \\
(g / h r)\end{array}$ & $\begin{array}{c}\text { Avg } \\
\text { (g/hr) }\end{array}$ & $\begin{array}{c}\text { A } \\
(\mathrm{g} / \mathrm{hr})\end{array}$ & $\begin{array}{c}\text { B } \\
(g / h r)\end{array}$ & $\begin{array}{c}\text { Avg } \\
\text { (g/hr) }\end{array}$ & & \\
\hline $\mathrm{Hg}^{\mathrm{PB}}$ & $\begin{array}{l}13: 30-16: 07 \\
09: 32-11: 56 \\
12: 40-15: 37\end{array}$ & $\begin{array}{l}0.101 \\
0.114 \\
0.119\end{array}$ & $\begin{array}{l}0.087 \\
0.103 \\
0.080\end{array}$ & $\begin{array}{l}0.094 \\
0.109 \\
0.099\end{array}$ & $\begin{array}{l}-0.010 \\
-0.010 \\
-0.010\end{array}$ & $\begin{array}{r}0.006 \\
-0.010 \\
-0.010\end{array}$ & $\begin{array}{l}-0.002 \\
-0.010 \\
-0.010\end{array}$ & $\begin{array}{l}286 \\
286 \\
286\end{array}$ & $\begin{array}{l}459 \\
459 \\
458 \\
\end{array}$ \\
\hline \begin{tabular}{|l} 
Total Avg \\
Total Stdev
\end{tabular} & & & & $\begin{array}{l}0.101 \\
0.015\end{array}$ & & & $\begin{array}{r}-0.008 \\
0.007\end{array}$ & 286 & 459 \\
\hline
\end{tabular}

\begin{tabular}{|l|lll}
\hline $\mathrm{Hg}^{\mathrm{PB}}$ Mass Flow ESP Inlet (4 Ducts): & $0.40 \quad \pm \quad 0.03 \mathrm{~g} / \mathrm{hr}$
\end{tabular}

\begin{tabular}{l|c}
$\mathrm{Hg}^{\mathrm{PB}}$ Mass Flow Stack: & $-0.01 \quad \pm 0.01 \mathrm{~g} / \mathrm{hr}$
\end{tabular}

Ontario-Hydro - $\mathrm{Hg}^{2+}$ Comparison \& Balance

\begin{tabular}{|c|c|c|c|c|c|c|c|c|c|}
\hline & \multirow[b]{3}{*}{ Test Time } & \multicolumn{6}{|c|}{ Mass Flow } & \multicolumn{2}{|c|}{ Process Conditions } \\
\hline & & \multicolumn{3}{|c|}{ ESP Inlet - B West } & \multicolumn{3}{|c|}{ Stack } & \multirow{2}{*}{$\begin{array}{c}\text { Coal } \\
\text { Flow } \\
\text { (Ton/hr) }\end{array}$} & \multirow{2}{*}{$\begin{array}{l}\text { Load } \\
\text { Level } \\
\text { (MW) }\end{array}$} \\
\hline & & $\begin{array}{c}A \\
(g / h r)\end{array}$ & $\begin{array}{c}\text { B } \\
(\mathrm{g} / \mathrm{hr})\end{array}$ & $\begin{array}{c}\text { Avg } \\
\text { (g/hr) }\end{array}$ & $\begin{array}{c}A \\
(g / h r)\end{array}$ & $\begin{array}{c}B \\
(g / h r)\end{array}$ & $\begin{array}{c}\text { Avg } \\
\text { (g/hr) }\end{array}$ & & \\
\hline \multirow[t]{3}{*}{$\mathrm{Hg}^{2+}$} & $13: 30-16: 07$ & 0.324 & 0.323 & 0.324 & 3.046 & 3.255 & 3.150 & 286 & 459 \\
\hline & 09:32-11:56 & 0.319 & 0.427 & 0.373 & 4.223 & 4.535 & 4.379 & 286 & 459 \\
\hline & $12: 40-15: 37$ & 0.300 & 0.253 & 0.276 & 3.299 & 3.322 & 3.311 & 286 & 458 \\
\hline Total Avg & & & & 0.324 & & & 3.613 & 286 & 459 \\
\hline Total Stdev & & & & 0.057 & & & 0.609 & & \\
\hline
\end{tabular}

\begin{tabular}{|l|ccc}
\hline $\mathrm{Hg}^{2+}$ Mass Flow ESP Inlet (4 Ducts): & 1.30 & \pm & $0.10 \mathrm{~g} / \mathrm{hr}$
\end{tabular}

\begin{tabular}{l|c}
$\mathrm{Hg}^{2+}$ Mass Flow Stack: & $3.61 \pm 0.61 \mathrm{~g} / \mathrm{hr}$ \\
\hline
\end{tabular}

Ontario-Hydro - $\mathrm{Hg}^{0}$ Comparison \& Balance

\begin{tabular}{|c|c|c|c|c|c|c|c|c|c|}
\hline & \multirow[b]{3}{*}{ Test Time } & \multicolumn{6}{|c|}{ Mass Flow } & \multicolumn{2}{|c|}{ Process Conditions } \\
\hline & & \multicolumn{3}{|c|}{ ESP Inlet - B West } & \multicolumn{3}{|c|}{ Stack } & \multirow{2}{*}{$\begin{array}{c}\text { Coal } \\
\text { Flow } \\
\text { (Ton/hr) }\end{array}$} & \multirow{2}{*}{$\begin{array}{l}\text { Load } \\
\text { Level } \\
\text { (MW) }\end{array}$} \\
\hline & & $\begin{array}{c}A \\
(\mathrm{~g} / \mathrm{hr})\end{array}$ & $\begin{array}{c}\text { B } \\
(\mathrm{g} / \mathrm{hr})\end{array}$ & $\begin{array}{c}\text { Avg } \\
\text { (g/hr) }\end{array}$ & $\underset{(\mathrm{g} / \mathrm{hr})}{\mathrm{A}}$ & $\begin{array}{c}\text { B } \\
(g / h r)\end{array}$ & $\begin{array}{c}\text { Avg } \\
\text { (g/hr) }\end{array}$ & & \\
\hline \multirow[t]{3}{*}{$\mathrm{Hg}^{0}$} & 13:30-16:07 & 3.618 & 3.594 & 3.606 & 11.340 & 11.318 & 11.329 & 286 & 459 \\
\hline & 09:32-11:56 & 3.443 & 3.627 & 3.535 & 11.373 & 11.189 & 11.281 & 286 & 459 \\
\hline & $12: 40-15: 37$ & 3.810 & 3.539 & 3.674 & 11.280 & 11.169 & 11.224 & 286 & 458 \\
\hline Total Avg & & & & 3.605 & & & 11.278 & 286 & 459 \\
\hline Total Stdev & & & & 0.121 & & & 0.083 & & \\
\hline
\end{tabular}

\begin{tabular}{|l|lll|}
\hline $\mathrm{Hg}^{0}$ Mass Flow ESP Inlet (4 Ducts): & 14.42 & \pm & $0.21 \mathrm{~g} / \mathrm{hr}$ \\
$\mathrm{Hg}^{0}$ Mass Flow Stack: & 11.28 & \pm & $0.08 \mathrm{~g} / \mathrm{hr}$ \\
\hline
\end{tabular}


A-3

Ontario Hydro Mass Balance Calculations

Ontario-Hydro - HgT Comparison \& Balance

\begin{tabular}{|c|c|c|c|c|c|c|c|c|c|}
\hline & \multirow[b]{3}{*}{ Test Time } & \multicolumn{6}{|c|}{$\begin{array}{c}\text { Mass Flow } \\
\end{array}$} & \multicolumn{2}{|c|}{ Process Conditions } \\
\hline & & \multicolumn{3}{|c|}{ ESP Inlet - B West } & \multicolumn{3}{|c|}{ Stack } & \multirow{2}{*}{$\begin{array}{c}\text { Coal } \\
\text { Flow } \\
\text { (Ton/hr) }\end{array}$} & \multirow{2}{*}{$\begin{array}{l}\text { Load } \\
\text { Level } \\
\text { (MW) }\end{array}$} \\
\hline & & $\begin{array}{c}A \\
(\mathrm{~g} / \mathrm{hr})\end{array}$ & $\begin{array}{c}\text { B } \\
(g / h r)\end{array}$ & $\begin{array}{c}\text { Avg } \\
\text { (g/hr) }\end{array}$ & $\begin{array}{c}\text { A } \\
(\mathrm{g} / \mathrm{hr})\end{array}$ & $\begin{array}{c}B \\
(g / h r)\end{array}$ & $\begin{array}{c}\text { Avg } \\
\text { (g/hr) }\end{array}$ & & \\
\hline \multirow[t]{3}{*}{ Total } & 13:30-16:07 & 4.044 & 4.003 & 4.024 & 14.385 & 14.580 & 14.482 & 286 & 459 \\
\hline & 09:32-11:56 & 3.876 & 4.156 & 4.016 & 15.597 & 15.724 & 15.660 & 286 & 459 \\
\hline & $12: 40-15: 37$ & 4.228 & 3.871 & 4.050 & 14.578 & 14.491 & 14.535 & 286 & 458 \\
\hline Total Avg & & & & 4.030 & & & 14.893 & 286 & 459 \\
\hline Total Stdev & & & & 0.145 & & & 0.600 & & \\
\hline
\end{tabular}

\begin{tabular}{|l|rrr|}
\hline Total Mass Flow from Coal: & 15.79 & & $\mathrm{~g} / \mathrm{hr}$ \\
Total Mass Flow ESP Inlet (4 Ducts): & 16.12 & \pm & $0.25 \mathrm{~g} / \mathrm{hr}$ \\
Total Mass Flow Stack: & 14.89 & \pm & $0.60 \mathrm{~g} / \mathrm{hr}$ \\
Total Mass Flow Fly Ash (ESP): & 0.19 & & $\mathrm{~g} / \mathrm{hr}$ \\
\hline Removal Efficiency across ESP: & 7.6 & \pm & $4.0 \%$ \\
\hline
\end{tabular}

Overall plant $\mathrm{Hg}$ material balance

\begin{tabular}{|llc|}
\hline Inlet $\mathrm{Hg}$ & $\mathrm{Hg}$ from coal & $15.79 \mathrm{~g} / \mathrm{hr}$ \\
Outlet $\mathrm{Hg}$ & $\mathrm{Hg}$ exiting the stack & $14.89 \mathrm{~g} / \mathrm{hr}$ \\
& $\mathrm{Hg}$ in ESP hopper ash & $0.19 \mathrm{~g} / \mathrm{hr}$ \\
Outlet/lnlet Balance & $\mathbf{9 5 . 6 \%}$ \\
\hline
\end{tabular}

Hg mass flow rates across air pollution control devices

\begin{tabular}{|lc|}
\hline $\mathrm{Hg}$ at the ESP Inlet & $16.12 \mathrm{~g} / \mathrm{hr}$ \\
$\mathrm{Hg}$ at the outlet of the ESP & $14.89 \mathrm{~g} / \mathrm{hr}$ \\
$\mathrm{Hg}$ in ESP hopper ash & $0.19 \mathrm{~g} / \mathrm{hr}$ \\
Outlet/Inlet Balance & $\mathbf{9 3 . 6 \%}$ \\
\hline
\end{tabular}




\section{Method 324 Data}

Method 324

Total Gaseous Mercury ( $\left.\mathrm{Hg}^{\text {Total }}\right)$ Results

Sorbent ID
Date (2005)
Start Time (approx.)
Stop Time (approx.)
Sampling Data
$V_{\text {mstd }}$ Volume metered, standard (dsccm)
Laboratory Data
$m_{n} \quad$ Total Mercury (ng/trap)
Total Results
$C_{\text {ad }}$ Concentration $(\mu g / d s c m)$
$C_{\text {avg }}$ Avg Concentration $(\mu g / d s c m)$
RD Relative Deviation $(\mu g / d s c m)$
RD $\left.A B S\left[C_{A}-C_{B}\right] / C_{A}+C_{\Xi}\right]$
RPD Relative Percent Difference $(\mu g / d s c m)$
$\quad R P D=A B S\left[C_{A}-C_{g}\right] / A V G\left[C_{A}+C_{B}\right]$

\begin{tabular}{|c|c|c|c|c|c|c|c|c|c|c|c|}
\hline & & & & & \multicolumn{7}{|c|}{ Field Spike } \\
\hline 1737 & 1738 & 1739 & 1740 & 1741 & 1742 & 1743 & 1744 & 1736 & 1745 & 1746 & 1747 \\
\hline June 29 & June 29 & June 29 & June 29 & June 29 & June 29 & June 30 & June 30 & June 30 & June 30 & June 30 & June 30 \\
\hline $09: 52: 51$ & $09: 52: 29$ & $12: 52: 56$ & $12: 52: 33$ & $16: 30: 41$ & $16: 30: 19$ & $09: 33: 58$ & 09:33:37 & $12: 25: 19$ & $12: 27: 20$ & $16: 06: 20$ & $16: 05: 59$ \\
\hline $11: 52.47$ & $11: 52: 24$ & $14: 52: 47$ & $14: 52: 47$ & $18: 31: 03$ & $18: 30: 39$ & $11: 31: 52$ & 11:31:31 & $14: 41: 38$ & $14: 41: 14$ & $17: 02: 40$ & $17: 02: 19$ \\
\hline 42105.0260 & 42192.7933 & 39761.0680 & 44971.1078 & 47714.7669 & 39040.5400 & 42324.5715 & 39931.3557 & 45774.8123 & 50975.5663 & 19252.3428 & 19670.7523 \\
\hline 294.7320 & 295.2040 & 262.0770 & 311.2320 & 304.8180 & 275.5800 & 273.6400 & 284.4280 & 1186,2150 & 320.9490 & 148.7390 & 148.8470 \\
\hline 6.9999 & 6.9966 & 6.5913 & 6.9207 & 6.3883 & 7.0588 & 6.4653 & 7.1229 & 25.9141 & 6.2961 & 7.7258 & 7.5669 \\
\hline 6.9982 & & 6.7560 & & 6.7236 & & 6.7941 & & Percent Reco & very & 7.6463 & \\
\hline 0.02 & & 2.44 & & 4.99 & & 4.84 & & $\begin{array}{r}89.80 \\
\text { (volume adjus }\end{array}$ & & 1.04 & \\
\hline 0.05 & & 4.88 & & 9.97 & & 9.68 & & & & 2.08 & \\
\hline
\end{tabular}

Ontario Hydro Results

$C_{9 d}$ Concentration $(\mu \mathrm{g} / \mathrm{dscm})$

$\mathrm{C}_{\text {avg }}$ Avg Concentration $(\mathrm{\mu g} / \mathrm{dscm})$

Relative Deviation $(\mu \mathrm{g} / \mathrm{dscm})$ $R D=A B S\left[C_{A}-C_{B}\right]\left\{C_{A}+C_{B}\right]$

RPD Relative Percent Difference ( $\mu \mathrm{g} / \mathrm{dscm})$

\begin{tabular}{|c|c|c|c|c|c|c|c|c|}
\hline $\begin{array}{r}\mathrm{A1} \\
7.4990 \mathrm{E}+00\end{array}$ & $\begin{array}{r}\mathrm{B1} \\
6.8606 \mathrm{E}+00\end{array}$ & $\begin{array}{r}A 2 \\
\begin{array}{r}A 2 \\
1.1531 E+01\end{array}\end{array}$ & $\begin{array}{r}\mathrm{B} 2 \\
1.0856 \mathrm{E}+01\end{array}$ & $\begin{array}{r}A 3 \\
6.7407 E+00\end{array}$ & $\begin{array}{r}\mathrm{B} 3 \\
8.2047 \mathrm{E}+00\end{array}$ & $\begin{array}{r}\mathrm{A4} \\
7.2038 \mathrm{E}+00\end{array}$ & $\begin{array}{r}\mathrm{B4} \\
6.8466 \mathrm{E}+00\end{array}$ & \begin{tabular}{r|r|} 
A5 & B5 \\
$6.5638 \mathrm{E}+00$ & $6.6756 \mathrm{E}+00$
\end{tabular} \\
\hline 7.1798 & & 11.1938 & & 7.4727 & & 7.0252 & & 6.6197 \\
\hline 4.45 & & 3.01 & & 9.80 & & 2.54 & & 0.84 \\
\hline 8.89 & & 6.03 & & 19.59 & & 5.08 & & 1.69 \\
\hline
\end{tabular}

$R P D=A B S\left[C_{A}-C_{B} / A V G\left[C_{A}+C_{B}\right]\right.$ 
A-5

Unit 1 Stack - Ontario-Hydro vs. Metho0d 324 Sorbent Traps

\begin{tabular}{|c|c|c|c|c|c|c|}
\hline Run No. & Start Time & Date 2005 & $\begin{array}{r}\text { Ontario-Hydro } \\
\left(\mathrm{ug} / \mathrm{Nm}^{3}\right)\end{array}$ & $\begin{array}{r}M 324 \\
\left(\mathrm{ug} / \mathrm{Nm}^{3}\right)\end{array}$ & $\begin{array}{r}\text { Difference } \\
\left(\mathrm{ug} / \mathrm{m}^{3}\right)\end{array}$ & $\begin{array}{r}\text { Percent } \\
\text { Difference }\end{array}$ \\
\hline 1 & $9: 52$ & Jun 29 & 7.18 & 7.00 & 0.18 & $2.53 \%$ \\
\hline 2 & $12: 52$ & Jun 29 & 11.19 & 6.76 & 4.44 & $39.65 \%$ \\
\hline 3 & $16: 30$ & Jun 29 & 7.47 & 6.72 & 0.75 & $10.02 \%$ \\
\hline 4 & 9:33 & Jun 30 & 7.03 & 6.79 & 0.23 & $3.29 \%$ \\
\hline 5 & $12: 25$ & Jun 30 & 6.62 & 6.30 & 0.32 & $4.89 \%$ \\
\hline 7 & $13: 31$ & Jul 6 & 6.55 & 6.20 & 0.35 & $5.36 \%$ \\
\hline 8 & $9: 31$ & Jul 7 & 7.19 & 6.30 & 0.89 & $12.38 \%$ \\
\hline 9 & $12: 41$ & Jul 7 & 6.61 & 6.78 & -0.17 & $-2.52 \%$ \\
\hline 10 & $16: 53$ & Jul 7 & 7.10 & 6.31 & 0.79 & $11.19 \%$ \\
\hline Average & & & 6.97 & 6.55 & 0.42 & $6.02 \%$ \\
\hline
\end{tabular}

\begin{tabular}{|c|c|c|}
\hline & RATA & \\
\hline Standard Deviation & 0.3626 & \\
\hline Confidence Coefficient & 0.3032 & \\
\hline Relative Accuracy (as \% of RM) & $10.37 \%$ & $\begin{array}{r}\text { LImItS } \\
\mathbf{2 0 . 0 0 \%} \\
\end{array}$ \\
\hline Average Absolute Difference $\left(\mathrm{ug} / \mathrm{m}^{3}\right)$ & 0.4609 & 1 \\
\hline
\end{tabular}

* Indicates that the run was not included in the RATA calculations.

8 Runs are being considered in the RATA calculations

1 Runs are being excluded from the RATA calculations

RM = Reference Method (Ontario-Hydro)

M324 = Sorbent-Based Monitoring System

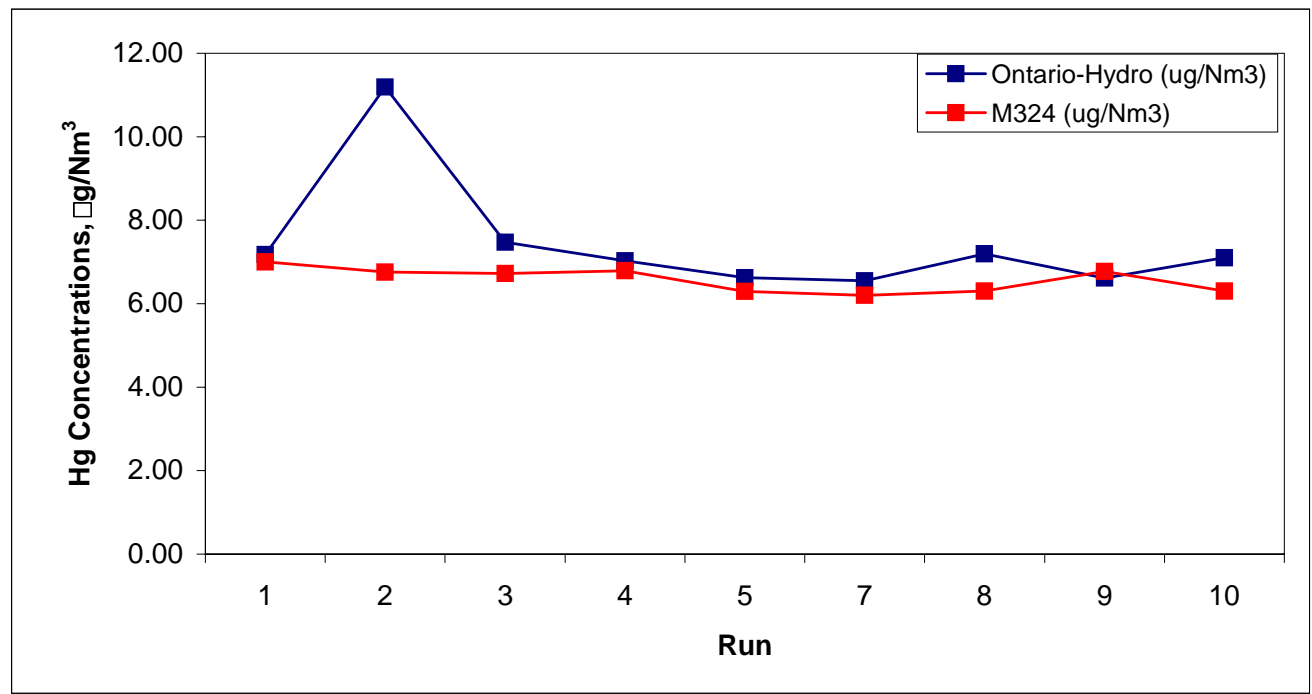




\section{A-6}

\section{Method 324 Quality Assurance and Quality Control Description}

There are several QA/QC criteria specified in Table 324-2 of 67 FR 4467 that are applicable to the work performed in this program. The following QA/QC criteria were monitored during the course of the program:

1. Pre and Post Sampling Leak-check: Leak rate less than $2 \%$ of prevalent sampling rate.

2. Breakthrough: Sorbent trap backup section mercury loading less than $2 \%$ or, alternatively, 5ng/trap of the main section mercury loading.

3. Paired Trap Agreement: Relative deviation (RD) between results of paired traps less than or equal to $10 \%$.

4. Field Spike Recovery: Spiked sorbent trap section mercury mass equal to $80-120 \%$ of original elemental mercury spike amount.

A field spike run was conducted from 08/10/05 - 08/17/05. During this sampling run a sorbent trap spiked with a known amount of gaseous elemental mercury $\left(M_{r e f}\right)$ onto the main section of the trap was sampled side-by-side with a regular two-section trap. Relating the mass of total gaseous mercury captured in both sections of the regular sorbent trap $\left(M_{1}\right)$ to the mass of total gaseous mercury captured in both sections of the spiked sorbent trap $\left(M_{2}\right)$ according to the following equation yields the percent spike recovery $(\% R)$.

$\% R=\frac{M_{2}-M_{1}}{M_{r e f}} \times 100$

According to this equation, the field spike was recovered to $90 \%$, passing the field spike QA/QC criteria of $80 \%$ to $120 \%$ recovery. Note that the mercury mass loadings are corrected for a slight difference in flue gas volumes sampled through each trap.

Table A6-1 summarizes how well these criteria were met during the test program. As is evident, all validated sorbent trap results met the breakthrough criteria. The same holds true for the paired sorbent trap agreement for the sampling runs that yielded two valid sorbent trap results. 
Table A6-1. QA/QC Summary - Sorbent Trap Breakthrough Performance

\begin{tabular}{|c|c|c|c|c|c|c|}
\hline \multirow{2}{*}{$\begin{array}{l}\text { Start Date/ } \\
\text { Start Time }\end{array}$} & \multirow{2}{*}{$\begin{array}{l}\text { Stop Date/ } \\
\text { Stop Time }\end{array}$} & \multicolumn{4}{|c|}{ Backup Section Analysis (Breakthrough) } & \multirow{2}{*}{$\begin{array}{c}\text { Paired Trap } \\
\text { Agreement } \\
\text { \%RD } \\
\end{array}$} \\
\hline & & $\begin{array}{c}\text { Trap A } \\
\text { ng }\end{array}$ & $\begin{array}{c}\text { Trap B } \\
\text { ng }\end{array}$ & $\begin{array}{c}\text { Trap A } \\
\%^{7}\end{array}$ & $\begin{array}{c}\text { Trap B } \\
\%^{7}\end{array}$ & \\
\hline 07/08/05 16:22 & 07/14/05 08:55 & $\mathrm{N} / \mathrm{A}^{1}$ & 1.94 & $\mathrm{~N} / \mathrm{A}^{1}$ & $0.02 \%$ & $\mathrm{~N} / \mathrm{A}^{1}$ \\
\hline 07/14/05 13:30 & 07/21/05 06:52 & $\mathrm{N} / \mathrm{A}^{2}$ & 5.49 & $\mathrm{~N} / \mathrm{A}^{2}$ & $0.02 \%$ & $\mathrm{~N} / \mathrm{A}^{2}$ \\
\hline 07/21/05 10:09 & 07/28/05 10:30 & 3.89 & $N / A^{3}$ & $0.01 \%$ & $\mathrm{~N} / \mathrm{A}^{3}$ & $\mathrm{~N} / \mathrm{A}^{3}$ \\
\hline 08/04/05 08:05 & 08/10/05 07:28 & $\mathrm{N} / \mathrm{A}^{4}$ & 0.00 & $\mathrm{~N} / \mathrm{A}^{4}$ & $0.00 \%$ & $\mathrm{~N} / \mathrm{A}^{4}$ \\
\hline 08/10/05 09:51 & 08/17/05 07:35 & 0.00 & 0.24 & $0.00 \%$ & $0.00 \%$ & $\mathrm{~N} / \mathrm{A}^{5}$ \\
\hline 08/17/05 16:30 & 08/22/05 09:53 & 0.28 & 0.12 & $0.00 \%$ & $0.00 \%$ & 0.34 \\
\hline 08/22/05 12:50 & 08/29/05 09:49 & $1.01^{6}$ & 0.03 & $0.01 \%{ }^{6}$ & $0.00 \%$ & 9.46 \\
\hline 08/29/05 10:46 & 09/06/05 09:49 & 0.00 & 0.00 & $0.00 \%$ & $0.00 \%$ & 3.87 \\
\hline
\end{tabular}

1 Sorbent trap breakage during trap recovery

2 Autosampler software malfunction and hardware failure

3 Autosampler hardware failure

4 Autosampler software malfunction

5 Sorbent trap with spike in the main section (field spike)

6 Sorbent trap breakage during recovery and subsequent loss of approximately $60 \%$ of the sorbent content of the backup section. Remainder of the backup section was recovered, analyzed and reported.

7 Percent recovery with respect to the main section. 
Table A6-2 summarizes the results for the analytical QA/QC, some of which are listed in Table 324-2 of US EPA Method 324, while others are presented in sections 11.6 - 11.14 of US EPA Method 324. All of the criteria are met except for the low recoveries of the Certified Reference Material (NIST 1641d) during the analysis of sorbent traps 830, 832, 833, 839 and 828. These percent recoveries fall outside of the allowed $90 \%-110 \%$ range.

Table A6-2. QA/QC Summary - Analytical Criteria

\begin{tabular}{|c|c|c|c|c|c|c|}
\hline $\begin{array}{c}\text { Sorbent } \\
\text { Trap } \\
\text { ID } \\
\end{array}$ & $\begin{array}{c}\text { Digestion } \\
\text { Blanks } \\
\text { ng/trap }\end{array}$ & $\begin{array}{l}\mathrm{MDL}^{1} \\
\mathrm{ng} / \text { trap }^{1}\end{array}$ & $\begin{array}{c}\text { CRM }^{2} \\
\text { (NIST 1641d) } \\
\text { \% Recovery } \\
\end{array}$ & $\begin{array}{c}\text { Laboratory } \\
\text { Matrix Spike }^{3} \\
\text { \% Recovery }\end{array}$ & $\begin{array}{c}\text { Lab Matrix } \\
\text { Duplicate } \\
\text { RPD }^{4} \\
\end{array}$ & $\begin{array}{c}\text { Lab Matrix } \\
\text { Spike Duplicate } \\
\text { RPD }\end{array}$ \\
\hline 830 & 0.50 & 3.35 & $82.2 \%$ & $101.6 \%$ & $1.3 \%$ & $0.4 \%$ \\
\hline 832,833 & 2.70 & 1.93 & $83.3 \%$ & $101.1 \%$ & $6.6 \%$ & $1.2 \%$ \\
\hline 838 & 0.14 & 0.42 & $96.7 \%$ & $99.1 \%$ & $0.6 \%$ & $1.5 \%$ \\
\hline 839 & 2.70 & 1.93 & $83.3 \%$ & $101.1 \%$ & $6.6 \%$ & $1.2 \%$ \\
\hline $828^{5}$ & 2.70 & 1.93 & $83.3 \%$ & $100.4 \%$ & $3.8 \%$ & $6.5 \%$ \\
\hline 840,841 & 0.10 & 0.09 & $103.0 \%$ & $102.9 \%$ & $7.1 \%$ & $6.0 \%$ \\
\hline $842,843,844,845$ & 0.39 & 2.42 & $104.6 \%$ & $91.4 \%$ & $2.1 \%$ & $10.6 \%$ \\
\hline
\end{tabular}

${ }^{1}$ Estimated Method Detection Limit (three times the standard deviation of sucessive digestion blank results)

2 Certified Reference Material (CRM)

3 Average of duplicate analysis

${ }^{4}$ Relative Percent Deviation (RPD)

${ }^{5}$ Sorbent trap with spike in the main section (field spike) 


\section{Unit 1 Stack - Ontario-Hydro vs. Hg-CEMS}

\begin{tabular}{|c|c|c|c|c|c|c|}
\hline Run No. & Start Time & Date 2005 & $\left|\begin{array}{r}\text { Ontario-Hydro } \\
\left(\mathrm{ug} / \mathrm{Nm}^{3}\right)\end{array}\right|$ & $\begin{array}{r}\mathrm{Hg} \text { CEMS } \\
\left(\mathrm{ug} / \mathrm{Nm}^{3}\right)\end{array}$ & $\begin{array}{r}\text { Difference } \\
\left(\mathrm{ug} / \mathrm{Nm}^{3}\right)\end{array}$ & $\begin{array}{r}\text { Percent } \\
\text { Difference }\end{array}$ \\
\hline 1 & $9: 52$ & Jun 29 & $\begin{array}{r}7.18 \\
\end{array}$ & 6.41 & 0.77 & $10.73 \%$ \\
\hline 2 & $12: 52$ & Jun 29 & 11.19 & 5.21 & 5.99 & $53.47 \%$ \\
\hline 3 & $16: 30$ & Jun 29 & 7.47 & 5.94 & 1.53 & $20.44 \%$ \\
\hline 4 & $9: 33$ & Jun 30 & 7.03 & 5.50 & 1.53 & $21.76 \%$ \\
\hline 5 & $12: 25$ & Jun 30 & 6.62 & 5.25 & 1.37 & $20.74 \%$ \\
\hline 6 & 13:31 & Jul 6 & 6.55 & 2.01 & 4.54 & $69.37 \%$ \\
\hline 7 & 9:31 & Jul 7 & 7.19 & 2.15 & 5.05 & $70.16 \%$ \\
\hline 8 & $12: 41$ & Jul 7 & 6.61 & 2.37 & 4.24 & $64.15 \%$ \\
\hline 9 & 16:53 & Jul 7 & 7.10 & 2.26 & 4.84 & $68.12 \%$ \\
\hline Aver & & & 6.97 & 3.99 & 2.98 & $42.81 \%$ \\
\hline
\end{tabular}

Standard Deviation

Confidence Coefficient

Relative Accuracy (as \% of RM)

Average Absolute Difference $\left(\mathrm{ug} / \mathrm{m}^{3}\right)$

\section{RATA}

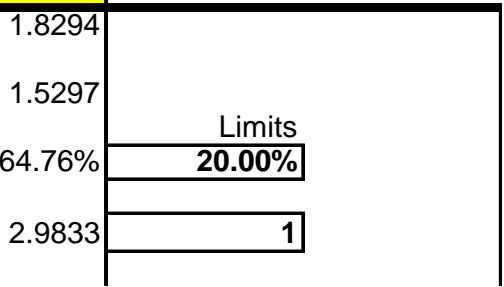

* Indicates that the run was not included in the RATA calculations.

8 Runs are being considered in the RATA calculations

1 Runs are being excluded from the RATA calculations

$\mathrm{RM}=$ Reference Method (Ontario-Hydro)

CEMS = Continuous Emissions Monitoring System (Hg-CEMS; DM-6)

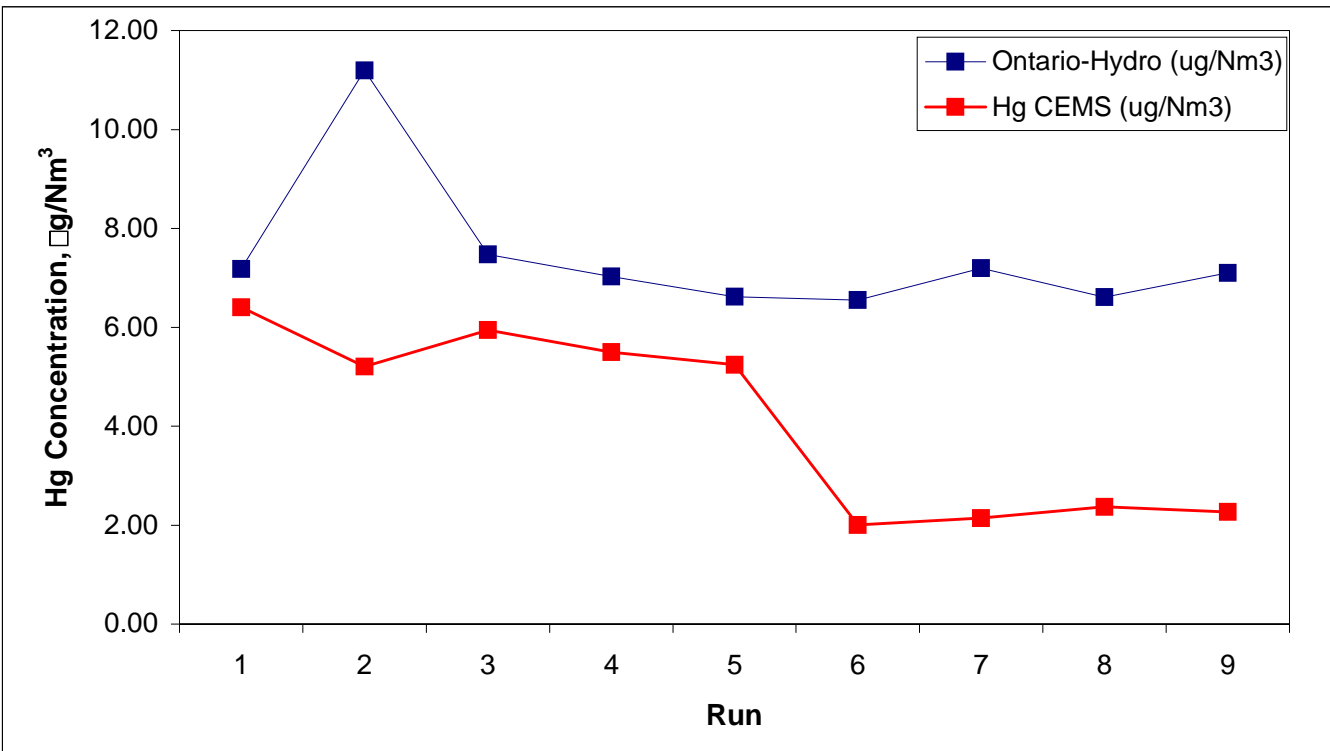

